\title{
Designed Parameters
}

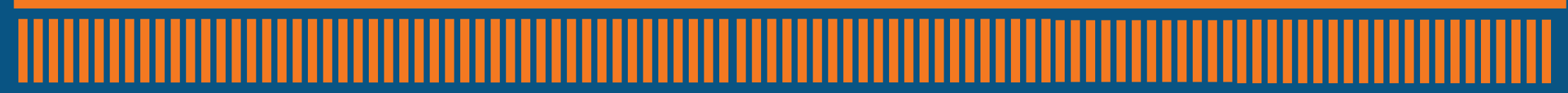

Advancing Parametric Software in the Architectural Design Process

Thomas Le Comte

A 120 point thesis submitted in partial fulfillment of the requirements of the degree of Master of Architecture (Professional) Victoria University of Wellington School of Architecture

2017 



\section{III}

|||||||||||||||||||||||||||||||||||||||||||||||||||||

III Acknowledgements

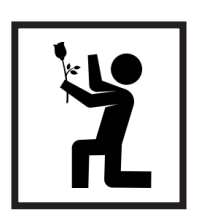


There are many individuals I wish to thank who helped me along the way;

My supervisor Kevin Sweet, whose encouragement and counsel helped drive this research.

My dearest parents, who provided morale and support during my expedition through academia.

My great friends and comrades who helped me balance life along the way.

Finally, the staff of Victoria University School of Architecture and Design, for facilitating a boundless learning environment. 


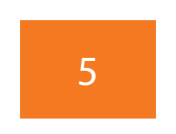





\section{II}

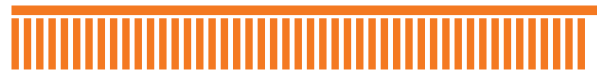

Il Abstract

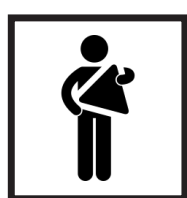


Architects use computers predominantly to digitise a design process that has been in use prior to the advent of the computer. Traditional analogue concepts are transferred into and sculpted through the digital world but the overall process has remained mostly unchanged for decades. Merely digitising a known process does not utilise the full power of the computer and its near limitless ability to compute.

For an architect, design of the built environment is highly important especially if they are to optimise the physical, phenomenological and psychological aspects of the space. The process of designing an architectural space is riddled with possibilities or variables that architects have used historically to aid in the design of the built environment, including but not limited to: object relationships, climate, site conditions, history, habitibility and the clients input all project requirements that must somehow be quantified into a built object. This information is key for an architect as it will inform and form the architecture which is to be designed for the project at hand.

This information, however useful, is not easy to integrate into every aspect of the design without intensive 
planning, problem solving and an exploration of almost an infinite number of possibilities. This is where parametric design can be used to aid in the design. More of the fundamental aspects of the information gathered in a project can be programmed into a computer as parameters or relationships. Once this information has been quantified, the designer can run through iterations of a design which are defined by these parameters. This is not a random process. It is controlled by the designer and the outcome is a product of how the architect designs the parameters, or relationships between components of the design.

Parametric design offers a shift from merely digitising design ideas to using programmed constraints derived through the design process to influence and augment the design envisioned by the architect. Parametric design allows the system to be changed holistically and updated through the alteration of individual components that will then impact the form of the design as a whole - creating a non-linear process that is connected throughout all design phases.

This thesis seeks to explore parametric design through its implementation within a group design project 
to decipher how a parametric process grounded in an understanding of contemporary digital fabrication can inform architectural space. To explore parametric design, this thesis will practice this re-envisioned design process through three design phases. The first phase is the foundational knowledge stage where the applications of digital workflow, computer models, tools and material explorations are examined. Second is the production of a prototype to investigate lessons learnt from phase one and apply these lessons to an actual parametric system used to design a prototype. The final stage will be a developed design process that will further explore a parametric system and its architectural applications. These phases will be developed through a series of prototypes in the form of material explorations and scale artefacts which will explore how it would be used to address many of the designs facets from sensual to corporeal. 


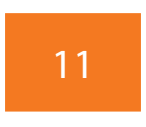





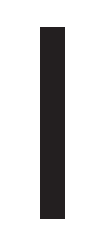

\section{|l||||||||||||||||||||||||||||||||||||||||||||||||}

I Table of Contents

㘣




\section{Table of Contents}

III Acknowledgements....................

II Abstract . . . . . . . . . . . . . . . . . . .

I Table of Contents . . . . . . . . . . . . . . . . . 13

1.0 Introduction. . . . . . . . . . . . . . . . . 17

1.1 Architecture and Parametric Design $\quad 19$

2.0 Methodology . . . . . . . . . . . . . . . . 25

2.1 Research Question .........................

2.2 Design Research Analysis . . . . . . . . . . 28

3.0 Literature Review . . . . . . . . . . . . . . . . . . 31

3.1 Theoretical Framework. . . . . . . . . . . . . . . . . . . .

3.2 Physical Framework . . . . . . . . . . . . . . . . 38

4.0 Phase One: Foundational Knowledge ........47

4.1 Initial Investigation . . . . . . . . . . . . 48

4.2 Investigation Parametric Modeling

4.3 Incremental Forming Experimentation

4.4 Conclusion . . 
5.0 Phase Two: The TATU System .............67

5.1 Definition and Tool Augmentation. ..............69

5.2 Design Exploration: Form Finding . . . . . . . . . . . . . . . . . . . . . . . .

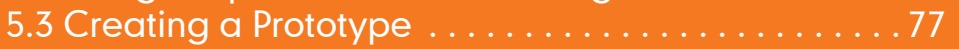

5.4 Conclusion . . . . . . . . . . . . . . . . . . . . 87

6.0 Phase Three: Developed System Design

6.1 Design Development .....................97

6.2 Prototype Form Finding . . . . . . . . . . . . . . . . . 101

6.3 Parametric System Prototype Iteration A

6.4 Parametric System Prototype Iteration B

6.5 Conclusion . . . . . . . . . . . . . . . . . . . . . . . 123

7.0 Discussion . . . . . . . . . . . . . . . . . 127

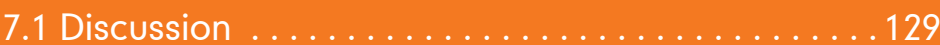

8.0 Bibliography......................135

9.0 Table of Figures . . 

1.0

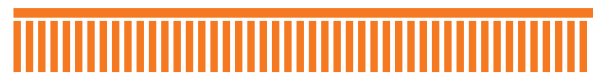

\subsection{Introduction}

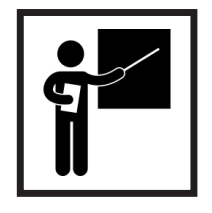


... The pencil adds and the eraser subtracts. Add a few tools, like a T-square, triangle, compass and scale and drawings can become more accurate and precise models of a design idea. Designers are used to working in this mode; add marks and take them away, with conventions for relating marks together. Conventional design systems are straightforward emulations of this centuries-old means of work. Parametric modelling ( also known as constraint modelling) introduces a fundamental change: "marks", that is, parts of the design that relate and change together in a coordinated way...(Woodbury, 2010) 


\subsection{Architecture and Parametric Design}

Architects are trained to manipulate form and space; in most practices, the computer is a powerful tool for visualising form and space by converting the creations of the architect into virtual three dimensional spaces. Through using the computer, architects are able to translate their concepts and ideas into a three-dimensional model from which they can extract elevations and plans to share their design with others.

These Building Information Models (BIM) can be seemingly comprehensive but are still mired in traditional processes and modes of representation. All aspects of the model are described independently without reference to other components of the model. This conventional way of working allows information to be extracted from the model through plans, sections and even renderings but limits design iterations due to its lack of interdependence with other parts of the model (Garber, 2009). While BIM software is making progress in closing the gap in a conventional linear process, it continues to support a more traditional design process rather than capitalising on the computational power of the computer. 
With the introduction of advanced parametric design software, relationships can be established amongst the components of the system which comprise the design model, allowing a non-linear workflow that updates at all stages of the design process. A parametric model can be defined by a set of rules or constraints, which define aspects of the building and their relationships to one another or its environment. These programmed relationships then drive the space and form of the building. Instead of just designing with modelling programs, an architect could design using parameters that the computer would utilise to iterate forms. These forms could then be assessed and altered by the architect, through the manipulation of the parameters and constraints.

Parametric design is a process grounded in a consistent network of relationships established between the individual components of a design. This relationship allows components to be manipulated independently whilst the entire system remains intact, providing the designer with a high level of control at all times in the design process. 
Fundamentally, parametric design enables an architect to design in such a way that the computational power of the computer can seamlessly process iterations of design. Parametric tools enable relationships to be designed and defined between components based on programmed rules created by the architect. Where conventional computer modelling explicitly describes the building model as a whole, individual components of the model are not inter-related. Thus, if a change takes place in the design, several other changes must be made to affected portions of the model to facilitate the change, as the rules for these components are implicit. On the contrary, in parametric modelling the model can be changed seamlessly as the form is implicit. With the parameters generating the model, explicit rules and relationships are established that allow for changes to passively alter the entire model.

Algorithmic design is often confused with parametric design but differs in that computer code is written for the computer to "automatically" generate form with little to no interference from the designer. This enables complex forms to mature through simple methods while preserving specific qualities. Essentially the designer defines a set of rules and the software program will arrange a form 
according to these rules. In contrast to parametric design this provides the designer with a somewhat unknown outcome, something that is not foreseeable until the computer has run the program (Terzidis, 2006a). These two processes are quite similar, however parametric design is a method for control and manipulation of design elements within a system, whilst algorithmic design is a system of objects producing complex form based on component rules (Terzidis, 2006a).

This thesis seeks to explore the adaptation of parametric design into a design process, in order to establish how it informs architectural form and space while allowing the designer to retain a sense of control in the process. To do this the thesis will take part in a contemporary design build project focusing around the production of several prototypes by incorporating an advanced parametric design process to facilitate a contemporary digital workflow. This paper will focus on the incorporation of parametric design in the early design stages of a project, its influence on the manufacturing process and how it can feed back into design from conception to fabrication. 



\section{0}

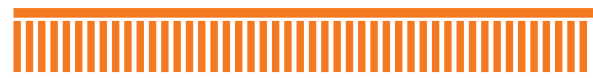

2.0 Methodology

O) (2) 


\subsection{Research Question}

The proposed research question is as follows: how can an advanced parametric process, grounded in an understanding of a contemporary digital workflow inform architectural space?

The investigation employs the techniques of designlead research. The design-lead research will employ the design prototype models in order to analyse parametric design in regards to its application to architecture. Full scale prototyping allows the testing of structural, aesthetic and technical realities of the design. These prototypes provide real world feedback to critique and analyse.

Fundamentally this thesis will look at how designed relationships and constraints based on project-specific information such as environmental, material or tool constraints programmed in a computer model can be used to drive the formation of three-dimensional architectural forms.

The goal is to investigate the design of a full-scale piece artefact through a parametric process then build it using digital fabrication techniques embedded in the fabrication process. 
Having a physical output provides a mechanism to assess parametrically driven form. The critique of the actual physical form in regards to its strengths and weaknesses will provide a feedback loop, which will then provide a redefinition of the parametric definition driving the threedimensional form. This allows for strengths and weaknesses to be edited via the relationship of the parameters driving the components of the parametric system. 


\subsection{Design Research Analysis}

How work was evaluated, how it was achieved, and how you can tell when it was achieved.

To evaluate the work produced in the design and production of the prototype a variety of measures will be employed to ensure that they are achieved.

A parametric computer model will be designed and the result of the model fabricated. Once fabricated the prototype will be reviewed and strengths and weaknesses identified. Returning to the computer model the identified issues will be rectified and a new computer model will be generated and then fabricated. This feedback system will be employed to ensure lessons learnt are brought forward when designing all prototypes.

Parametric design will be the backbone of the research so it is important to ensure it is implemented into the design of the prototypes. Initially a place holder parametric system will be defined when learning the parametric software of Rhino's Grasshopper. This system 
will then be used for material testing and form finding. Once the potentials of the materials and tools are learned a critical feedback loop will ensure these conditions are implemented as parameters into the form finding system of the Grasshopper definition. This new definition will be implemented when designing the first prototype, allowing the system to be tested under real world conditions. The cycle will then repeat for the following prototypes. 



\section{0}

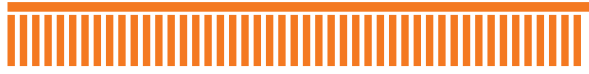

3.0 Literature Review

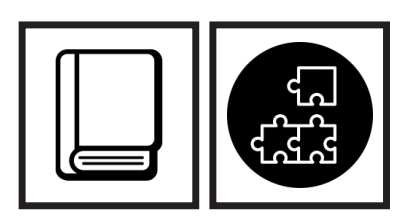




\subsection{Theoretical Framework}

The following sections explore both theoretical and physical frameworks of parametric design.

In understanding parametric design, it is important to provide some historical context for the assimilation of the computer into the field of architecture. Since the 1960s, architecture has employed the computer for its graphical capabilities.

With the computer came a seemingly unlimited capability for computation, a fantasy was shortly stimulated in designers: one that idealised the computer and its potential for optimising architectural design.

Computation is key to parametric design as it is used to evaluate the equations between parameters. In parametric design it is the parameters which are declared in the software program, not the form (Kolarevic, 2005). Different values are assigned to the parameters, these parameters being variables derived from information specific to a design project, such as: site, environment, material and physical conditions etc. Computation allows equations between these component parameters to be described and embedded with an associative geometry, a 
geometry which is directly influenced by the relationships between components. Through computation a potentially infinite number of similar iterations can be simulated through a manipulation of the constraints ruling the parameters. The computer uses the information set up through the parametric system and recalculates the new output.

Computation was originally employed to optimise engineered structural systems for buildings (Menges, 2011).

When it was translated into the design of buildings it was soon discovered optimisation of design was not feasible due to the variety of design constraints which envelope an architectural problem (Menges, 2011).

From this, automated design was theorised. The original idea envisioned a whole computer program which could interpret design briefs and provide architectural solutions. This however sparked debate as to how or even if a computer should mimic an architects thought process. The debate arose around the time Cybernetic Theory was popularised. Cybernetic Theory explores the control and communication of information processing in animals and machines (Pangaro, 2013). Most importantly what arose from this was a theoretical understanding of 
architecture as a computable system, the system being an understanding of complex interrelation of material parts, social engagement and the shaping of form, space and structure (Menges, 2011).

This systems approach to architecture began to develop in the computer program Sketchpad established by Ivan Sutherland. The program utilised constraints which could be varied to test relationships between geometries to provide the formation of an overall system (Menges, 2011). The program pioneered a graphical and tactile light pen interface and introduced a methodology for preserving rule-based geometric associations of parametric design and associative rule based system generation (Menges, 2011).

Sketchpad unfolded a logic to the interrelationship of geometries and how associations cause ripple effects in the forging of form. This promoted a shift from the conventional view of architecture as an object to architecture as a system that encompassed a series of interconnected components (Menges, 2011). This parametric methodology suggests that architecture can be interpreted as a summation of forces and relationships which realise a form (Menges, 
2011). Architecture is comprised of many elements and components that interrelate. Computation is key to understanding the relationships these elements share, what constrains them and the potential that is derived from it.

Computation in regards to design is the processing of information and interaction between elements. In relation to this thesis and, to a greater degree architecture, the most fundamental application of computation is in producing outcomes realised from the processing of internal and external properties. Computational design delivers a context for negotiating and impelling the interrelation of datasets of information with the capacity to generate complex order, form and structure of geometries (Menges, 2011). 
"Computation as a design methodology is to formulate the specific. Where computer aided processes begin with the specific and end with the object, computational processes start with the elemental properties and generative rules to end with information which derives form as a dynamic system" (Menges, 2011) 
Computational design was key in the seeding of parametric design in the greater scheme of architecture. Parametric design is the generation of a system which promotes the propagation of a form through projectspecific parameters. A parametric system allows for all components of a design to be considered and designed at the same time. A synergy is present where no elements of the design are left till the last minute, as the system is adaptable due to the established relationships of the components which animate it. 


\subsection{Physical Framework}

From theory, this thesis moves on to discuss practical applications of parametric design research. Material Swarm Articulations, developed by Evangelo Pantazis and David Jason Gerber investigates the application of parametric design in a form finding process, in order to develop an architectural folly. The project demonstrates that contemporary computational systems can be utilised in such a way that information from environmental parameters or in this instance, structural load paths, can be incorporated into a parametric scheme to drive a system which generates a form.

The project itself uses open source software plugin (Kangaroo) that operates within a commercial three-dimensional modelling software (RhinocerosGrasshopper). Through the use of this software the project explores a self-standing canopy system. The simulation within the software generates a panel system which rests in equilibrium, taking parameters from material strength and bending techniques to form a self-supporting structural system. This project is most relevant as it explores the use of parameters to govern the generation of a form through a definition within a software program, a technique that this thesis employs. 
What this thesis will explore is how parameters inform architecture. Examining Material Swarm there could be a potential to develop a system much like the component panels that are displayed in Figure. 1.

Not only does this project explore a form finding computational framework of tension and curved plywood panels based on material properties and force distribution, it also works through a contemporary design workflow.

The contemporary design workflow this thesis employs is a process that utilises contemporary methodologies such as parametric design and digital fabrication interconnected via a feedback cycle to design artefacts. A project will be modelled as a parametric system which will output an artefact. This artefact will then be rapidly prototyped with digital fabrication machines. Issues from this experimentation will be identified and feed back into the parametric model which can be altered seamlessly as to address the current output or future developed outputs. Unlike standard workflows this contemporary workflow can integrate changes at any time without the need for an entire redesign of the computer model, as the designed 
parameters allow for changes in the model to occur at any time. This workflow demonstrated in Figure. 3.

The contemporary workflow utilised the computer program Grasshopper which allowed the designers to test the structure of the designed system. The structure could be tested and then augmented so the integrity of the structure was suitable for its assembly. This contemporary workflow process in regards to creating a full-scale prototype which could be critiqued and learnt from is what provided the basis for this thesis. A well-defined workflow would be crucial as it would promote testing and analysis through design, ensuring successful iterations of experimentation are brought forward and unsuccessful iterations are reevaluated and augmented.

This thesis employs parametric design to develop architectural forms and test how they are influenced by designed parameters. A workflow will be introduced with a set of pioneer parameters that will be translated to a fabrication machine to begin tool and material exploration. Through these material and tool programming investigations a thorough set of parameters will be developed. These parameters will then be used to design 


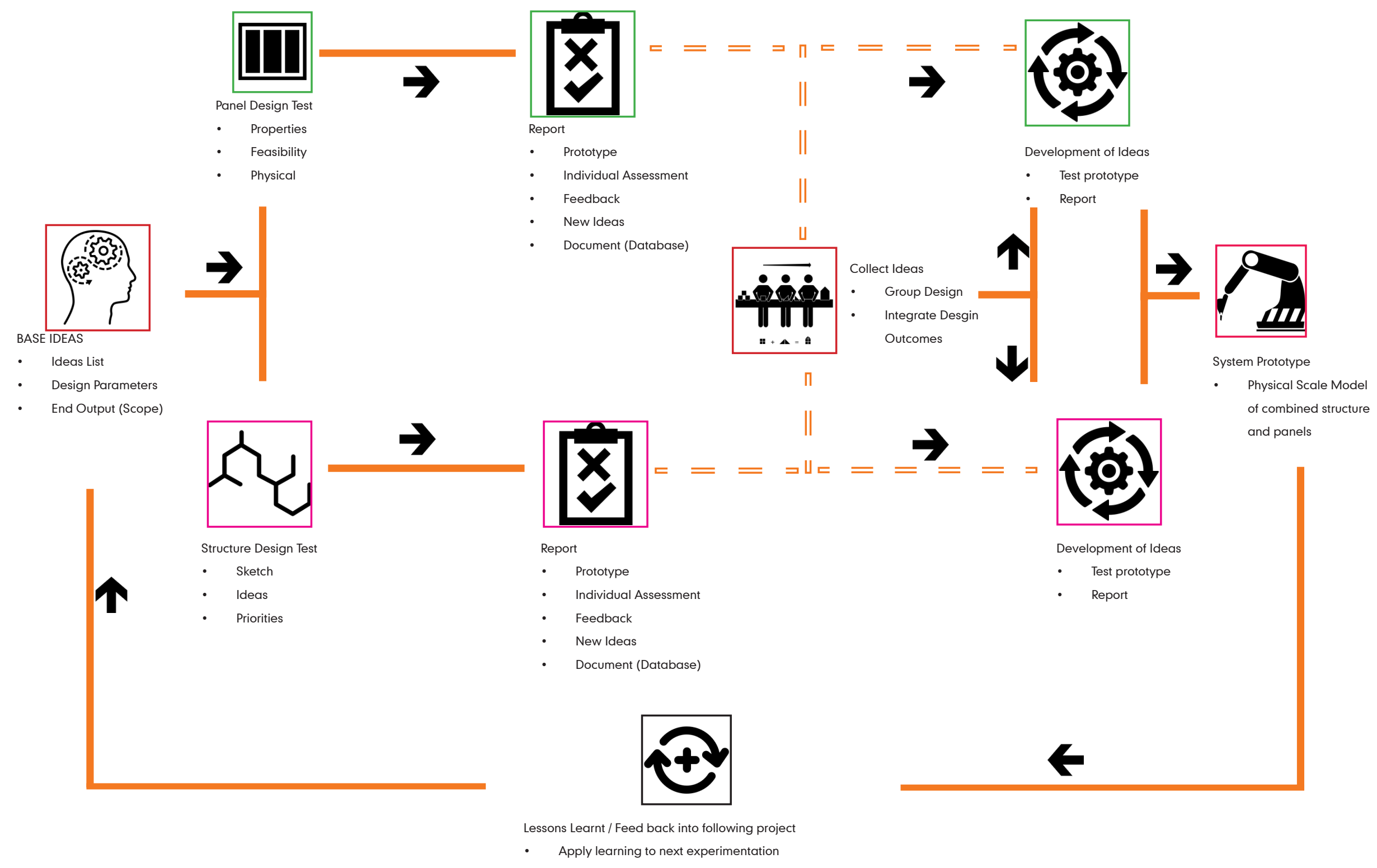

Figure. 3: Visualisation of Contemporary Digital Workflow- Green outline indicating the entailed role of this thesis and its design research. Pink= Other group members. Red $=$ All research members 
a prototype using this newly defined workflow. The end form will then be evaluated and the findings of the form's attributes will be used to fine-tune components of the parametric system.

A second parametric precedent are the experiments carried out by Ammar Kalo and Michael Jake Newsum. In their project Robotic Incremental Sheet Metal Forming, the researchers examine the process of incremental sheet metal forming. This is the procedure of using a tool to transform a metal sheet from a planar surface to a three-dimensional form. This process can be carried out through single point incremental forming (SPIF) where one tool head with a ball point is used to positively form the planar surface, or dual point incremental forming (DPIF) where there are two tool heads, one being the positive forming head and the other acting as the negative mould head (Figure. 4).

The research describes a process of using an industrial robotic arm equipped with a forming tool. The process takes a computer-driven three-dimensional object and converts it into data for the robot to form the geometry on the surface of the planar metal sheet as demonstrated in Figure. 5. 
Kalo and Newsum explored incremental forming for its ability to prototype highly variable and cost effective components. Through their findings and experimentations with the process Kalo and Newsum found that incremental sheet metal forming had a capacity for radicalising the ways in which architectural sheet metal was generated. Most importantly their research brought about functional design as they discovered that once the panels were formed, especially those of which had been formed with double curves were enhanced structurally (Newsum, 2014). This was especially evident in panel systems the researchers had developed during their studies.

With regards to architecture, incremental forming rethinks the way in which metal can be employed. Metal was originally employed for its structural integrity up until the 20th century where it was shifted into an aesthetic surfacing material (Newsum, 2014). Once sheet metal became a more staple material, designers and architects alike began to explore ways to manipulate its surface. Twodimensional fabrication processes proved to be efficient in mass customisation, simple geometries could be formed or a system of surface panels could be used to generate 
a whole form. However mass production meant that the panels were not bespoke. This is where Kalo and Newsum suggested that incremental forming is key as it gives the designer a method of generating bespoke panels that are not only aesthetic but have structural applications as well.

A paradigm, explored by Kalo and Newsum is Asymptote Architecture's, Hydra Pier (Figure. 6). The building façade is comprised of moulded surfaces. These surfaces had to be built from positive and negative moulds, which shaped molten metal as it solidified. This moulding process is time-consuming, so Kalo and Newsum suggested in their research that incremental forming could replace this moulding process by simply forming the material into its desired form from the start. Kalo and Newsum's research indicated that the design of performative façade systems can be made more efficient with incremental metal forming.

Kalo and Newsum focused on the attributes that incremental forming brings to a metal surface. Their research indicates that not only aspects of aesthetic but also structure can be enhanced and manipulated through incremental forming. From this knowledge, this thesis will employ incremental forming as a methodology for exploring 
parametric design and how it informs architecture.

For this thesis, parametric design will be used to provide the design research with a method of form finding. Through parametric modelling, forms can be generated via parameters driven by project specific information. These parameters can be augmented at all times during the design experimentation, due to the relationships that the parameters share with one another in the software program.

To turn these computer models into tangible artefacts which can be critiqued, the method of incremental metal forming will be used. The methodology of the contemporary digital workflow will then ensure issues raised in the modelling and construction of the prototypes are fed back into the design development of future prototypes.

The prototypes will be used to represent components which embody architectural forms, such as a panelling system or performative façade. These forms will be used to determine how the parametric design informed the abstract representation of the architectural space. 



\section{0}

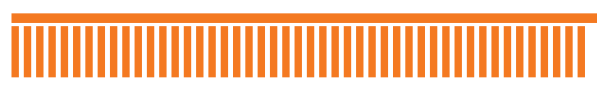

4.0 Phase One: Foundational Knowledge
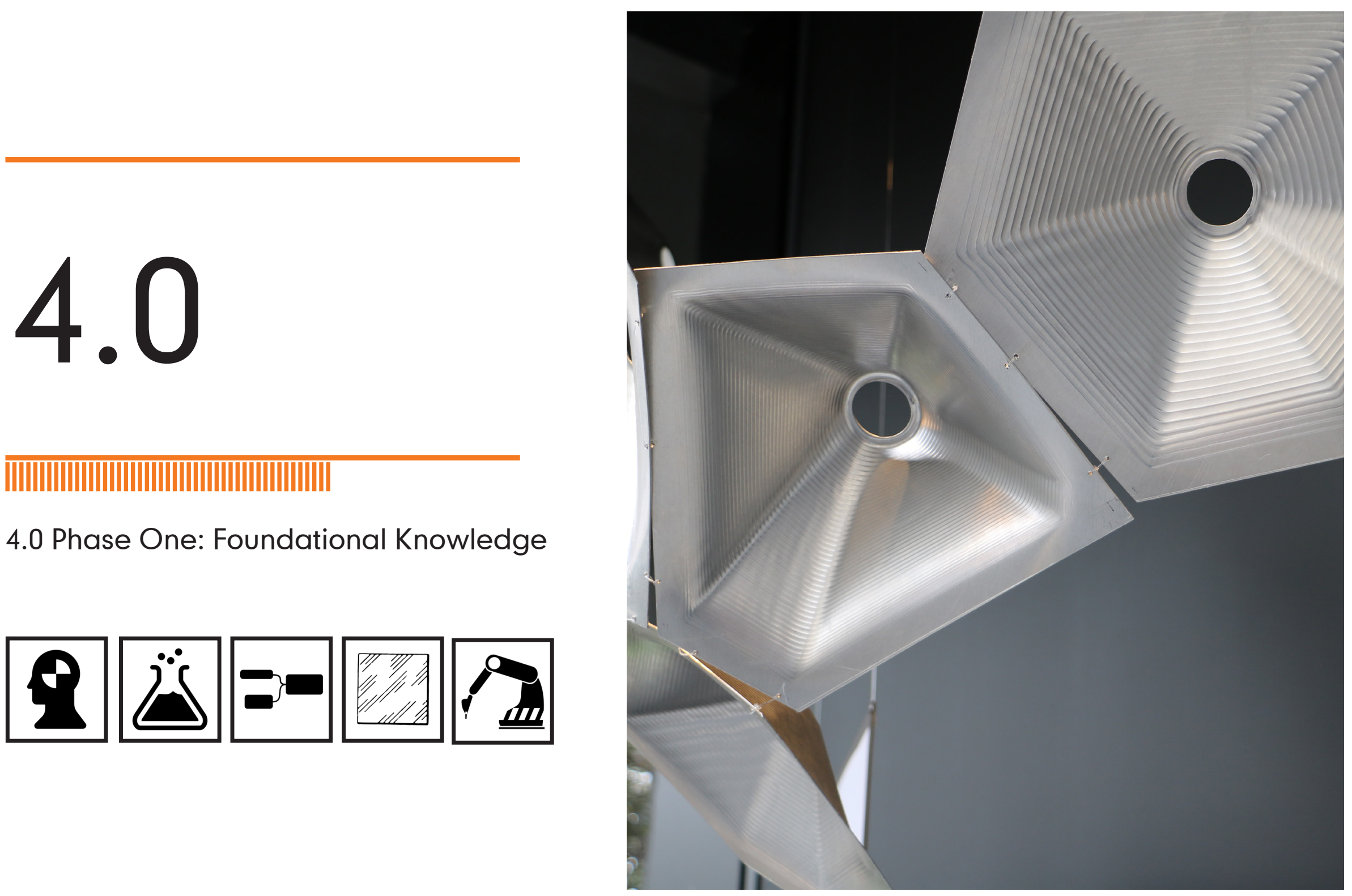


\subsection{Initial Investigation}

A team of individuals with separate research goals was assembled. This was to ensure a series of prototypes could be successfully produced, with each group member specialising in a certain role of the defined workflow. For this thesis to produce a response to the research question, the role of parametric design was undertaken.

Before design of the first prototype began, the research team had to learn what the specifics were of a parametric workflow in digital fabrication. The parametric process, including the concepts, software, and the details of digital fabrication techniques was new to the team. There was a short learning process to get up to speed. 
Through initial research it was found that experimentation with industrial robots was somewhat prevalent throughout the world. One example as shown above (Figure. 4), had undertaken a project that used an industrial robot to form aluminium into double curved surfaces. Kalo and Newsum's findings established that aluminium and cold rolled sheets could have geometries extruded from them, essentially augmenting the metal from planar to three-dimensional forms using an incremental forming tool attached to the end of the robot.

Aspiring to exemplify the process, the thesis had a starting point for experimentation that the robot could undertake. To carry out a metal deformation experiment, a system would have to be developed that allowed a piece of aluminium to be suspended in such a way it could be deformed. The team created a jig box which would not only lock the sheet of aluminium in place, it would also suspend it allowing for negative deformation to occur, exhibited in Figure. 7. An end effector, or tool for the end of the robot was also designed and created (visible in Figure. 7). 


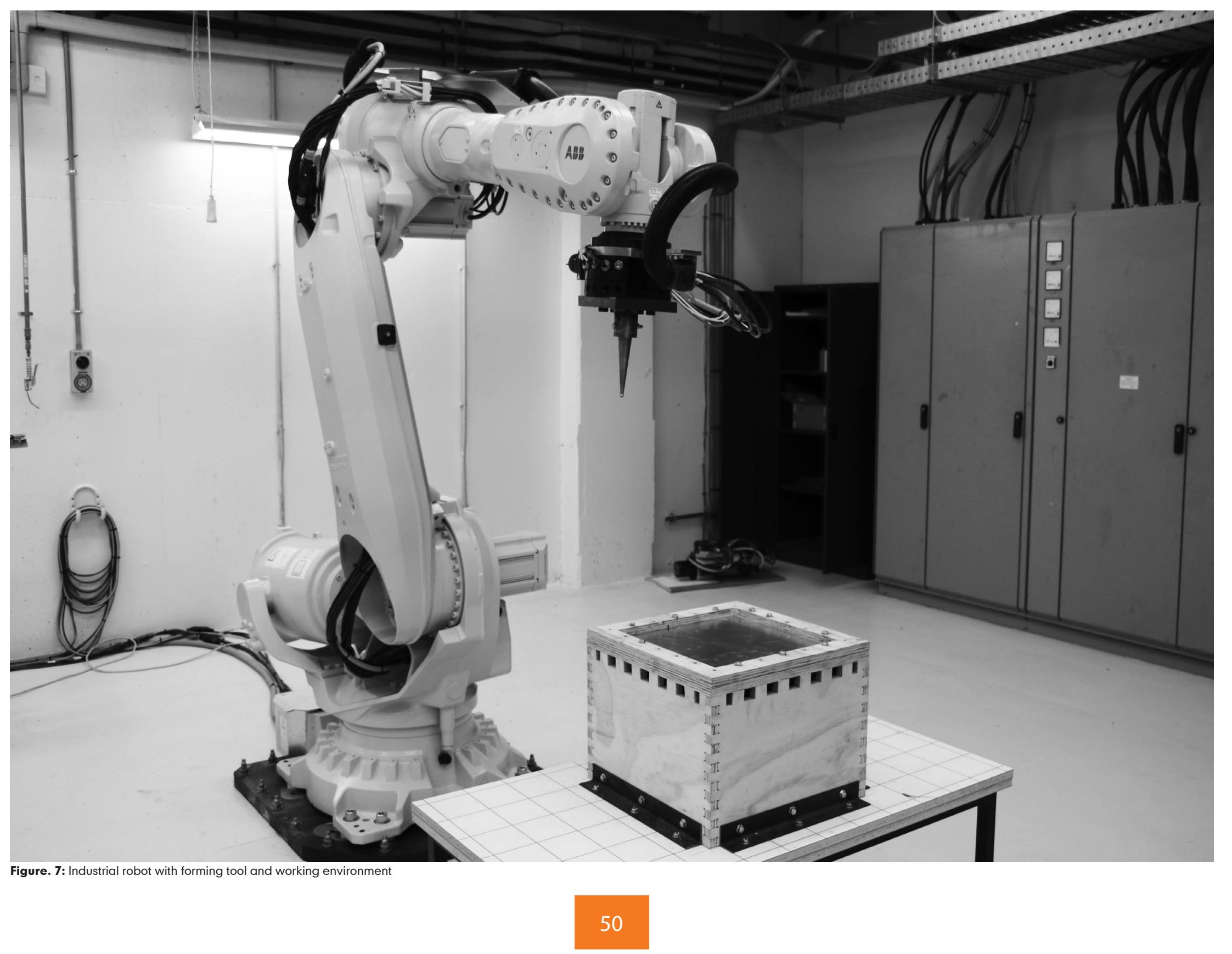


With tools being developed by the research team, learning of the software also occurred. To use the robot, a communication pathway had to be established. Enquiry quickly lead to HAL, a plugin for Grasshopper, a parametric design tool that is itself a plugin to the modelling software program Rhino. This program allowed the designer to generate geometry using parameters specific to the working environment, material, fabrication machine and the experimentation at the time. This program converted the geometry generated through this parametric process into a series of toolpaths. These toolpaths would dictate how the robot moved and control how it would form the aluminium with its forming tool. 


\subsection{Investigation Parametric Modeling}

Research and development began with modelling a definition using the programming of Grasshopper's visual code (displayed in Figure. 8). This code was then used to convert parametrically generated forms into toolpaths that the robot could use to manipulate the metal (as displayed in Figure. 9). Most importantly, for this thesis, was the exploration and development of a definition, the visual code parameters behind Grasshopper. The definition utilised specific parameters that our research was bound by, for instance the boundaries of the jig working area and the simulation of the robot in its environment. The parametric system had to account for the environment and the robot itself so the limits of the working area of the sheet of metal were maintained, ensuring the robotic arm would not encounter anything in its environment it was not supposed to. 


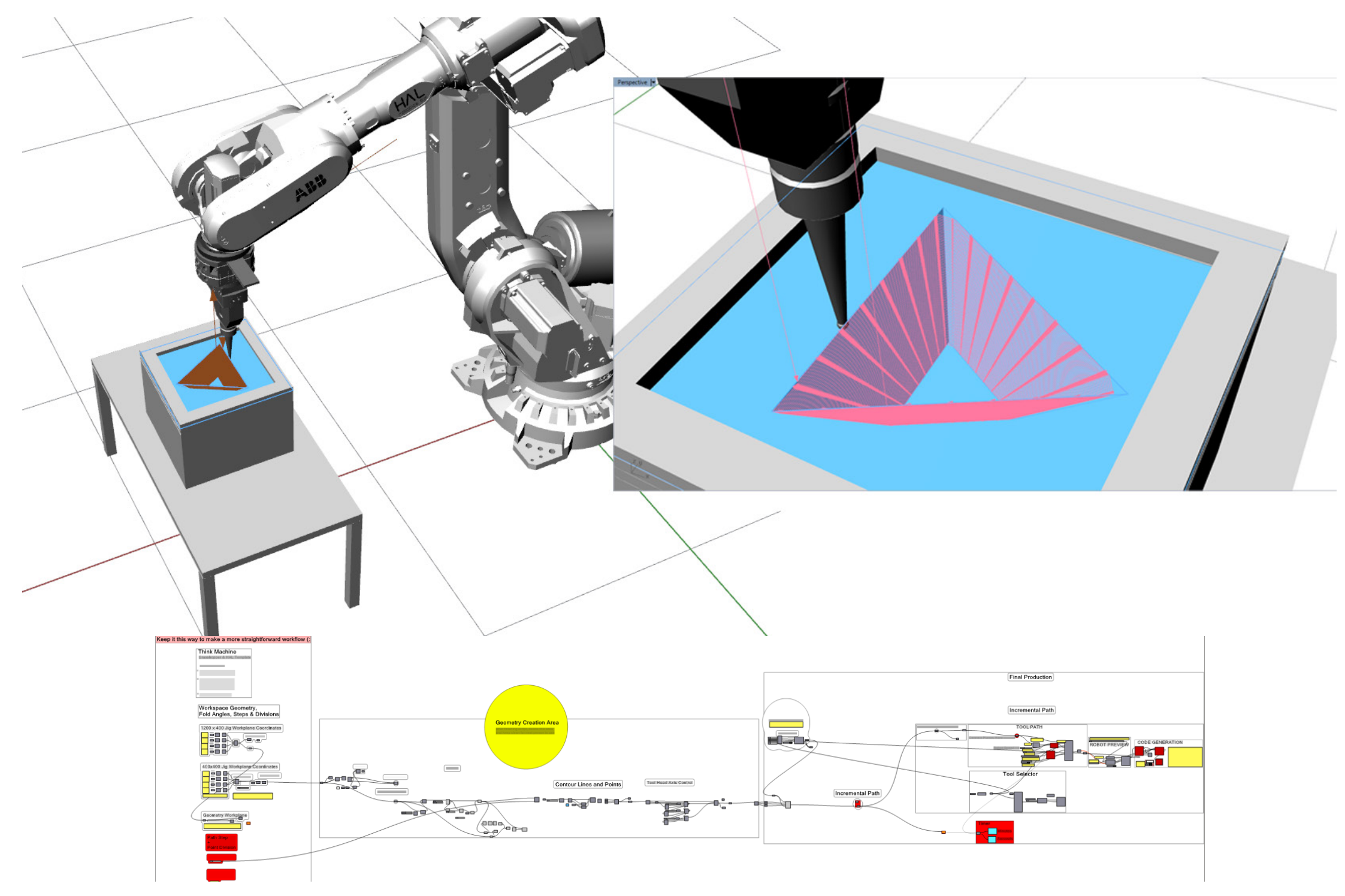

Figure. 8: Bottom- Pioneer Parametric Grasshopper Definition

Figure. 9: Top- Pioneer Parametric Grasshopper Definition- Demonstrating tool path simulation 


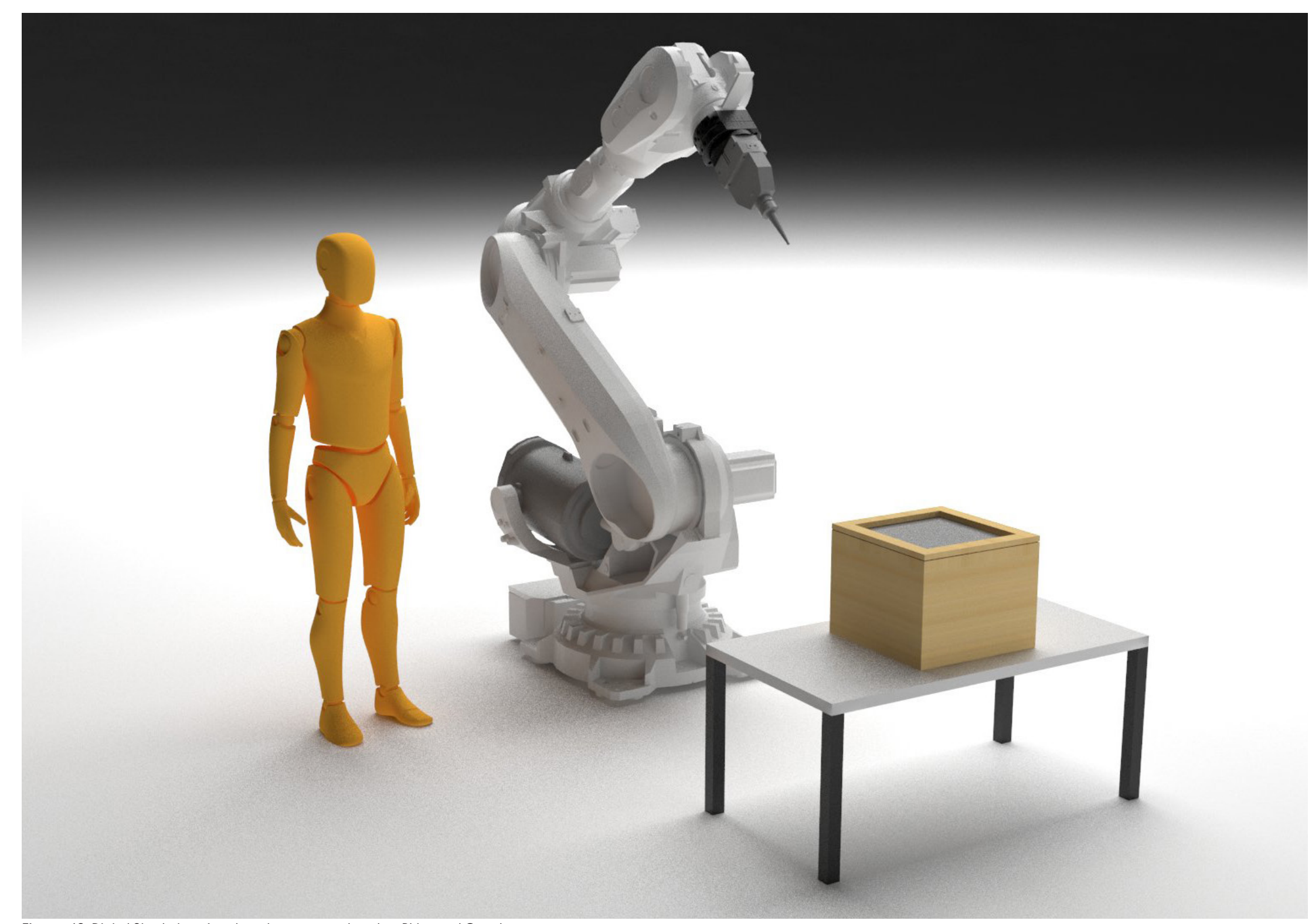

Figure. 10: Digital Simulation of work environment produced on Rhino and Grasshopper 


\subsection{Incremental Forming Experimentation}

Through the parametric applications of Grasshopper, a basic working environment could be simulated within the software, an environment which consisted of the robotic arm, jig, and the work surface of the metal sheet, as displayed in Figure. 10. These conditions were implemented into the Grasshopper definition as set parameters which would constrain generation of the form.

The next step in the process was material exploration. The first manipulations tested were basic geometries, so as to provide a pool of data that could be consulted and learnt from. Some of these properties included testing the depth that the aluminium could be extruded, the greatest angle the aluminium could be extruded, and also the size of the incremental step. A synopsis of tests and Grasshoppper simulations are demonstrated in Figure. 11, Figure. 13, and Figure. 15 on the proceeding pages. 

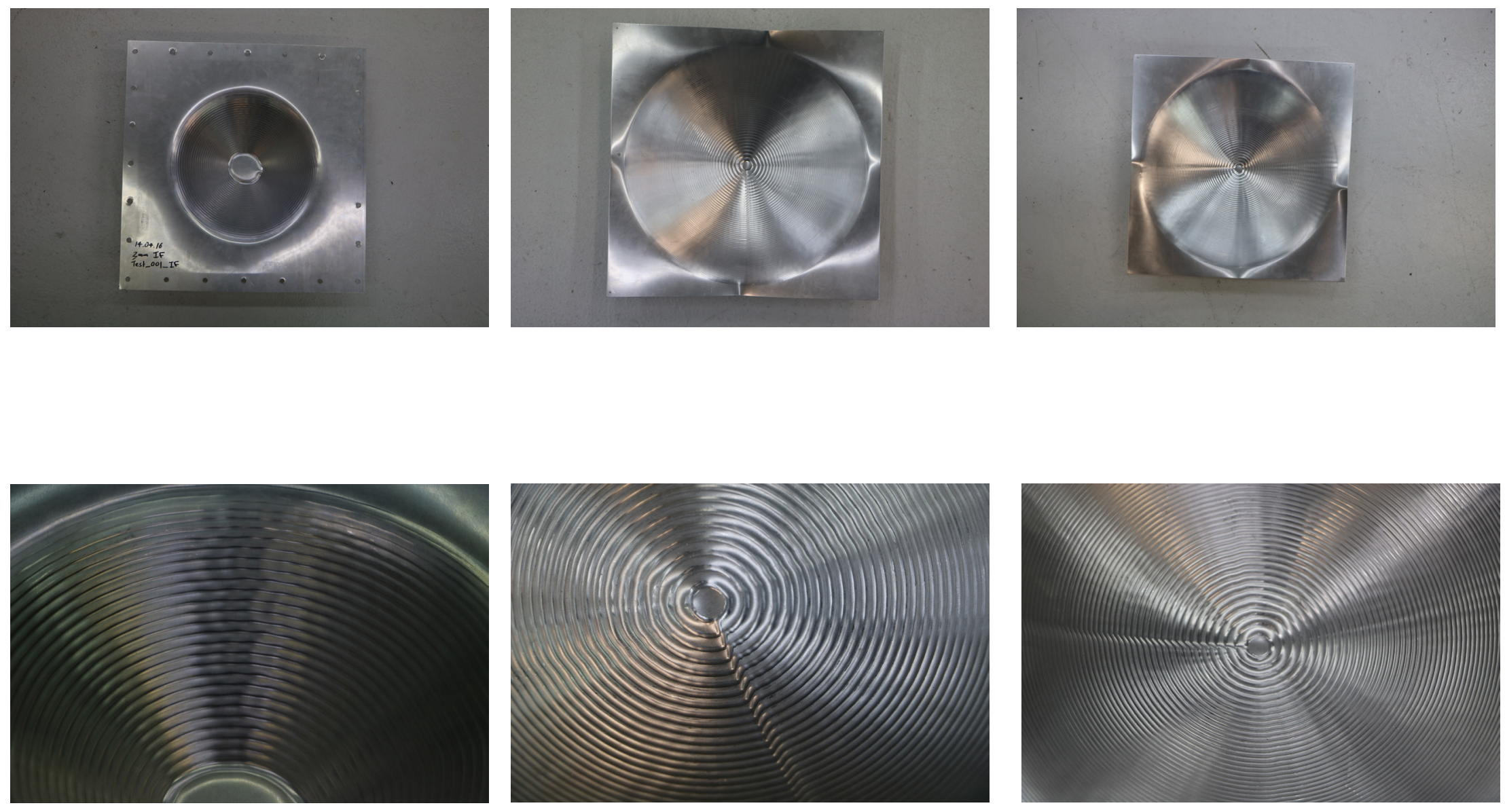

Figure. 11: Incremental forming tests: Increment step size- left to right- $2 \mathrm{~mm} / 1.2 \mathrm{~mm} / 0.8 \mathrm{~mm}$ 


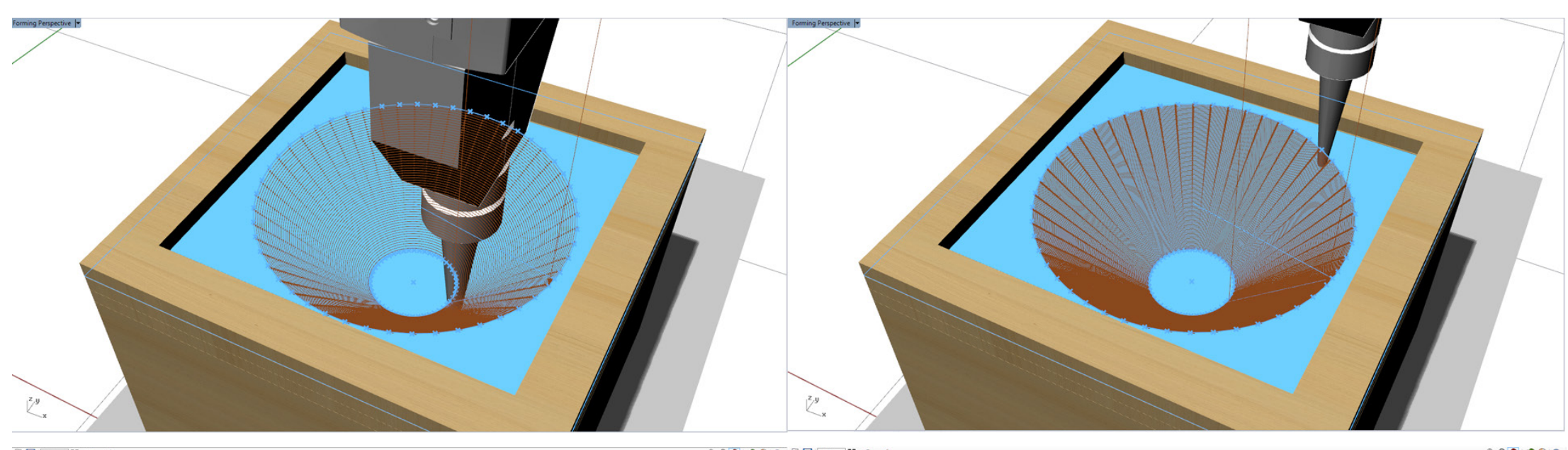

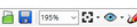

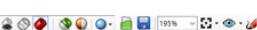

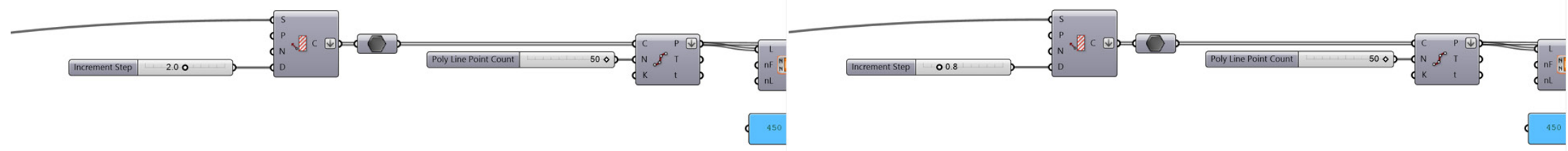

In⿴囗十)

Figure. 12: Incremental forming Grasshopper definition and Rhino simulation: increment step size- left to right- $2 \mathrm{~mm} / 0.8 \mathrm{~mm}$ 

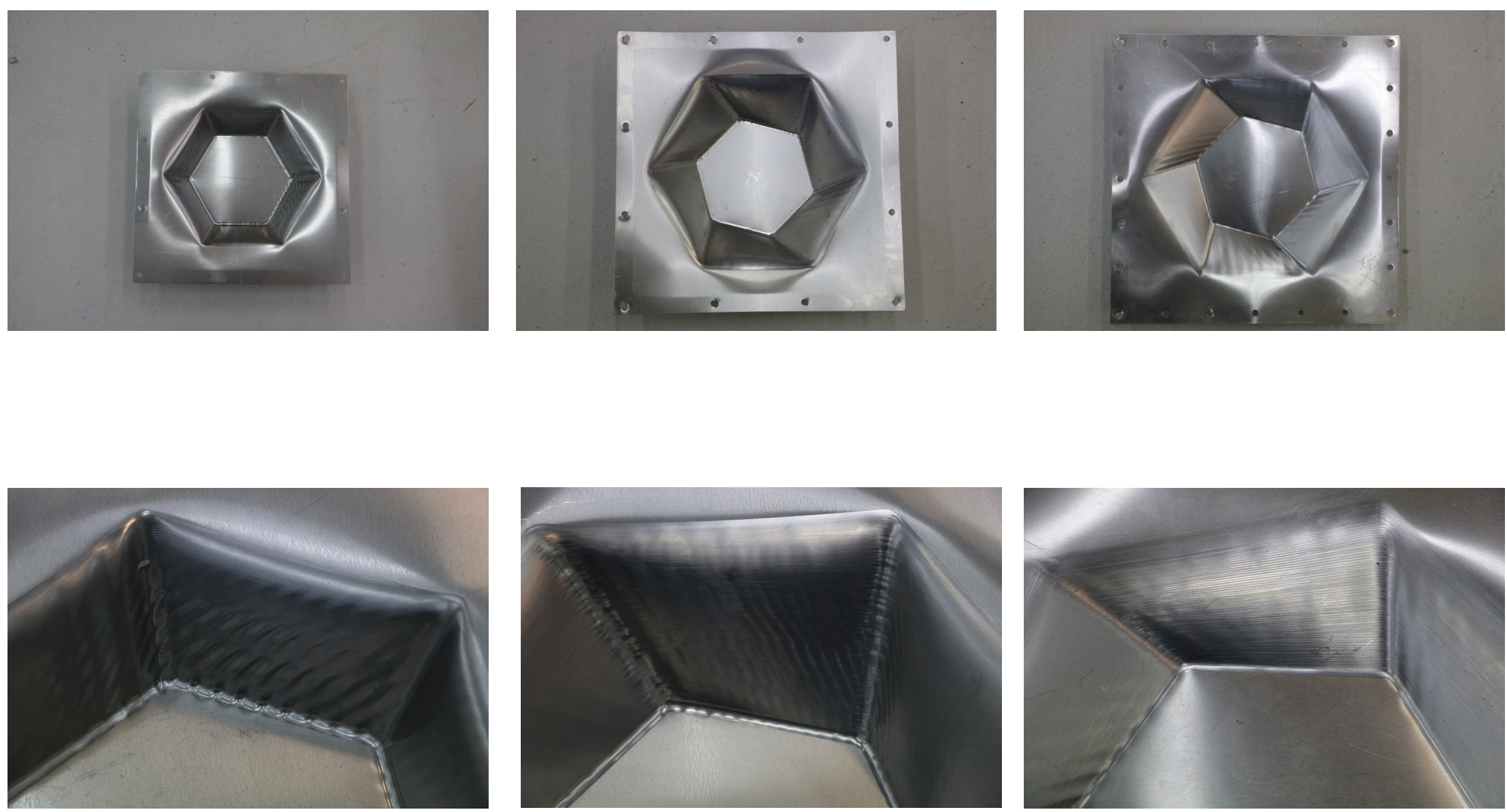

Figure. 13: Incremental forming tests: Rotation of extrusion- from left to right- rotations 30/45/60 degrees 

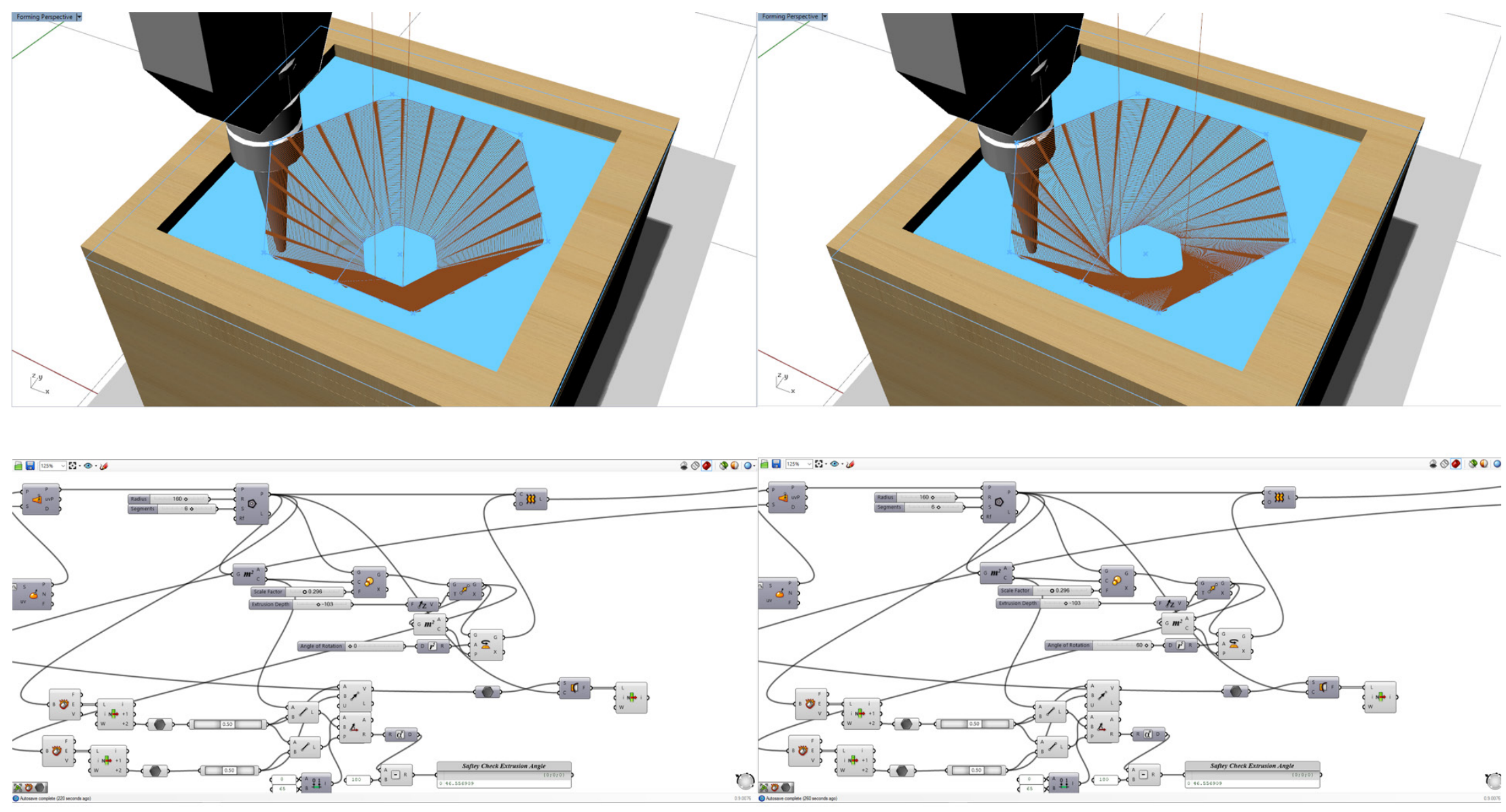

Figure. 14: Incremental forming Grasshopper definition and Rhino simulation: Angle of rotation through extrusion - left 0 degrees rotation- right 60 degrees rotation 

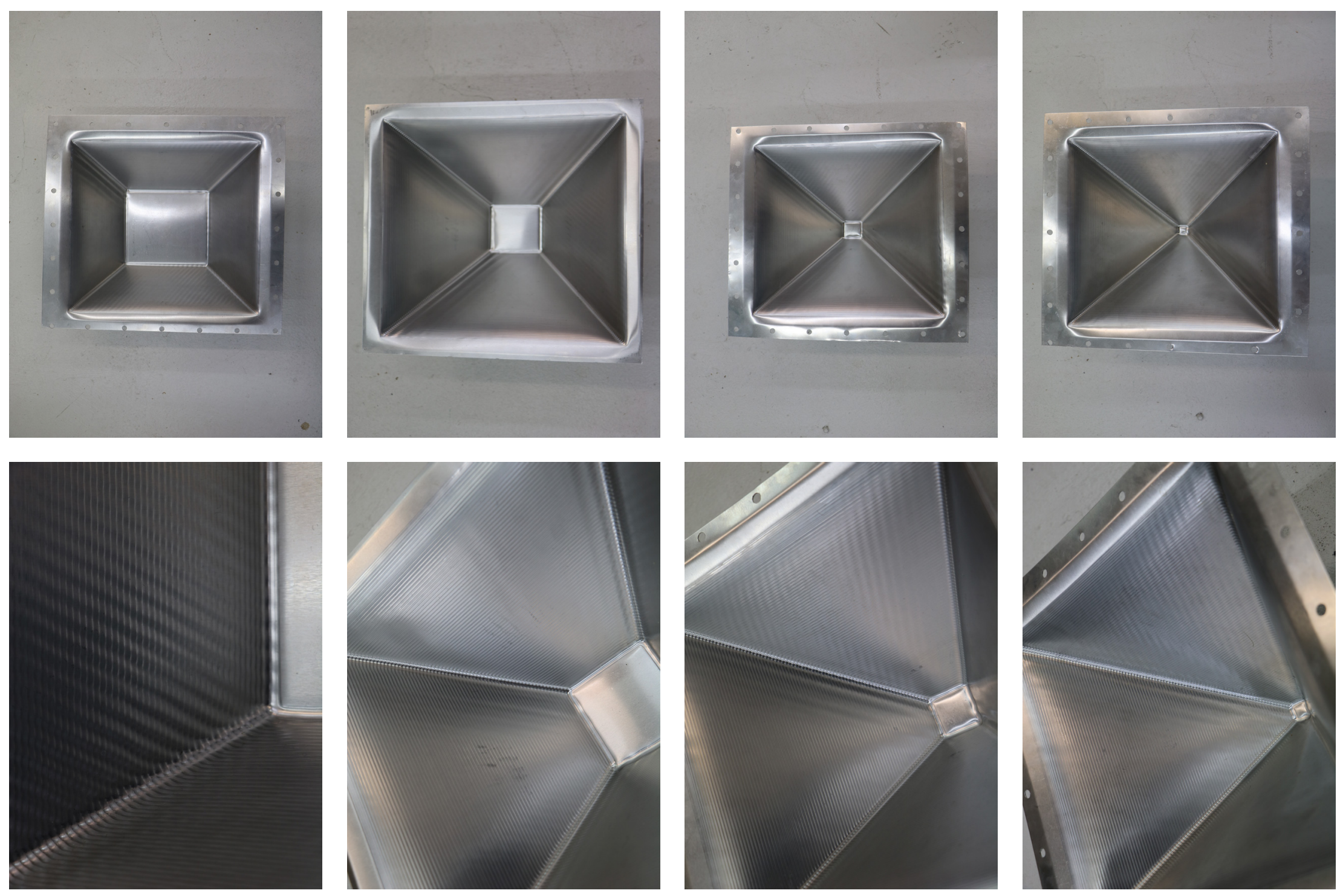

Figure. 15: Incremental forming tests: Depth of extrusion- left to right- $80 \mathrm{~mm} / 100 \mathrm{~mm} / 140 \mathrm{~mm} / 180 \mathrm{~mm}$ 


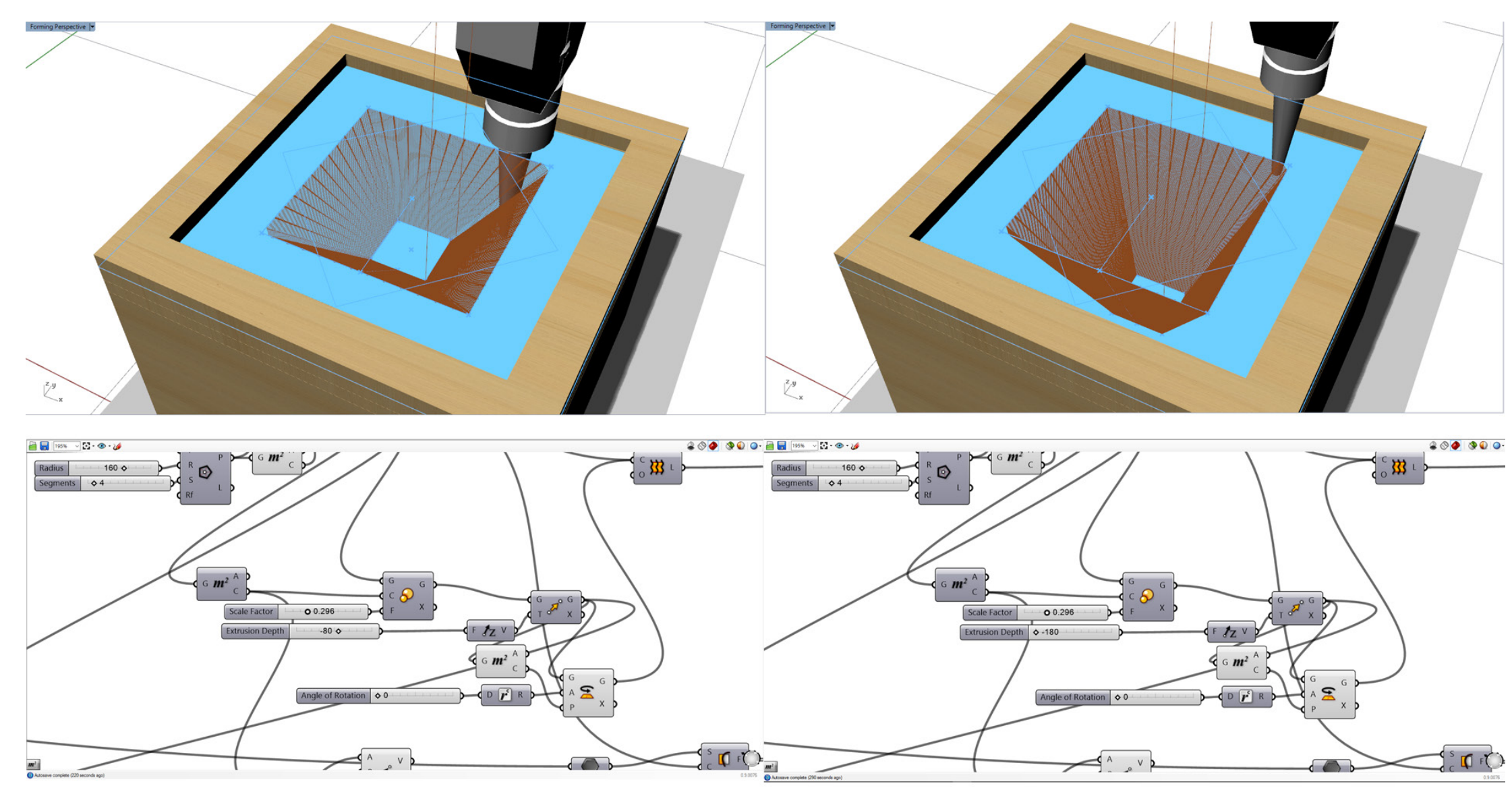

Figure. 16: Incremental forming Grasshopper definition and Rhino simulation: Extrusion depth - left $80 \mathrm{~mm}$ - right $180 \mathrm{~mm}$ 


\subsection{Conclusion}

During this phase, the research focused on design of the parameters that would be required for the first prototype. These were needed to generate a Grasshopper definition that would allow the input of basic constraints, such as the jig dimensions and the workable surface area of aluminium that was to be manipulated. These constraints then lead to the generation of a set of parameters that the geometry could be related to and abided by. This was the first iteration of a parametric system which allowed the designer to simply define the basic desired geometry of a triangle, circle, and square. The program would generate said forms three-dimensionally, then convert the forms into toolpaths. Once translated to the fabrication machine, these tool paths would control the robot in such a way the planar surface of the aluminium would be formed into the computer modelled geometry designed through the parametric system. 
This initial stage provided the preliminary building blocks of a parametric system and digital workflow. The initial tool and material exploration helped generate a set of macro parameters which helped govern the limitations of the forms. Blind parameters were originally established, because the exact variables of components within the system were unknown. This approach had to be employed to give the research a starting point to understand what was possible with not only the machines but the material. This learning could then be applied to the parametric definition with the constraints applied to future experiments so they would not undergo failures. For instance, if the metal was formed too steeply there was too much stress placed on the aluminium thus the surface integrity failed, resulting in torn or perforated sections as exhibited in Figure. 17. This lead to parameters being established which constrained the angle of rotational extrusion between 0 and 60 degrees.

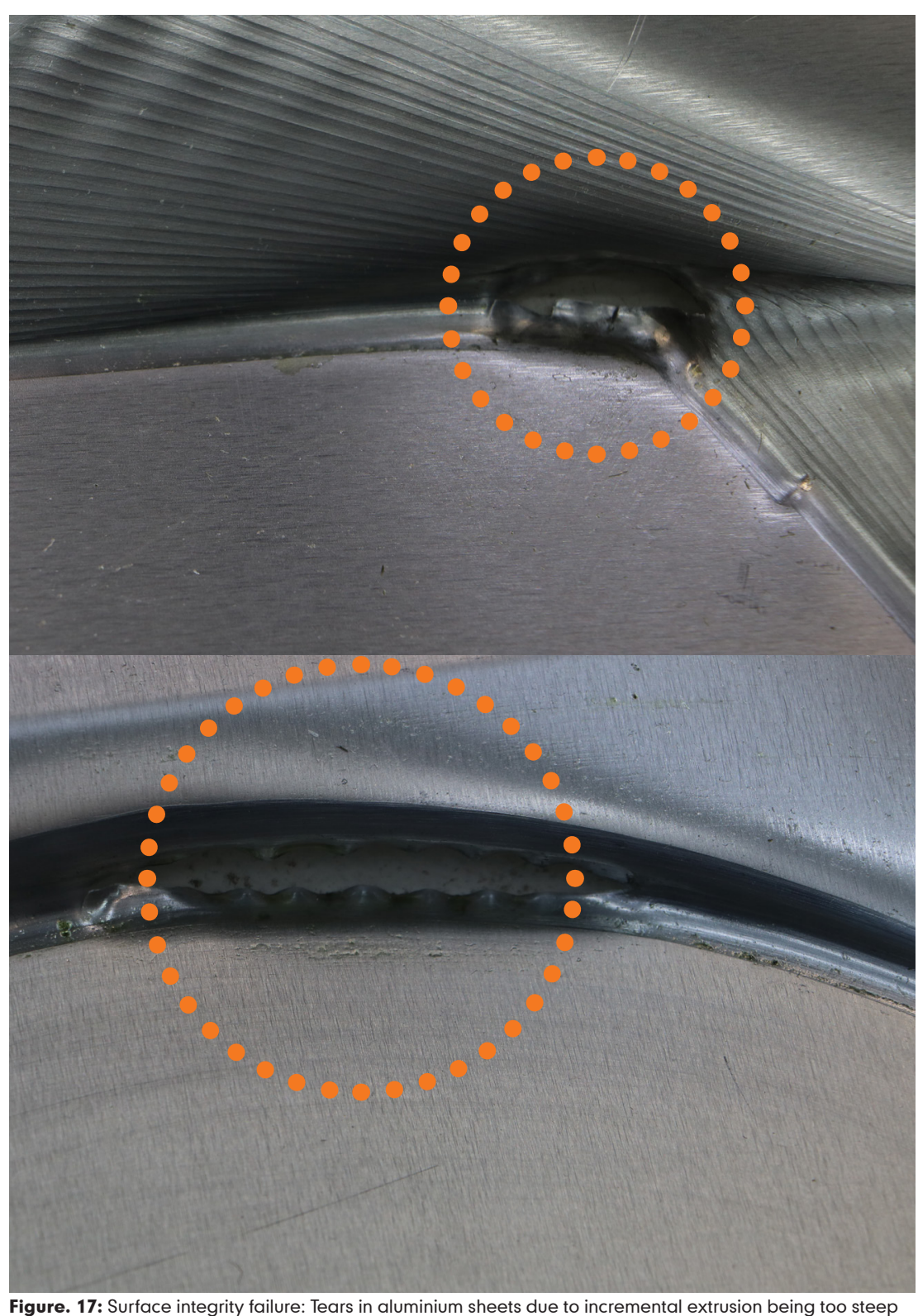

Figure. 17: Surface integrity failure: Tears in aluminium sheets due to incremental extrusion being too steep 
This initial experimentation process provided the research with some fundamental understandings of how to establish a parametric system. It was discovered that that the industrial robot had limitations regarding its movement as did the metal regarding its ductility. These limitations could then be input as parameters into a Grasshopper definition, to later ensure the parametric system generated a plausible form which the machine could generate. It also established that a designed and defined workflow was crucial, to ensure all learning which resulted from the initial experimentations were included in the parametric system. What was uncovered was the importance of the designer, as the parameters they input gave them control of the entire design process. Experimentation provided the designer with the data needed to design the parameters which could then find a suitable form the industrial robot could then replicate in the physical world. This was the beginning of understanding how this control provided by a parametric process exactly informed architectural space. 

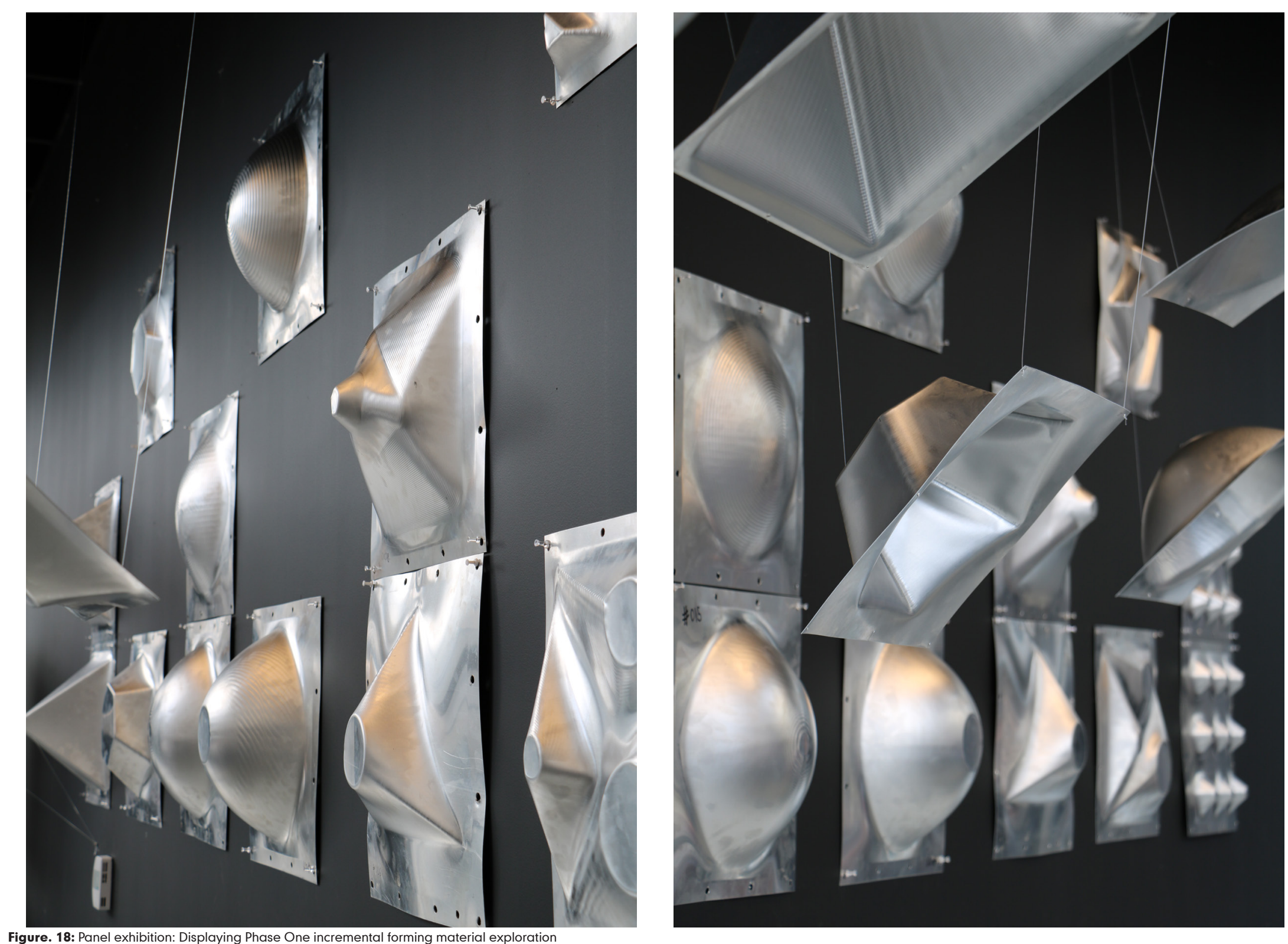



\section{0}

||||||||||||||||||||||||||||||||||||||||||||||||||||

5.0 Phase Two: The TATU System

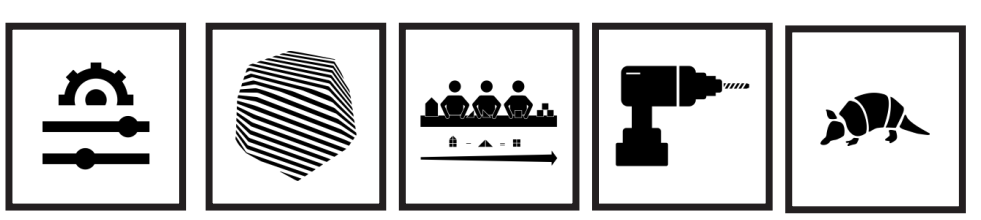

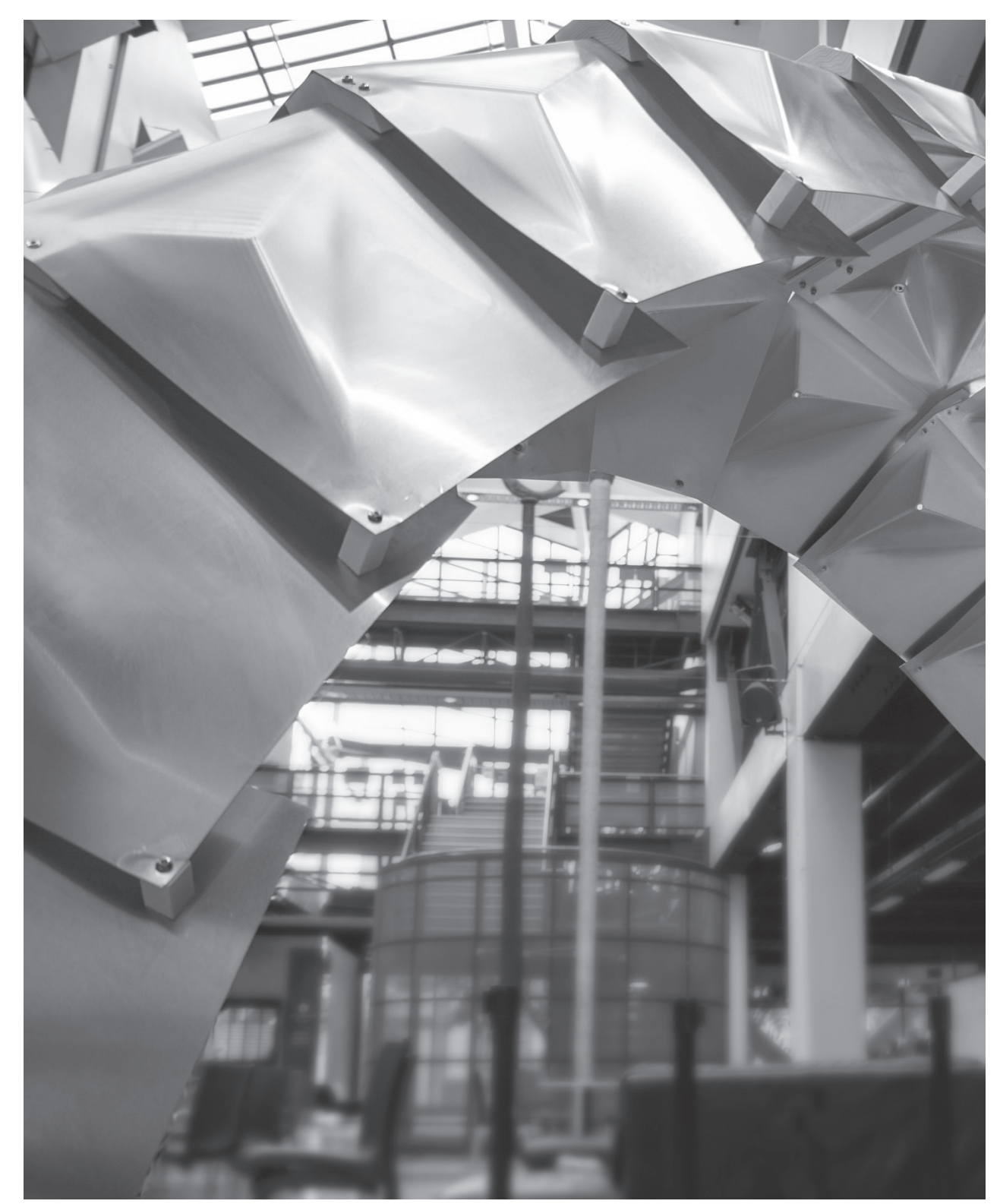




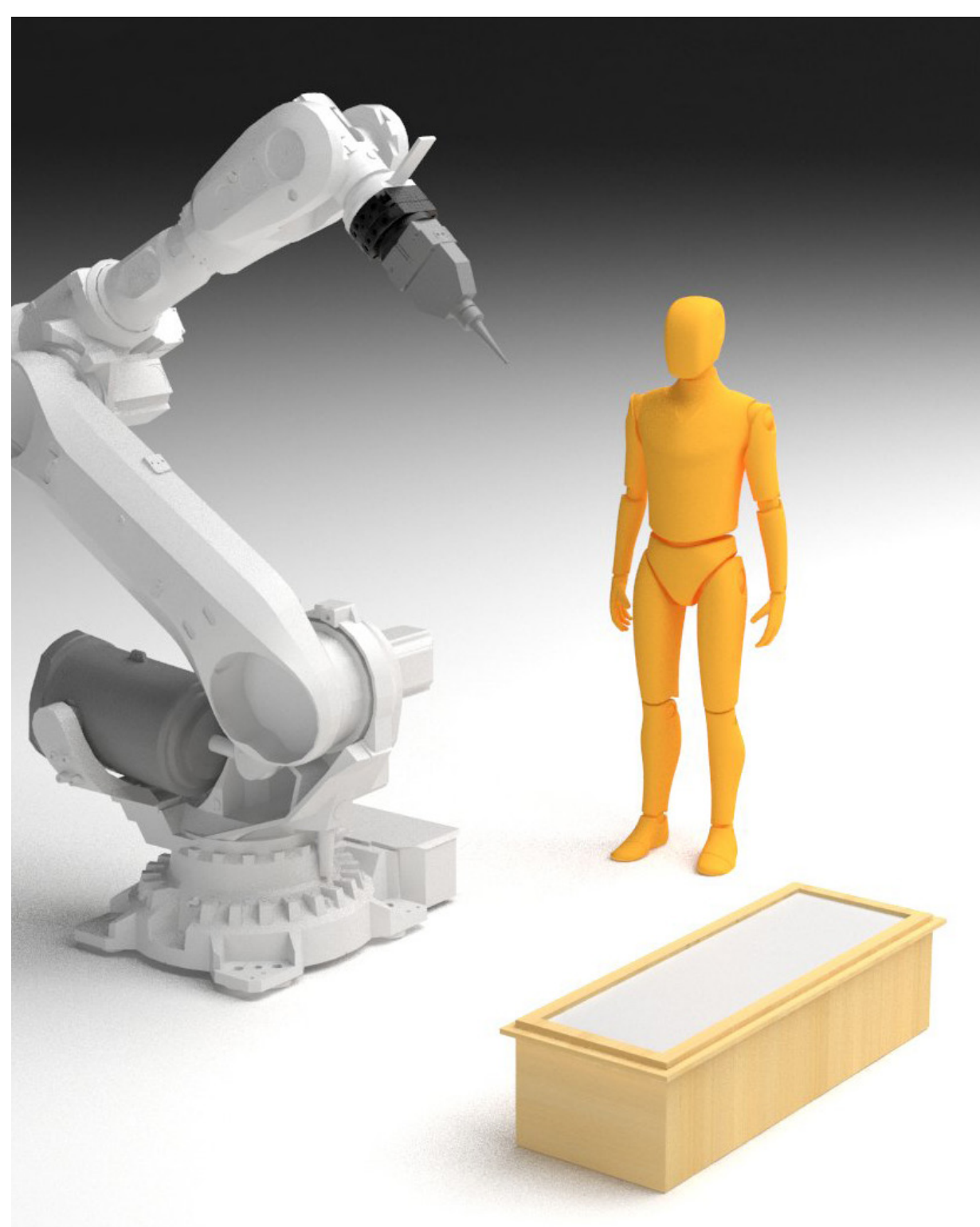

Figure. 19: Rhino and Grasshopper simulation model of the new large horizontal jig

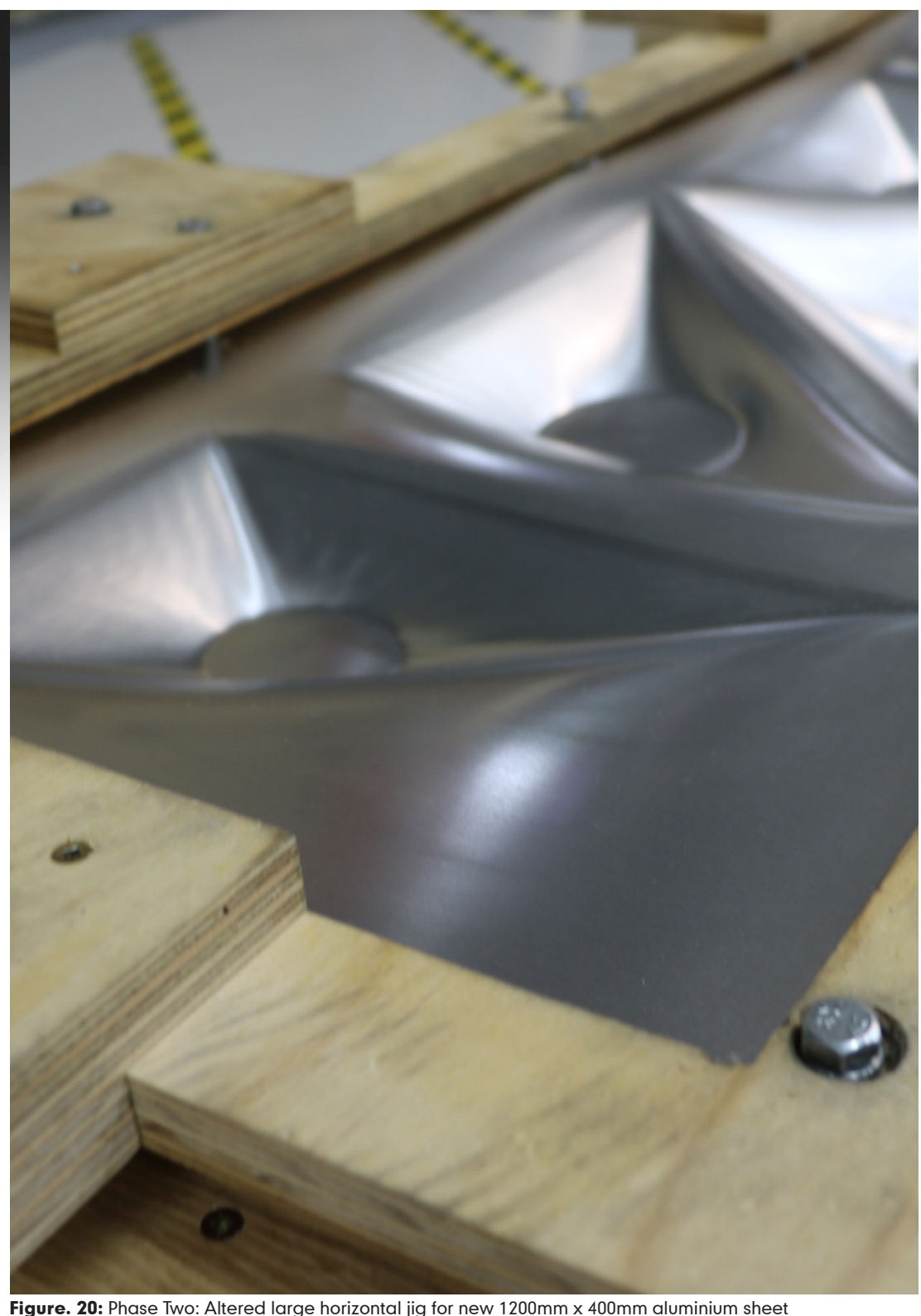




\subsection{Definition and Tool Augmentation}

The initial tests used a small, metal sheet in order to have more control and direct feedback during the experimentation of the processes and workflow. Phase Two altered the sheet size so that it may be used in a full-scale prototype (Figure. 19, Figure. 20). 


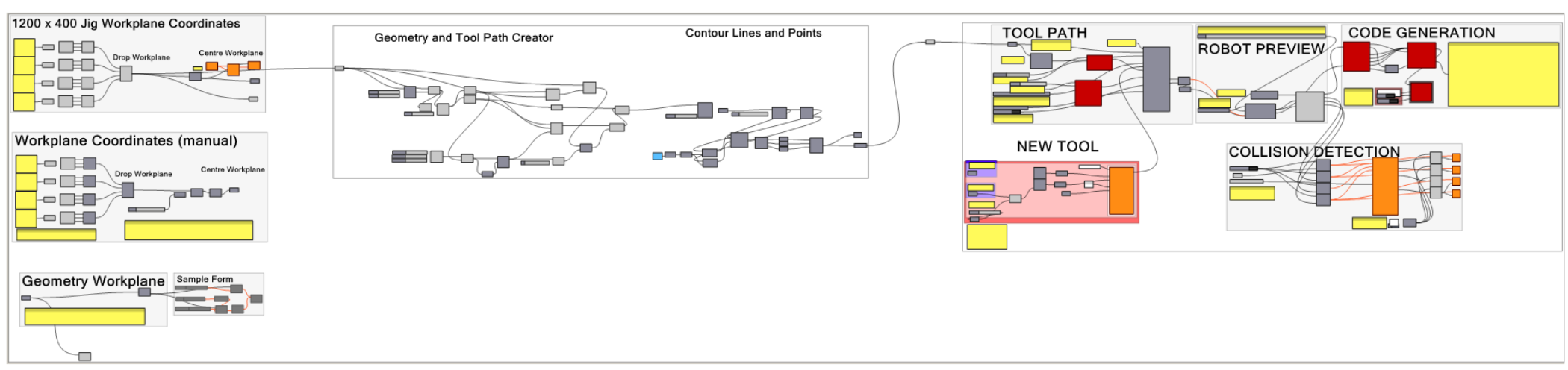

Figure. 21: Developed parametric Grasshopper definition for Phase Two 
The first prototype was going to increase the surface area of each panel, but also minimise waste from the native aluminium sheets the forming panels were cut from. Building on the knowledge from Phase One, an initial system was scripted in Grasshopper. The definition itself was set up with the macro parameters established in the first phase of testing, such as maximum working area, depth, and angular extrusion. This provided a fundamental parametric system to begin testing the new panels with (Figure. 21). 

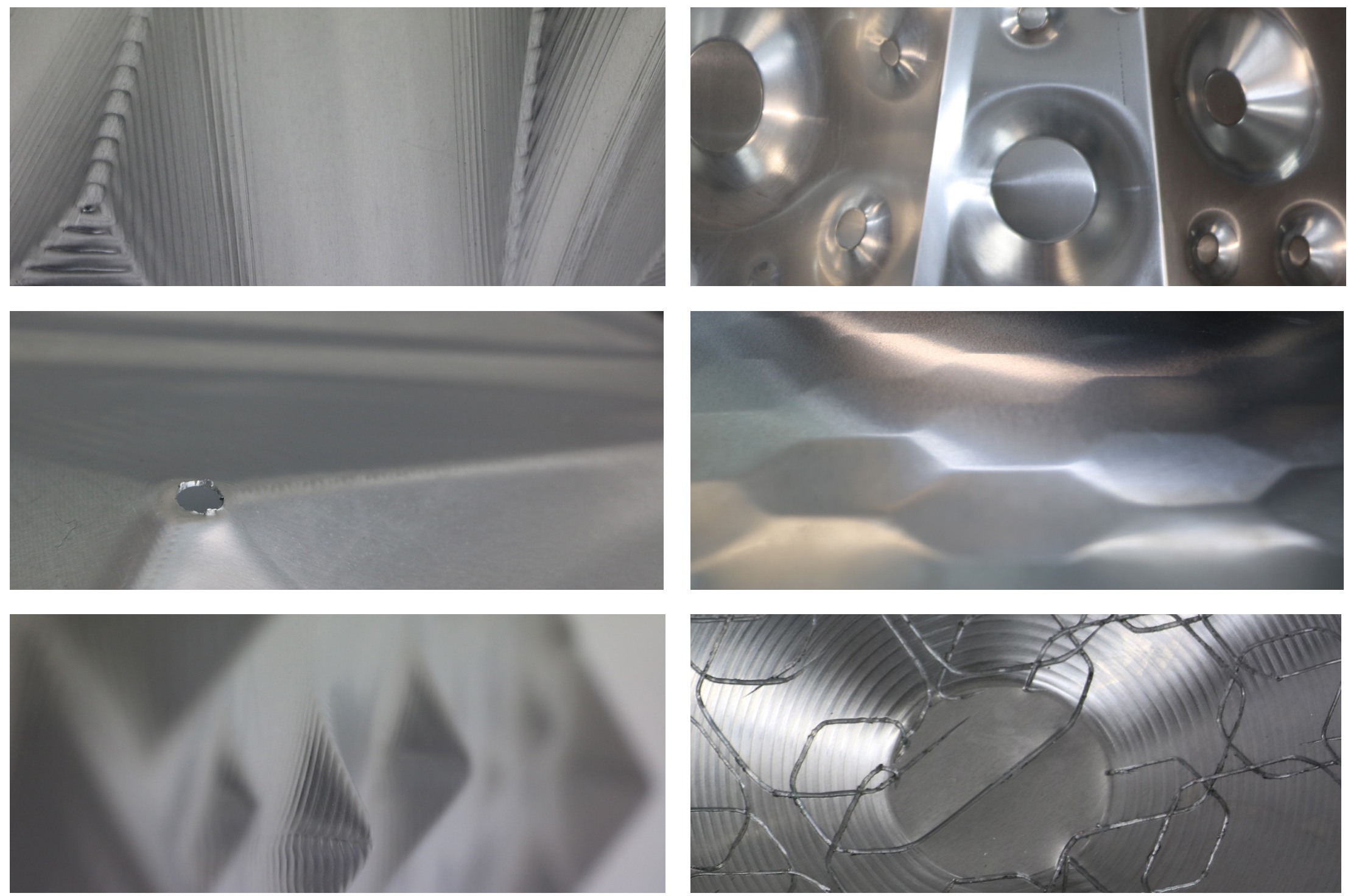

Figure. 22: Phase Two: Large aluminium sheet form finding experimentation 


\subsection{Design Exploration: Form Finding}

A conceptual panel design slowly came to fruition based on a form that was generated in the experimentation of Phase One and Phase Two (Figure. 22). The initial form was triangular extrusion, discovered to be the most suitable as it provided the panel with more rigidity, preventing it from bending as much as it would if it were not to be extruded. The material enhancement was a culmination of the preliminary research from Phase One. Enhancement of the panel's strength was observed through the research team's interaction with the panels (bending and manipulating the panels) and was not scientifically measured. Further research would be valuable to gauge the actual structural strength influenced by increased manipulations upon the panel, however this was not part of this research.

With knowledge of how the aluminium could be extruded and a basic concept of a system established, the underlying Grasshopper definition was created. The initial parametric system was able to generate a singular panel, however looking at applications in regards to an architectural structure the experimentations were merely individual panels and not an aggregated system. 


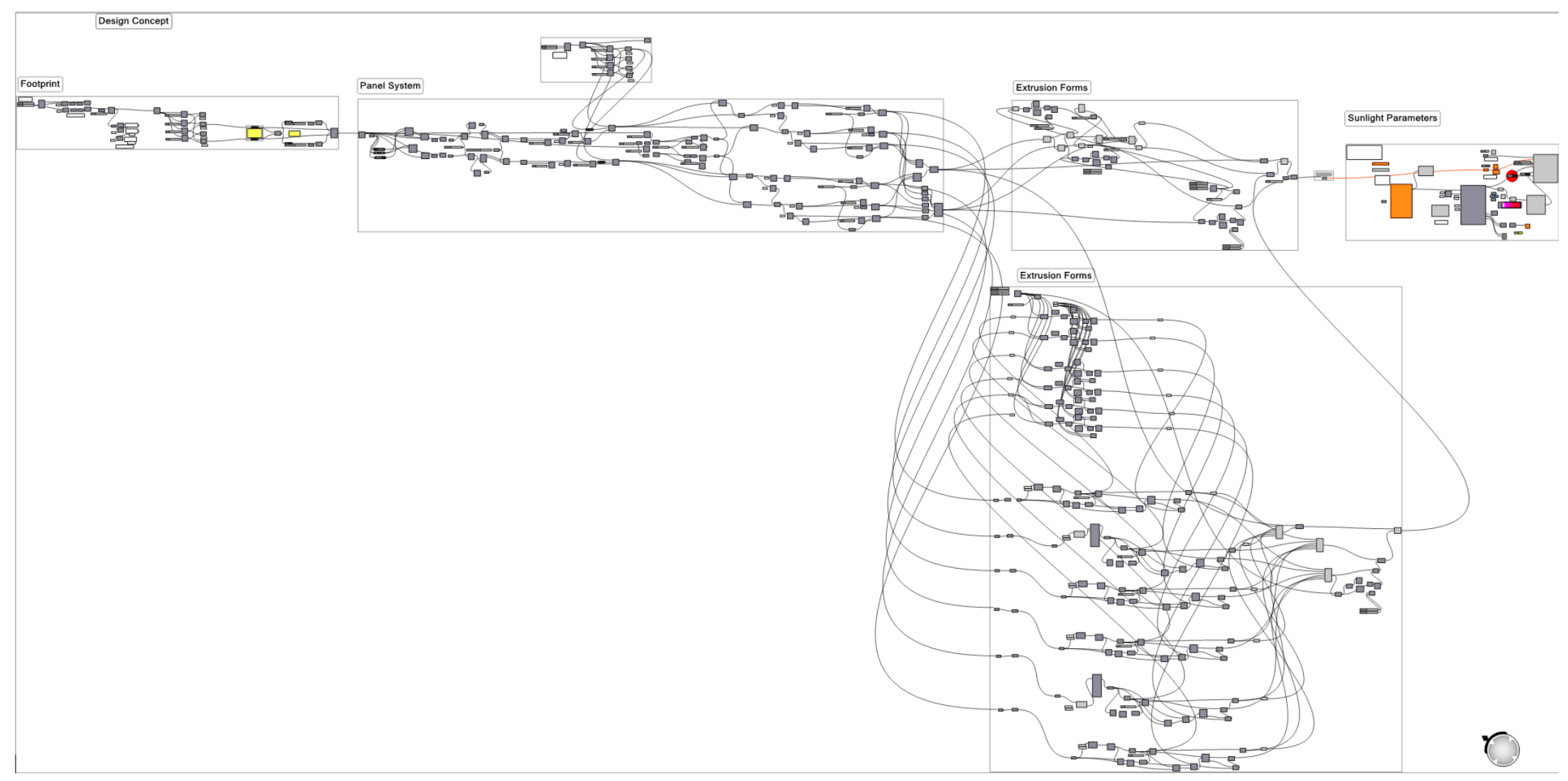

Figure. 23: TATU form finding definition- Grasshopper and HAL 
Recognising this, a progression of design meetings lead to the idea of aggregating a series of panels into a performative system, a system of panels which could potentially work together to generate an architectural artefact or structure. This system would mean that individual panels could be bespoke, yet act collectively to generate a complete form that was a result of all the individual panels, embodying the notion of a complete system structurally and aesthetically.

Phenomenological characteristics were also considered, such as the idea of light manipulation in a shading system, or a structural façade that could regulate light penetration. In order to follow through with this idea, aperture perforations were implemented into the apex of the triangle. This was done manually in this prototype; however, it is a possible function the industrial robot could perform with further exploration (not part of this research). 


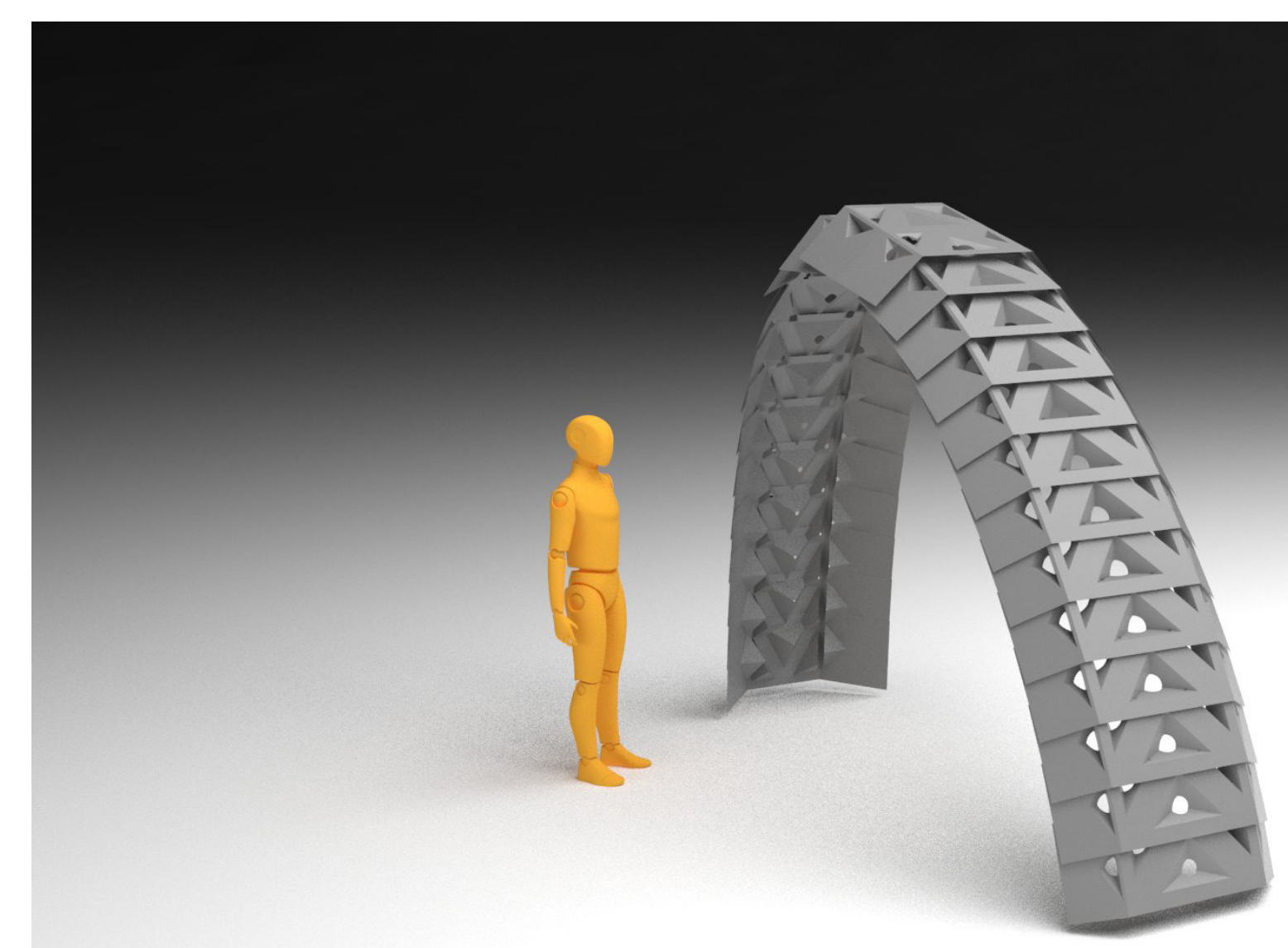

Figure. 24: Conceptual form finding definition output 


\subsection{Creating a Prototype}

In regard to the research question of this thesis, a pioneering parametric system was designed using Grasshopper. The initial shape of the structure was conceptualised through the material properties of the aluminium. A parametric definition came to fruition, with parameters based on the properties of the prior research and the tools the research team had been using. The parameters derived through experimenting with the metal provided constraints for the chosen geometry of the triangle, however the computer program itself was employed to calculate an actual overall form of the pavilion system. Figure. 24 demonstrates the end product of the research through design process. 

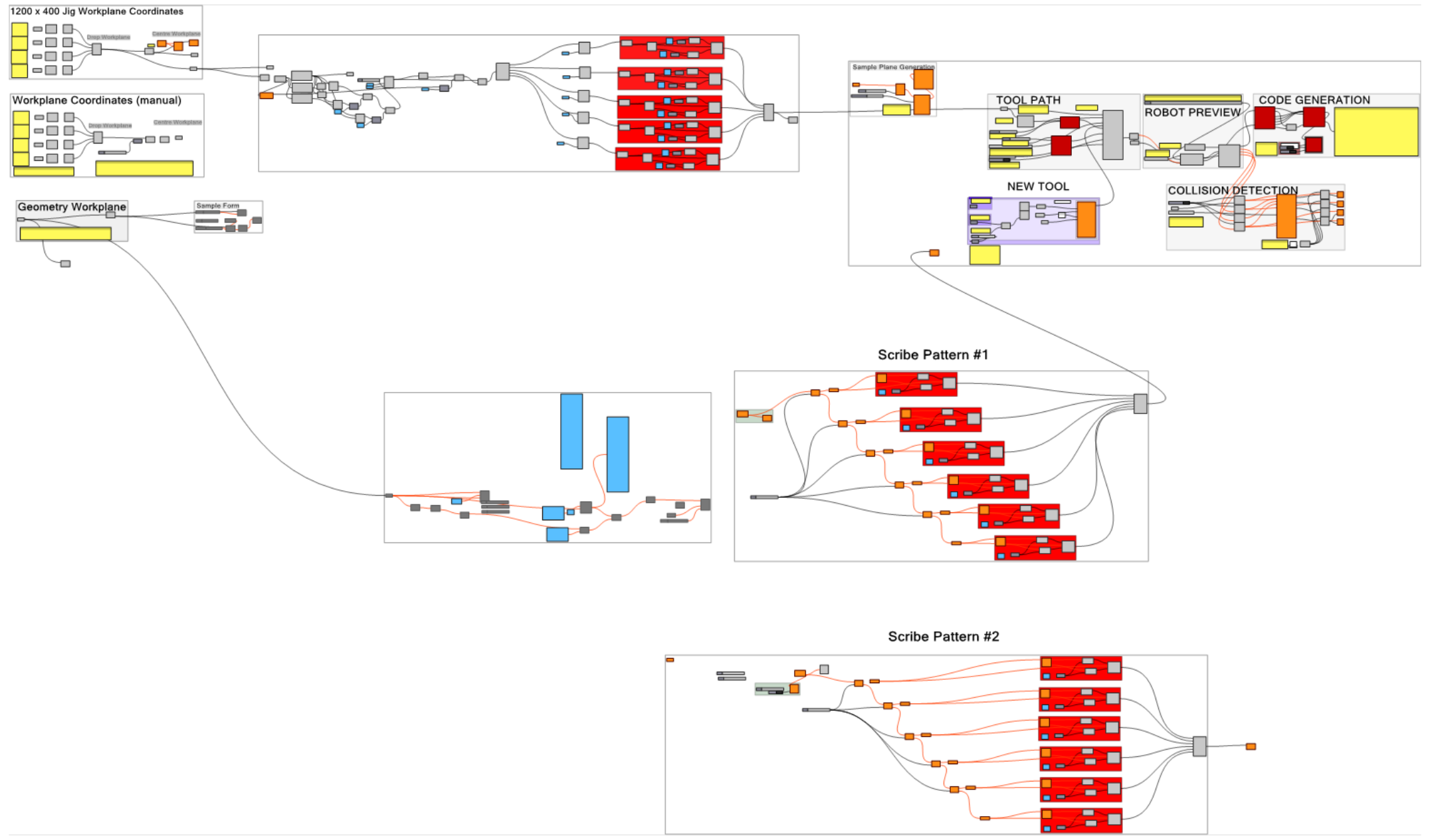
The Grasshopper definition as displayed in Figure. 25 was subdivided into smaller definitions. These smaller definitions in themselves were controlled by user input parameters including: the limitations of the panel dimensions, dictated by the jig and the tools of the working environment; the conceptualised forms of the deformations, dictated by the angular and depth limitations the aluminium was capable of; and the angles the panels could be bent at, controlled by the relationship of the structural fixing developed by the other research team members.

The system here demonstrated that it was possible to establish these macro parameters and constraints which could be used by the parametric software to generate a form. It was soon established that once parameters had been implemented, they could be altered to generate many different iterations. The designed system was a sum of its parts; an alteration to a parameter meant the system as a whole would adapt to a change. Whether it be the addition of more panels (Figure. 26) or the change of the extrusion, the computer could then use the system parameters and regenerate another prototype seamlessly as opposed to the research team redesigning a new form from scratch. 


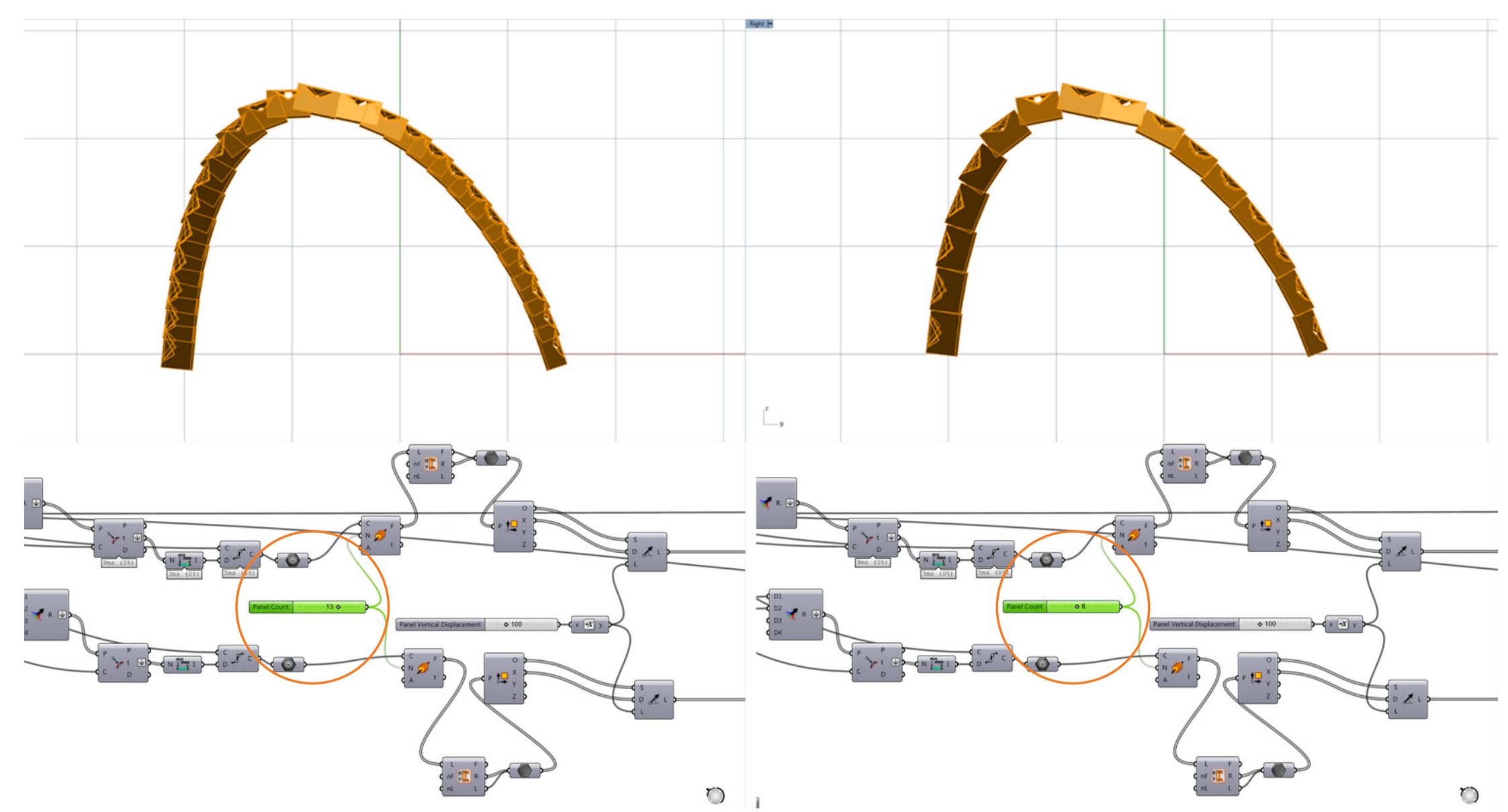

Figure. 26: Grasshopper definition displaying parameters that control the number of panels in the system 
The process of design through research divulged the notions of parametric design quite clearly through a design process. Parameters could be established in order to set up a series of geometric relationships. The threedimensional model was not designed in the standard format of visualising a concept then generating it, instead the form was found through design of the parameters. The system also meant that if a form was undesirable or failed, the parameters could be adjusted and the computer program could generate a new form based on the altered relationships between the designed parameters.

This new parametric definition provided the research team with a concept to create a physical prototype. With the basic system in place, forms could be taken from the definition and transformed into toolpaths the robot could use to translate onto the aluminium sheets. The initial form could then be passed on to another parametric application, CATIA, through extraction of parameters, where other research team members could then design structural fixing elements crucial to aid the construction of the prototype concept and their own research. 
The research team could work on the design of the panel system and the fixing structure that would hold them together simultaneously to generate the overall prototype. An overall system did govern both components, however both the fixing structure and the panel system in themselves had their own separate drivers and could be parametrically augmented if conflicts arose between the panels or the joinery. The workflow ensured a feedback process that features and dependencies the systems relied upon individually were conveyed to the rest of the team. This was to ensure the systems would work together and that the parameters were adjusted to accommodate all the components of the systems. 
The use of two discrete parametric application is something which could ideally be addressed in future design research, namely working on one system that took into account all aspects of the system harmoniously. This initial prototype was bottlenecked somewhat as multiple programmes and lead designers focused independently in some areas. Overall, the system itself was essentially components of smaller systems (both panels and fixings) brought together by the research team. This was a design choice as Grasshopper itself was more appropriate for parametric modelling for form finding, where CATIA was more appropriate for manufacturing joinery and structure. 


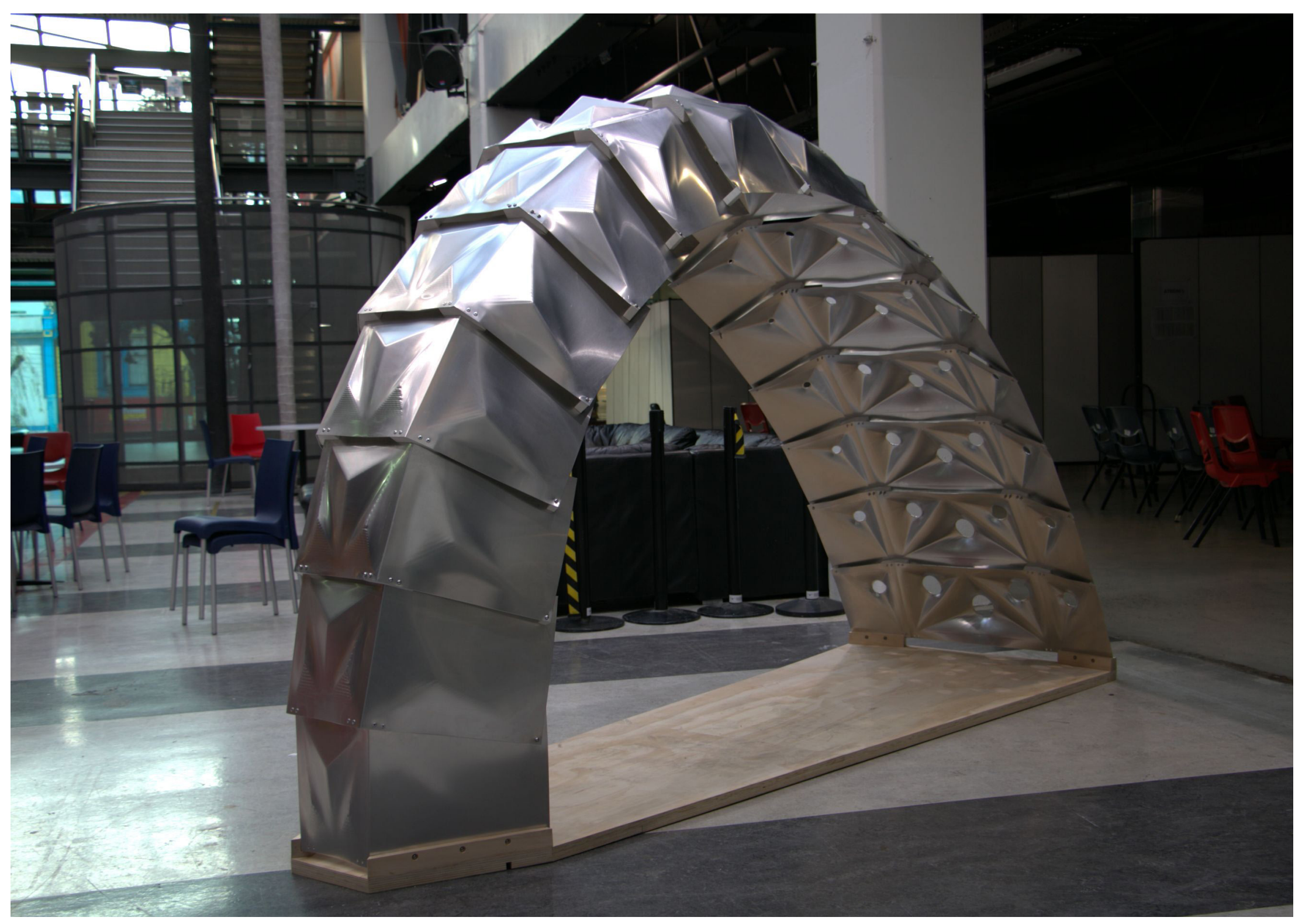

Figure. 27: The TATU: Performative Façade Pavilion 
Nonetheless the two systems were assimilated in such a way an understanding of what a parametrically designed system could achieve was divulged during this research through design. Prototype one, named the TATU

(Portuguese for armadillo) emerged from the research team's efforts at understanding their research goals (Figure. 27) 

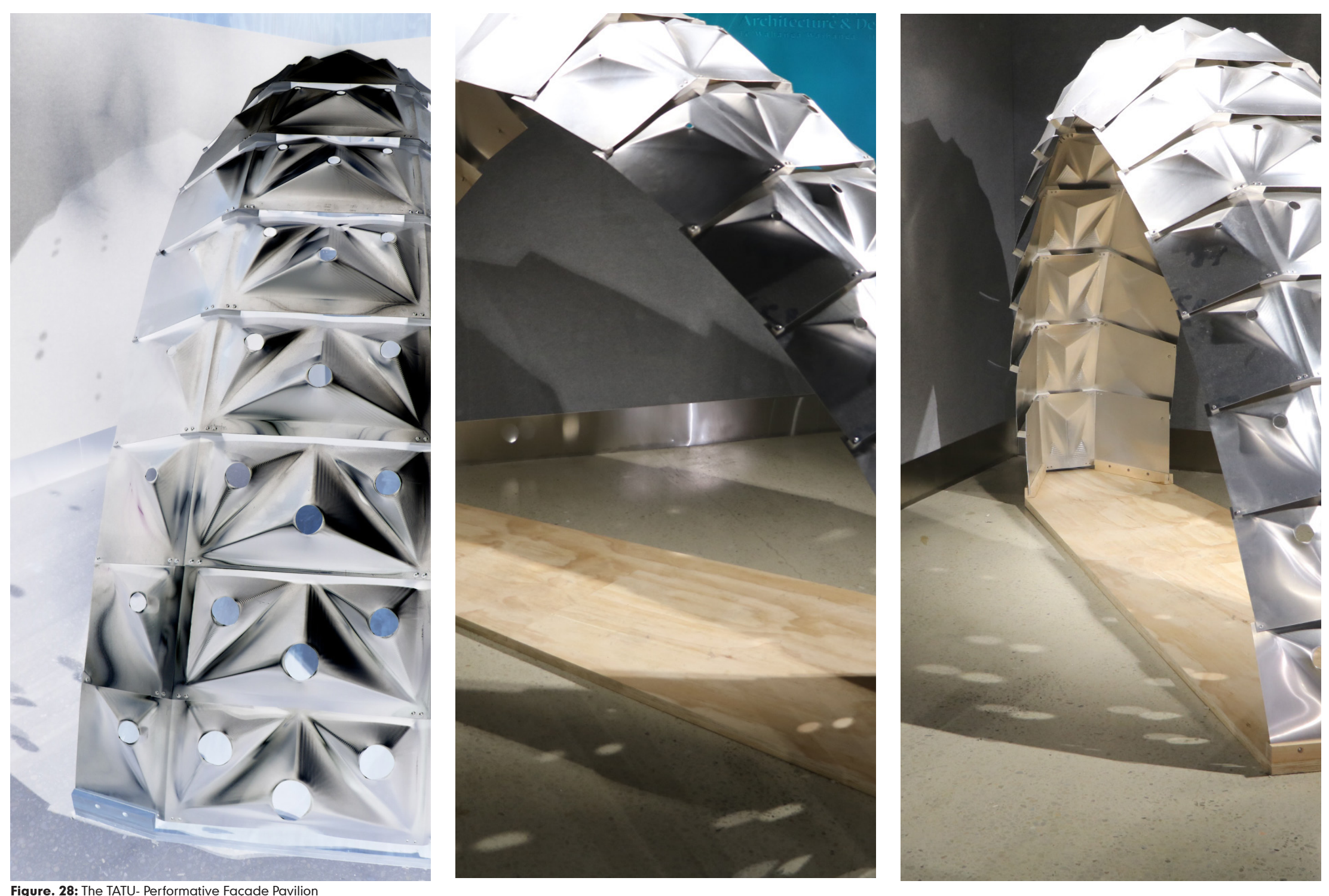

Figure. 28: The TATU- Performative Façade Pavilion 


\subsection{Conclusion}

Critical reflection of the prototype uncovered the elements necessary to understand the design and control of parameters in a parametric system, especially if a designer was to create parameters in which could have geometric relationships assigned to them to generate an inhabitable form. The research further uncovered the steps behind the parametric process, especially when converting a digital model into a physical artefact. Using the example of the aluminium, the experimentations with the incremental forming provided researchers with the knowledge of how the material behaved and the limitations and possibilities of the material. It was crucial as this research through design provided the feedback that informed further investigations.

With this information, the panels themselves could be converted from planar to three-dimensional forms, validating previous research to show that it was not only accurate but could be replicated. This knowledge informed this thesis by providing the understanding that threedimensional space could be manipulated and converted into a structure, a piece of architecture through a redefined parametric design process. 
The TATU provided a case study of how a basic parametric system can be used to sculpt geometric relationships in such a way that a form can be produced and inhabited. Parametric design in this instance provides the designer with the ability to generate and manipulate three-dimensional space that is not simply planar. This adds depth and volume, whether it be actual physical space or simply the mood or atmosphere where light plays on the surfaces of these generated forms as demonstrated in Figure. 29. 


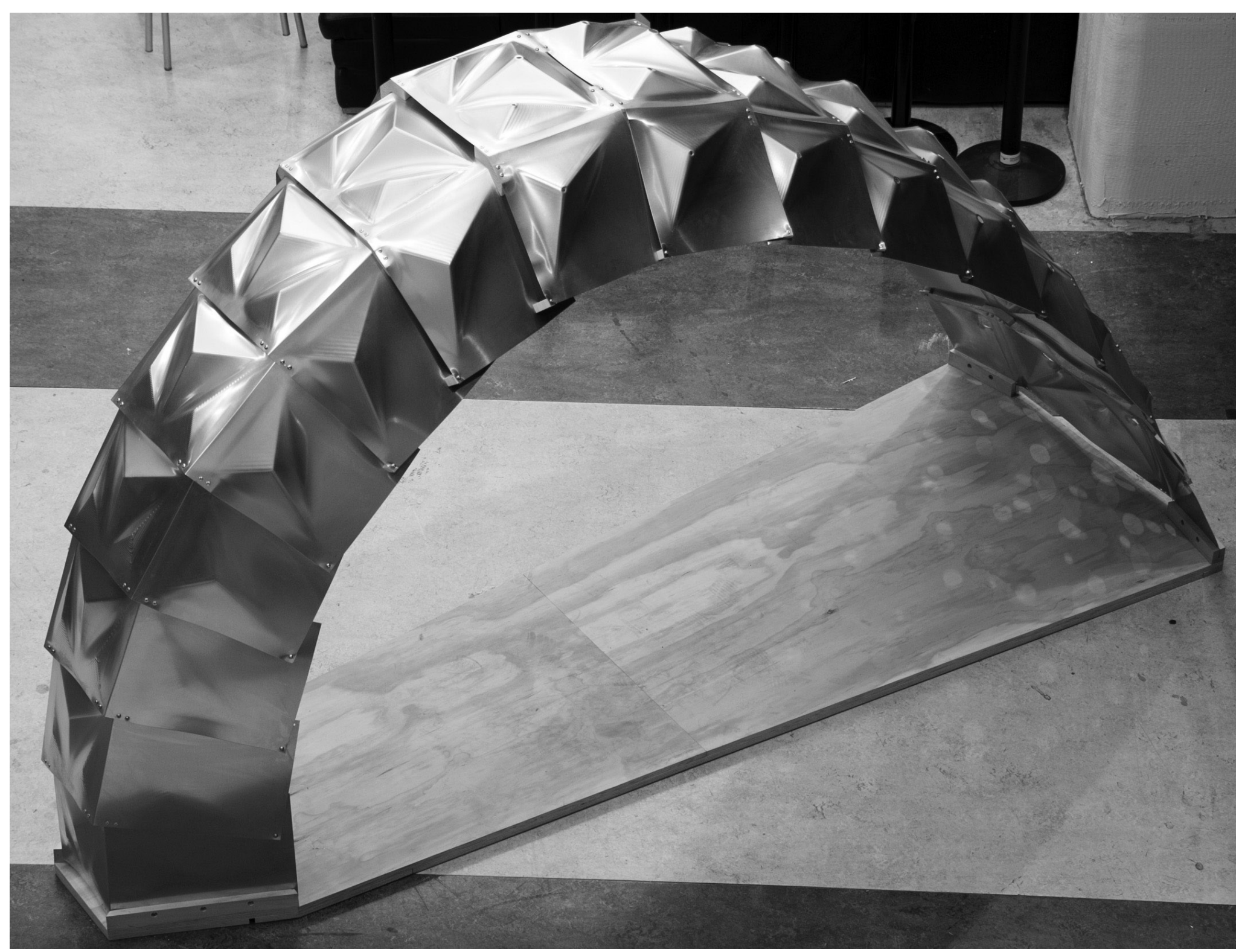

Figure. 29: The TATU- Performative Façade Pavilion 


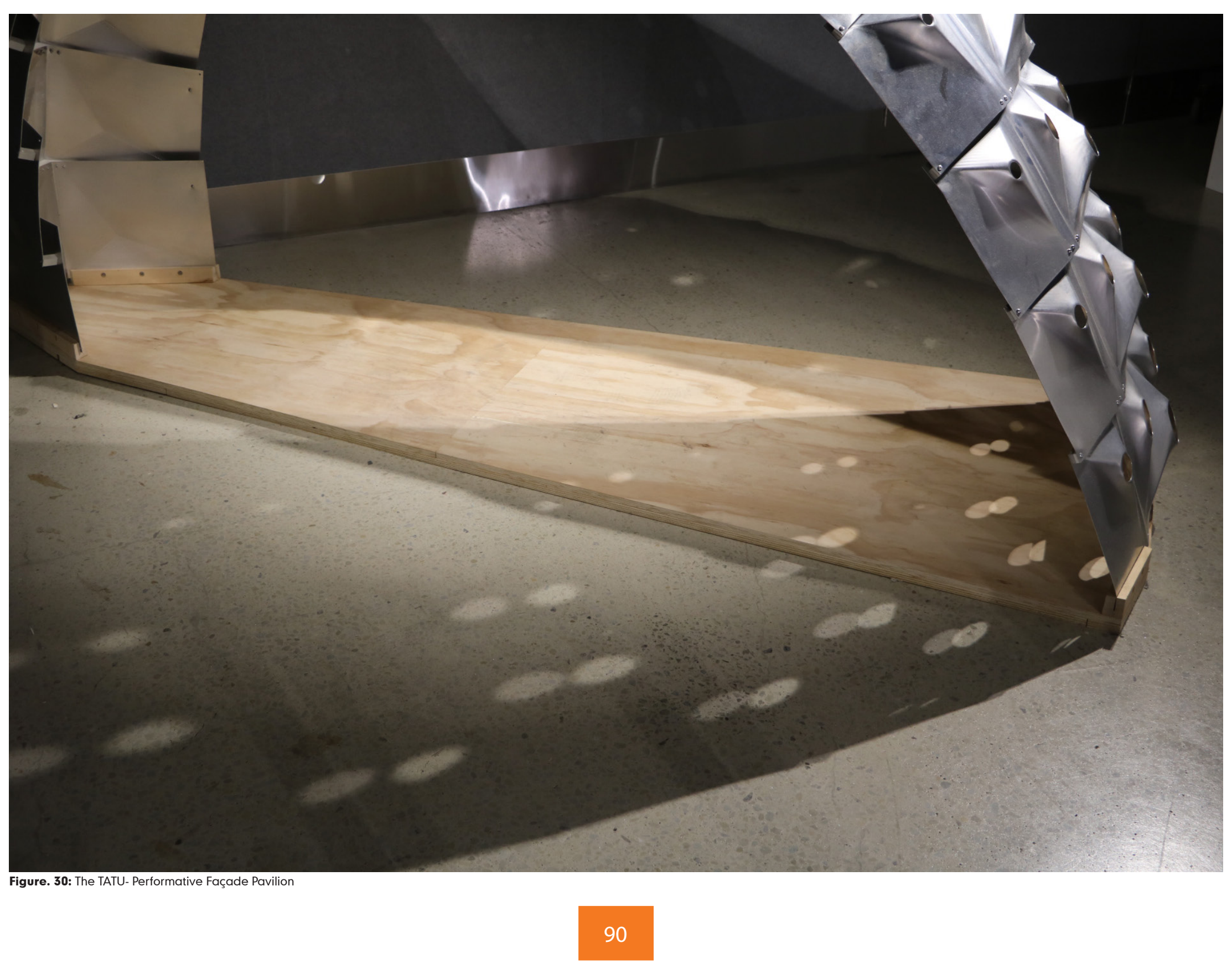


The parametric system provides the structure with a form which can be iterated and evaluated at any stage, this can then be brought into fruition via digital fabrication processes which provides the physical realisation of these attributes. However, unlike standard design methodologies, the parametric system can easily be manipulated through the augmentation of the relationships between the components of the system which drive the output of the geometric form. As opposed to redesigning it from scratch,

the system can be modified through the parameters instead of redesigned to address the failures.

When designing parameters for any parametric application, the parameters that are designed are black boxes. The information and conditions that are required to generate a desired outcome like form are unimportant when compared to the result. The actual designing of the parameters, or the black box, are important to control the preferred outcome, but once that is complete the goings on behind its fabrication are no longer important. This thesis seeks to understand how these parameters inform architecture and how they can be designed at the early stages of a design process. From the research performed 
in phase two, the power of well-designed parameters was evident This level of control not only informs the design of the architecture, but also provides the information needed for certain processes - such as CNC machines - to be able to fabricate it to a fundamental level of visual similarity to the computer-generated model. 



\section{0}

|||||||||||||||||||||||||||||||||||||||||||||||||||

6.0 Phase Three: Developed System Design

Z. 0.

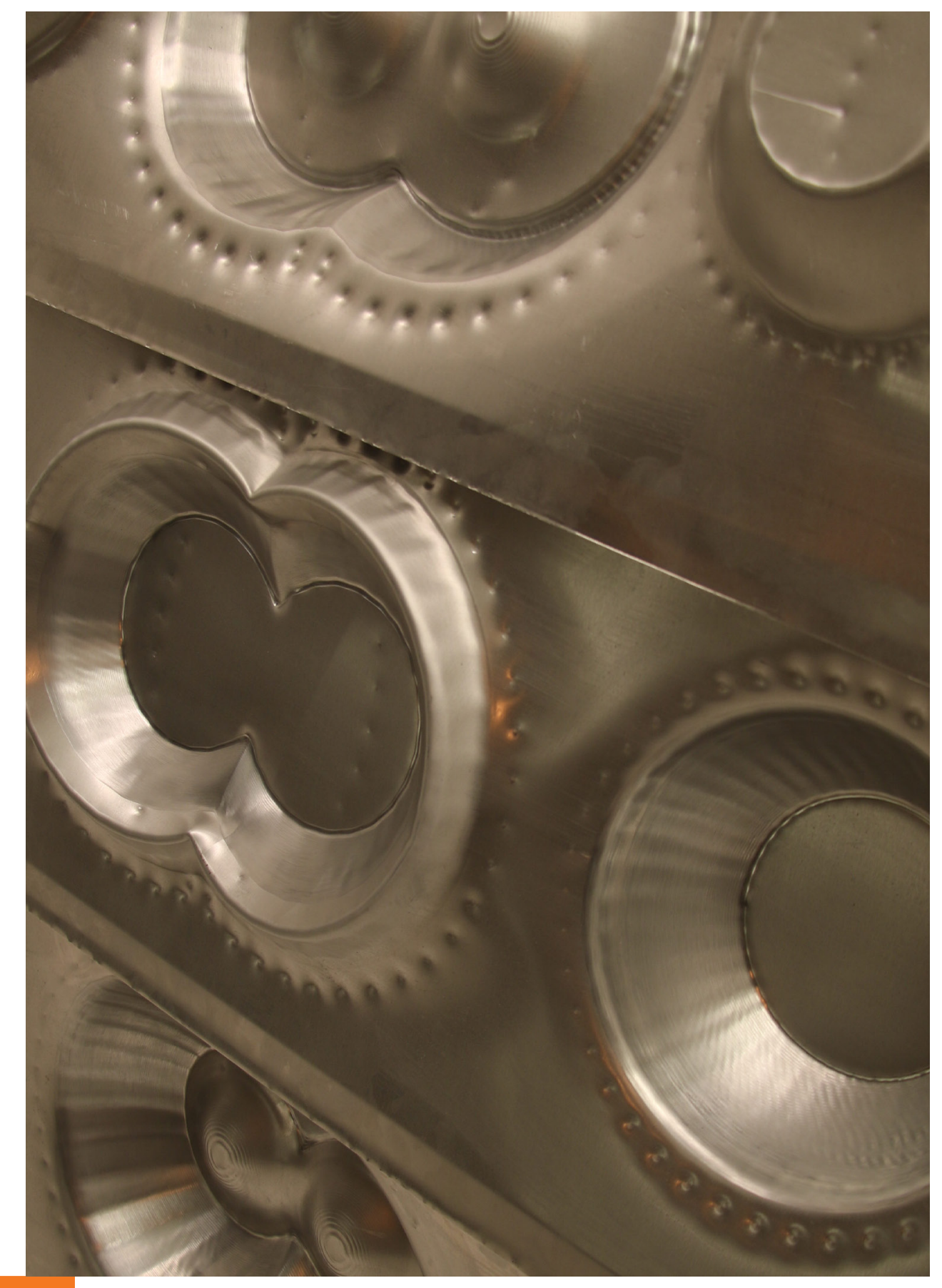




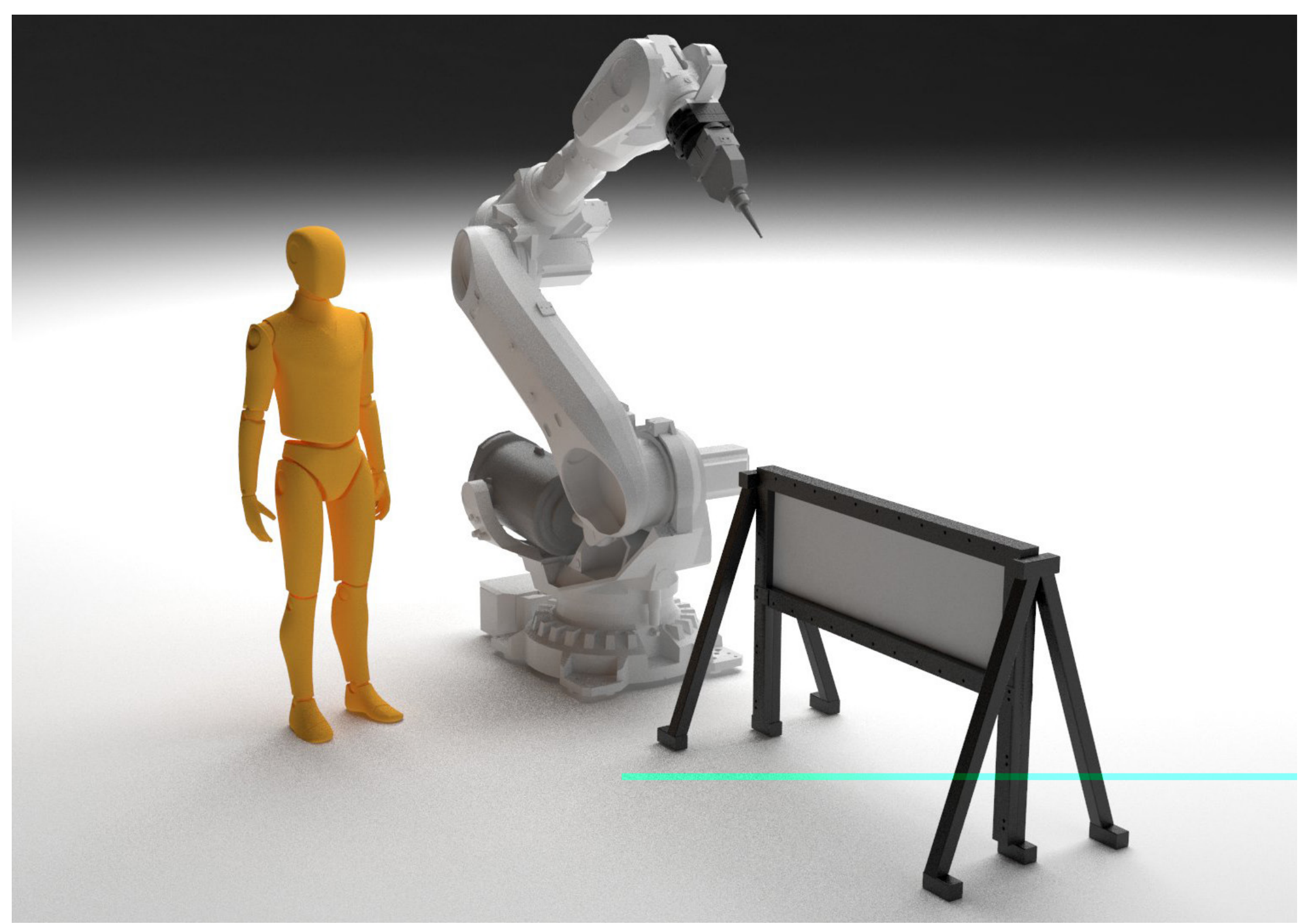

Figure. 31: Rhino and Grasshopper virtual working environment showcasing vertical jig 


\subsection{Design Development}

Phases One and Two provided the foundational knowledge necessary to develop a parametric workflow and design process. Phase Three provided a mechanism to apply that knowledge in a manner to inform architecture.

The studies so far manipulated the surface of the aluminium from only one direction. Due to the flexibility and degree of freedom offered by the robot, the next studies concentrated on manipulating the sheet from multiple directions. This step was seen as a progression primarily because of the ductility of the aluminium, but also because visual effects added depth as encountered with the TATU folly and its manipulated panels. This goal spearheaded the redesign of the jig, from a panel suspended horizontally to a vertical panel as demonstrated in Figure. 32.

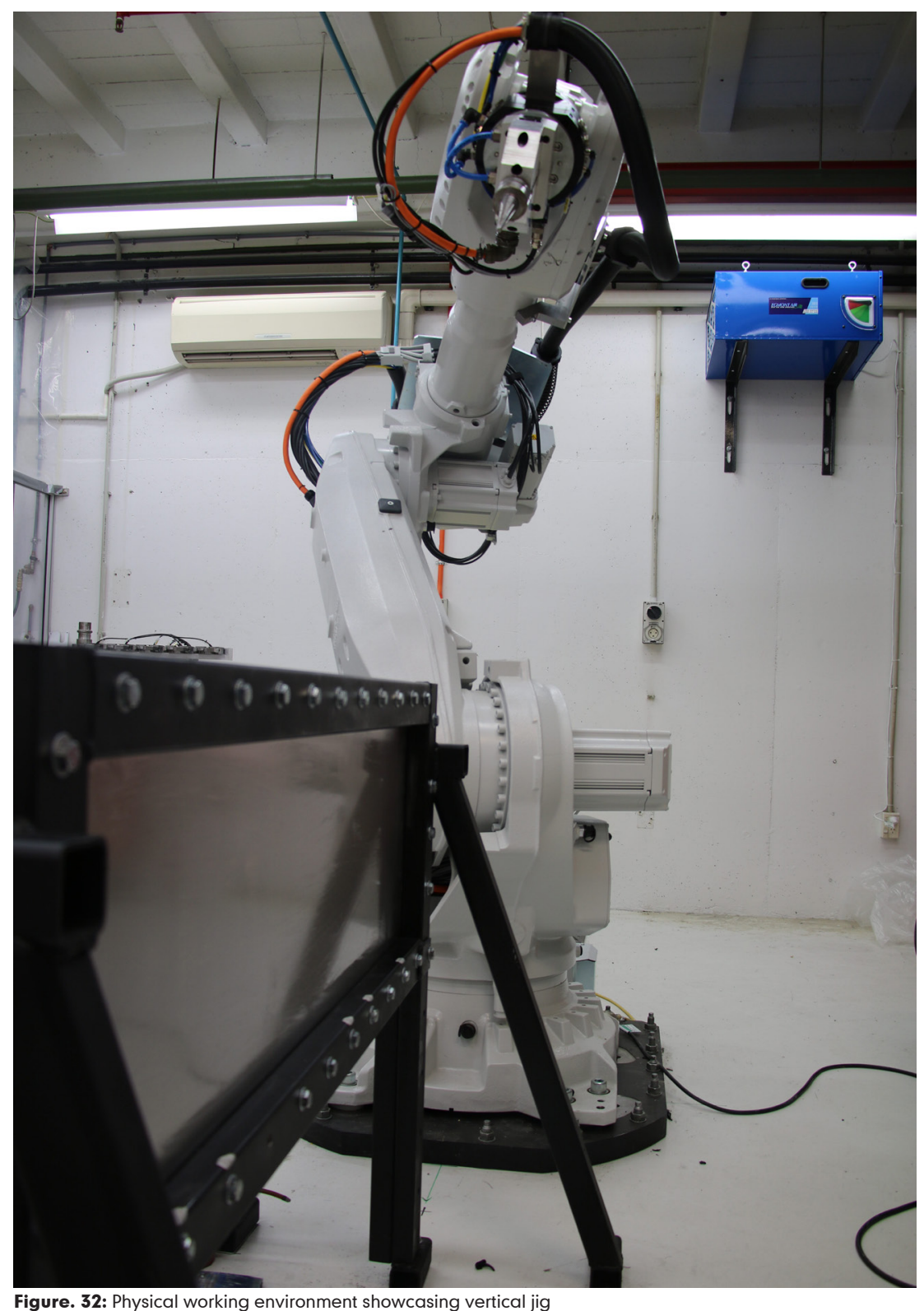

igure. 32: Physical working environment showcasing vertical jig 


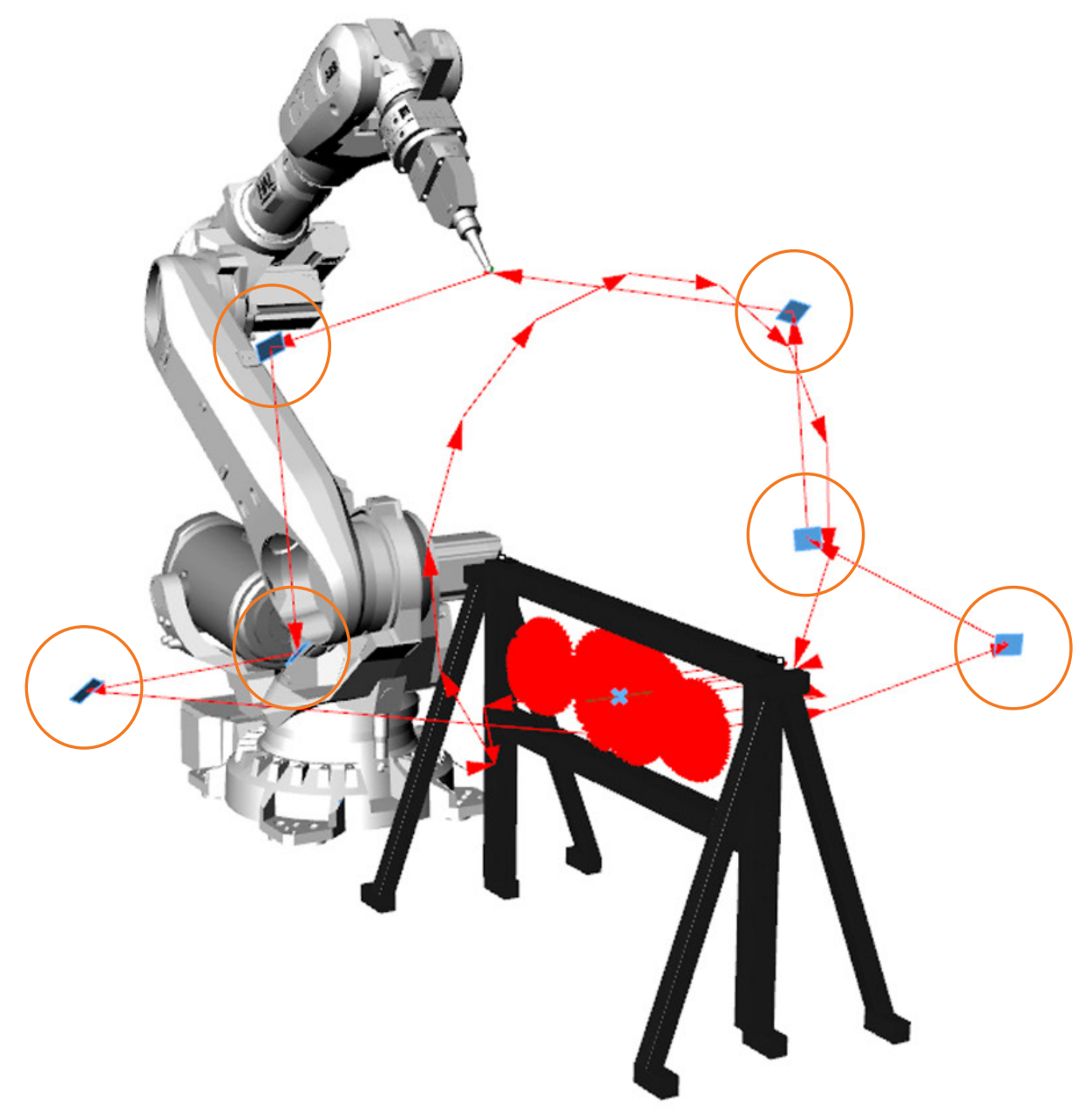

Figure. 33: Rhino virtual working environment: Demonstrating saftey planes (blue planes highlighted with orange circles) and tool path (red) 
This new system enabled the robot to reach both sides of the sheet allowing design experimentation to develop forms from two directions. The translation of the jig into a vertical axis required the addition of new parameters, which were easily designed based on the experience of the first two phases. For the robot to move about the jig safely, it was necessary to generate safety positions in order to avoid collisions between the appendage and the jig. These safety positions were converted into point dato and added to the sculpting toolpath for the robot to follow, as demonstrated in Figure. 33

The ability to form both sides of the material prompted explorations into more complex forms. Physical constraints set by the aluminium sheets and the learned understanding of how the aluminium could be manipulated by the robot, provided the basis for a new parametric system to be developed. While a seemingly daunting task because of all the new variables, the experience from the first two phases provided enough confidence to make the development easier. 

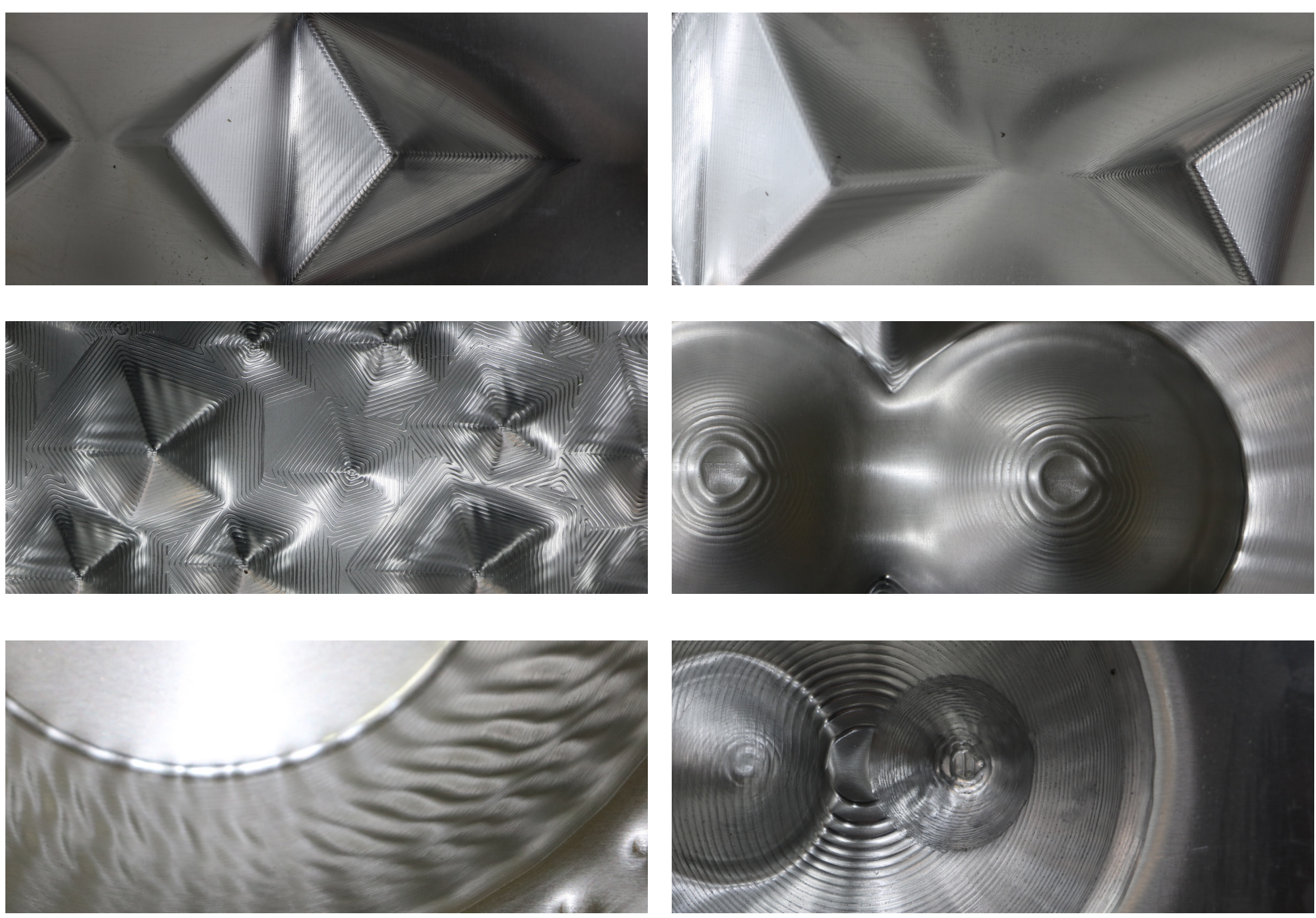

Figure. 34: Vertical sheet form finding material exploration: Phase Three 


\subsection{Prototype Form Finding}

Form finding for the next phase began with standard rectilinear geometries and slowly moved towards more spherical and curvilinear shapes, as demonstrated in figure Figure. 34.

Expanding on earlier developments of the parametric system devised in Grasshopper and with the new constraints the vertical jig required, experimentation focused on manipulating the sheet from both sides. The system devised had not only to incorporate conditions for the new forms but also conditions that would move the too to the correct side. As mentioned earlier, safety positions allowed the toolpath to be altered as it was seen fit and reposition the toolhead to the correct side to allow it to form the aluminium. 


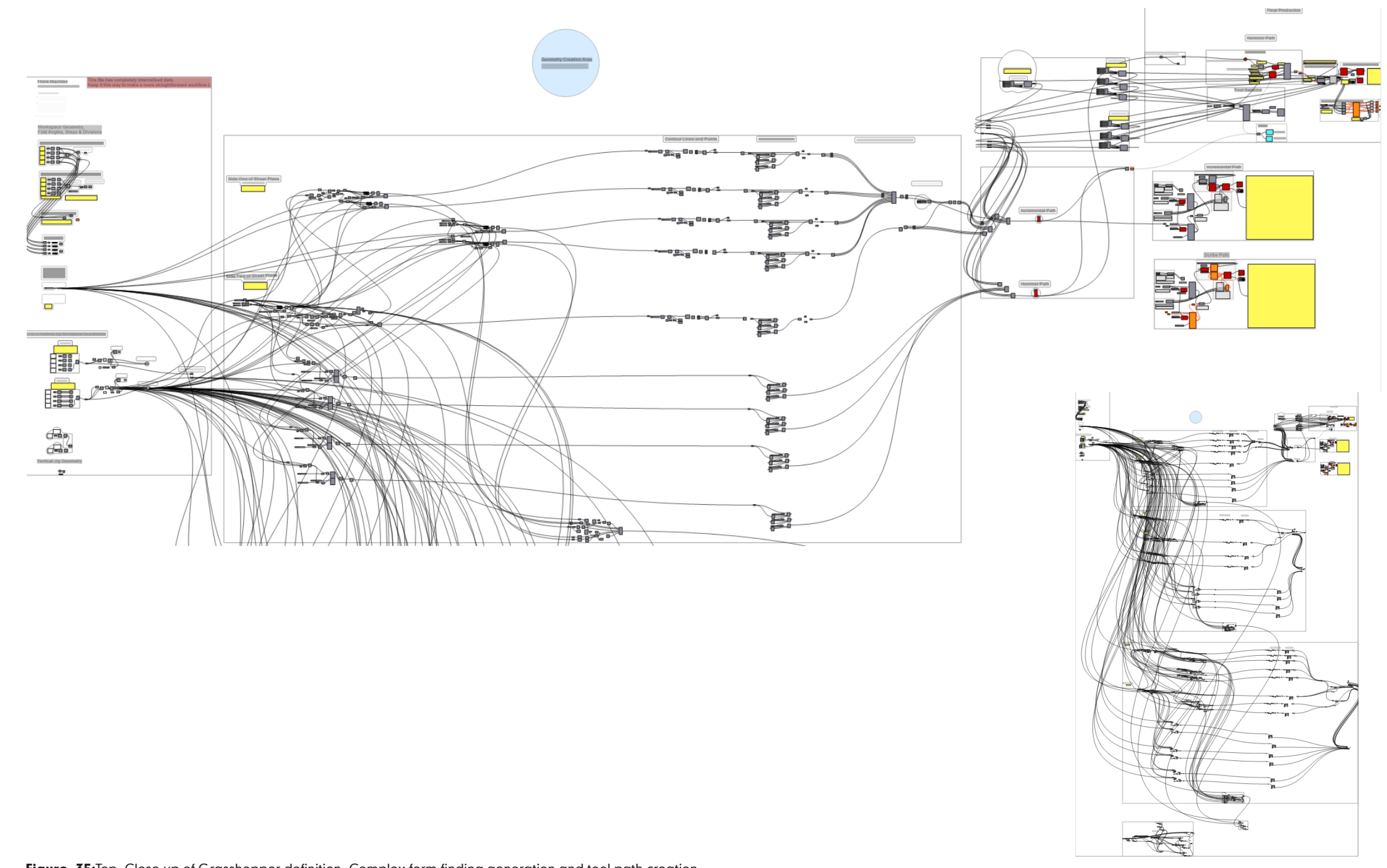

Figure. 35:Top- Close up of Grasshopper definition- Complex form finding generation and tool path creation

Figure. 36:Right- Overview of grasshopper definition for Phase Three 
As the development of the parametric system continued (Figure. 35), the way in which the extruded forms could be altered was developed further. Extrusions could be made on already extruded surfaces. Form finding started to become more complex as it was a simple matter of altering parameters within the defined system. This complexity through the deformation of the surface, as experienced in the TATU, made the panel more visually interesting. This multidirectional manipulation of the aluminium was something that the parametric system allowed in the design. Greater surface area was provided through manipulation of the aluminium multiple times over, generating undulating forms (Figure. 37). This manipulation expressed the ductile properties of the aluminium itself.

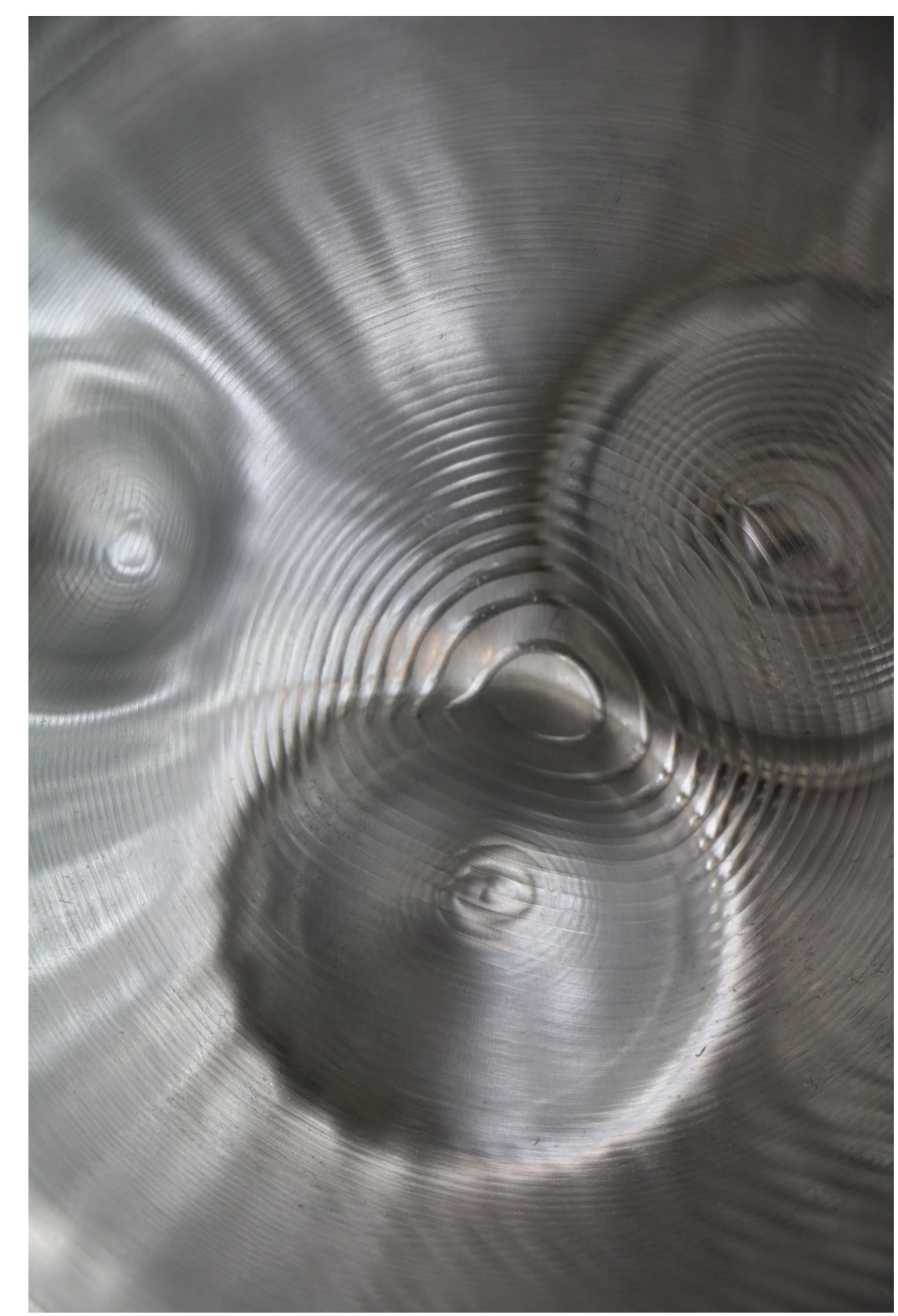

Figure. 37: Multidirectional surface manipulation 


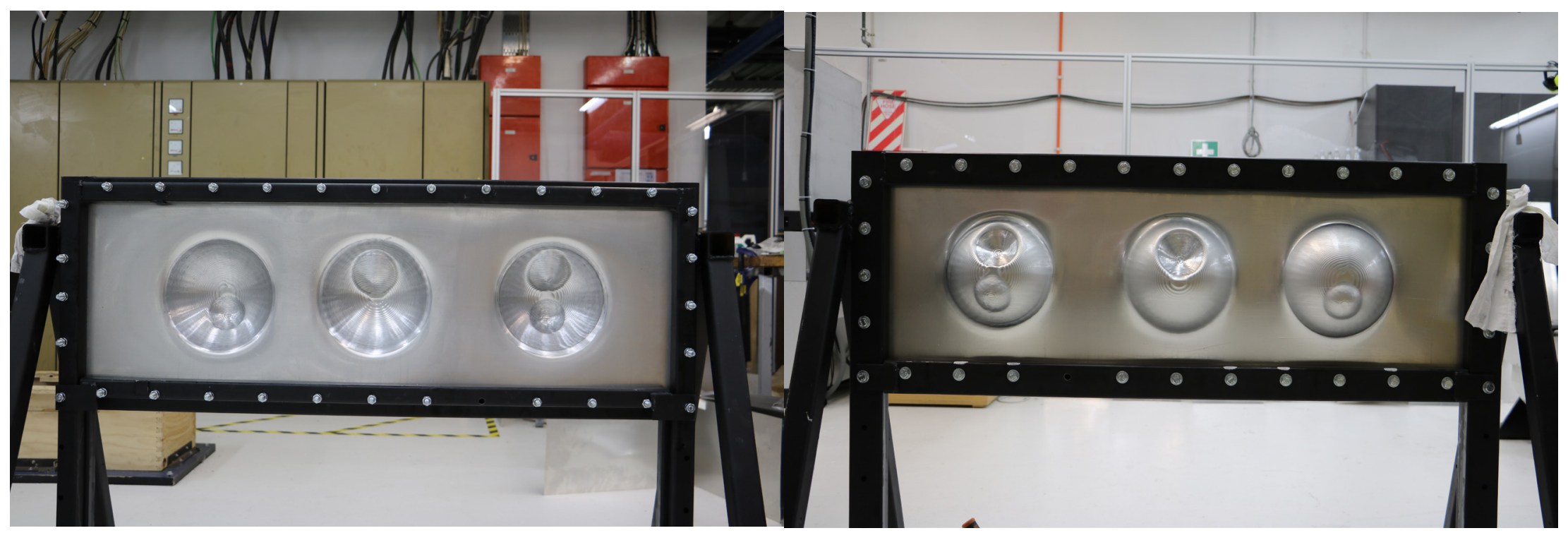

Figure. 38:Multidirectional dome extrusion- System prototype experimentation: Left-Front perspective- Right Back perspective 
This research looks at how parametric design can inform architecture through parametric systems. One way is through complexity and ornamentation. Complexity is introduced by a hierarchy of simple components aggregated together to generate a system (Simon, 1962). Hierarchy is key here: through exploration of the initial panels in Phase Three, it was noticed that there was a sense of arbitrariness (Figure. 38). The forms work by themselves but not as a system as they did in the TATU folly.

Through this stage the parameters were found to give the designer a significant advantage when finding a suitable form. Geometric relationships established through the designed parameters allowed for the form to be easily changed and to be edited seamlessly. This systematic design process was possible due to the parameters of the design which linked elements so when parameters were altered related elements were adjusted accordingly. This meant that the forms, patterns and ornamentation could be generated in such a way that they would blend together flawlessly. The prototype of the dome panel system (Figure. 
38) provided the fundamental understanding of this ability to generate an expressive system of formed panels. However, the prototype design for the dome panels was unsuccessful because its form had no visual hierarchy. This caused the domes to be aesthetically unpleasing as there was no relationship to the adjacent panels, but merely a rotation of sections of the forms.

Due to resource constraints, the design team was only able to develop a small portion of the full-scale output. Nonetheless the parametric system developed through Grasshopper in the previous experiments could be augmented and adapted for the prototype. Along with developing a panel system, the prototype looked at joinery of the sheets and a secondary structure.

The design of the new prototype iteration looked at changing the incrementally formed panels to enhance the visual aesthetic of the panels. A system was developed which then allowed a new prototype of panels to be designed. This iteration of the component panels lead to an overall form being generated. 


\subsection{Parametric System Prototype Iteration A}

The idea behind the new panel design was to promote the ductility of the aluminium being used and capture motion of the forming process. A parametric system was devised that could oscillate and ripple circles over a series of panels to take advantage of light. As with the results of the TATU prototype and the triangular formations on the panels, any slight contour or extension of a surface was to add depth and contrast to the panel, making the form more visually pleasing. The design of the ripple forms could also be focused on. From this point the manufacturing parameters had already been encoded into the system, which was key as it allowed the designer to focus on the design rather than the technicalities.

To achieve a design that used light through a ripple effect, the designed parameters generated a dome that oscillated in both directions of the panel. However as discovered through research of the TATU prototype, the incremental forming surface failed because the lofted form of the three-dimensional model in Grasshopper was too steep. The aluminium would only allow for a form to be generated between 0 and 65 degrees - this meant limitations to the angle of extrusion needed to be input 

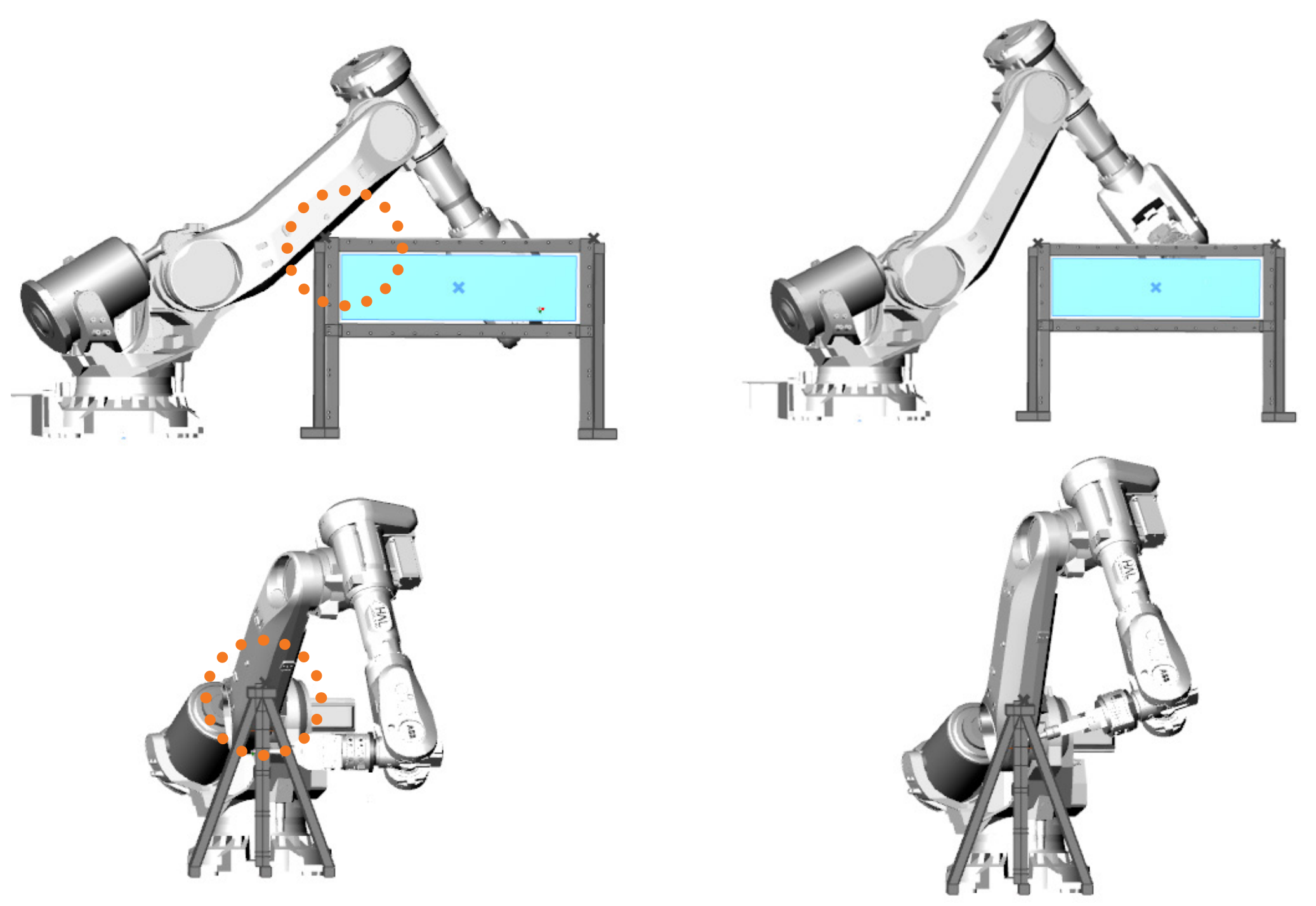

Figure. 39:Exhibits how controlling the angle to the tool axis to the working surface prevents collision of the industrial robot with the jig- Right collision- Left no collision 
into the Grasshopper definition. This altered the maximum depth and circumference of the dome forms.

It was also discovered that the industrial robot was not able to navigate all parts of the panel without colliding with the jig or itself when it was used to generate these dome forms. Therefore, safety planes had to be input as additional parameters into the Grasshopper definition. This restraint on the robot's ability to move meant conditions had to be established to prevent forms being generated outside working boundaries, and to prevent certain movements of the robotic arm, such as establishing parameters which altered native tangent angle of the tool heads to the sheet to an altered angle (explored in Figure. 39). 


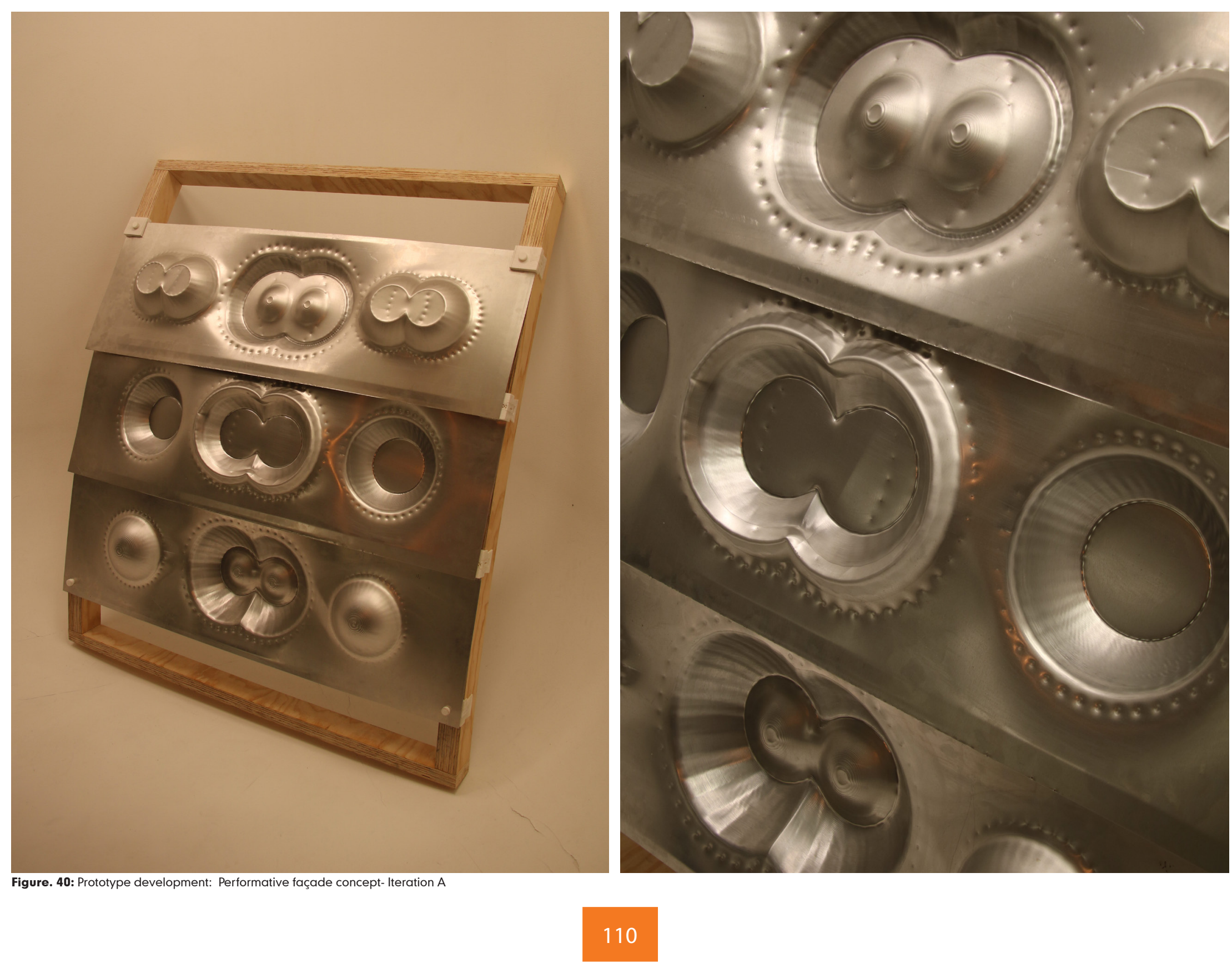


With these parameters added to the definition, a prototype was produced. This prototype demonstrated a plausible architectural artefact, in this case a performative façade. Only one section was modelled to provide instant analysis and feedback which the workflow could use to input into future explorations. This system was used to generate the forms as displayed in Figure. 40.

The ideas behind the panels was to explore the range of control the parameters gave the designer and to enhance aesthetic properties. It also established that the ductile properties of aluminium and movement of the industrial robot could be incorporated into the design.

The dome design in iteration A (Figure. 40) introduced a level of intrigue with a double formed surface. The ripple effect of the domes was successful and added depth to the panel, however the overall form domes did not read as a pattern. In this iteration, the hierarchy was lost amongst the variety of multidirectional ripples, making it confusing to look at. 

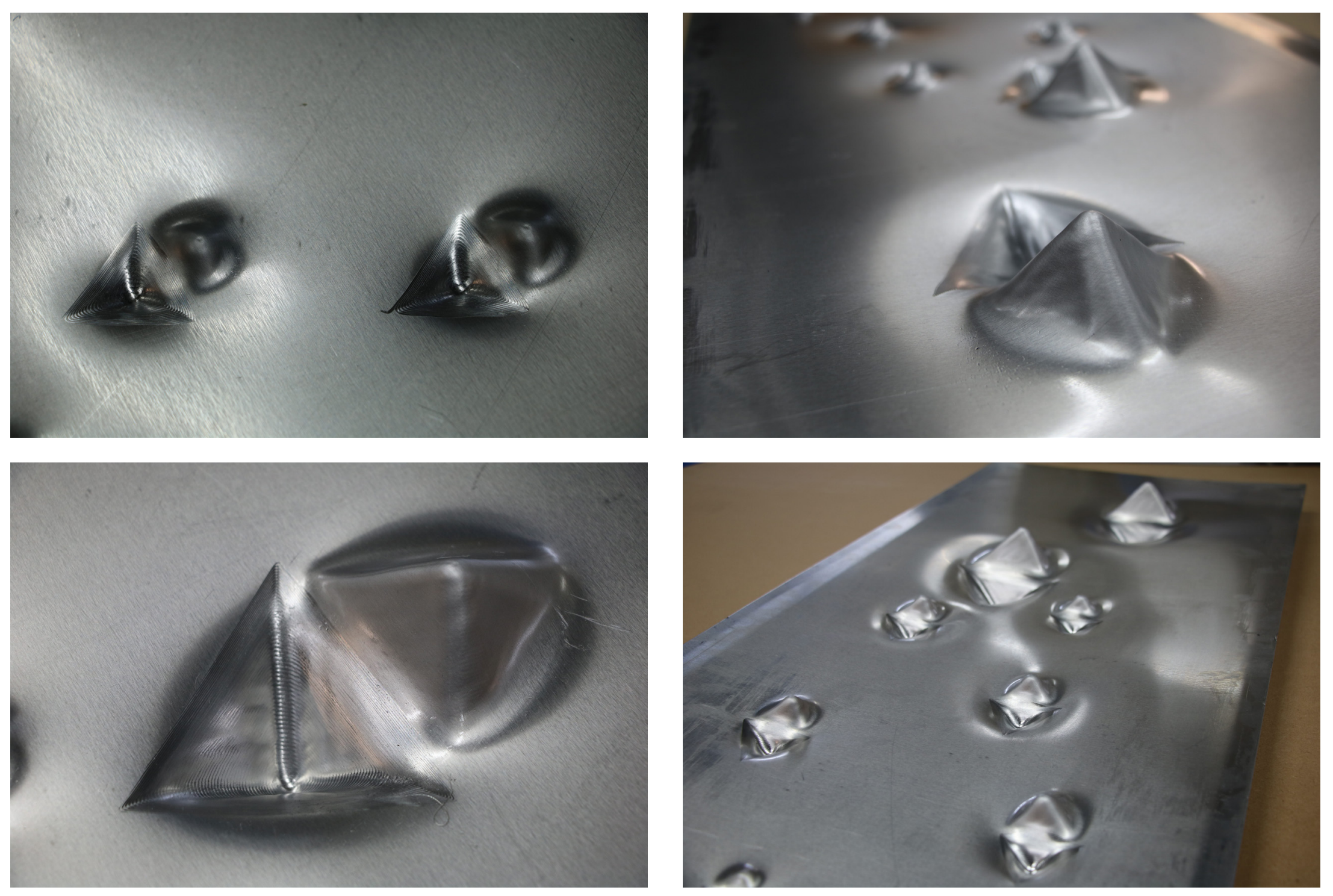

Figure. 41:lterative experimentation with triangular grid forming through parametric modelling- Iteration design development 


\subsection{Parametric System Prototype Iteration B}

After re-evaluating the design through the workflow, prior analysis of triangular geometries was found to be perferable, so experimentation with triangular double formed surfaces began (Figure. 41).

The extrusion of a triangle in two directions brought forth a diamond shape within the panels. This new surface geometry was unintentionally discovered through the pure input of the designed parameters. Research through a design process lead to the forms as opposed to primarily the designers input which was evident with the dome panels. Using the workflow and critically analysing the previous dome experiments and acknowledging its failure allowed the research to re-evaluate the design. The designed parameters and their ease of use, permitted the research to retry an old form to find a more successful design. This reassessment lead to a further development of the panel system to one which closely embodied the properties of the double formed triangle.

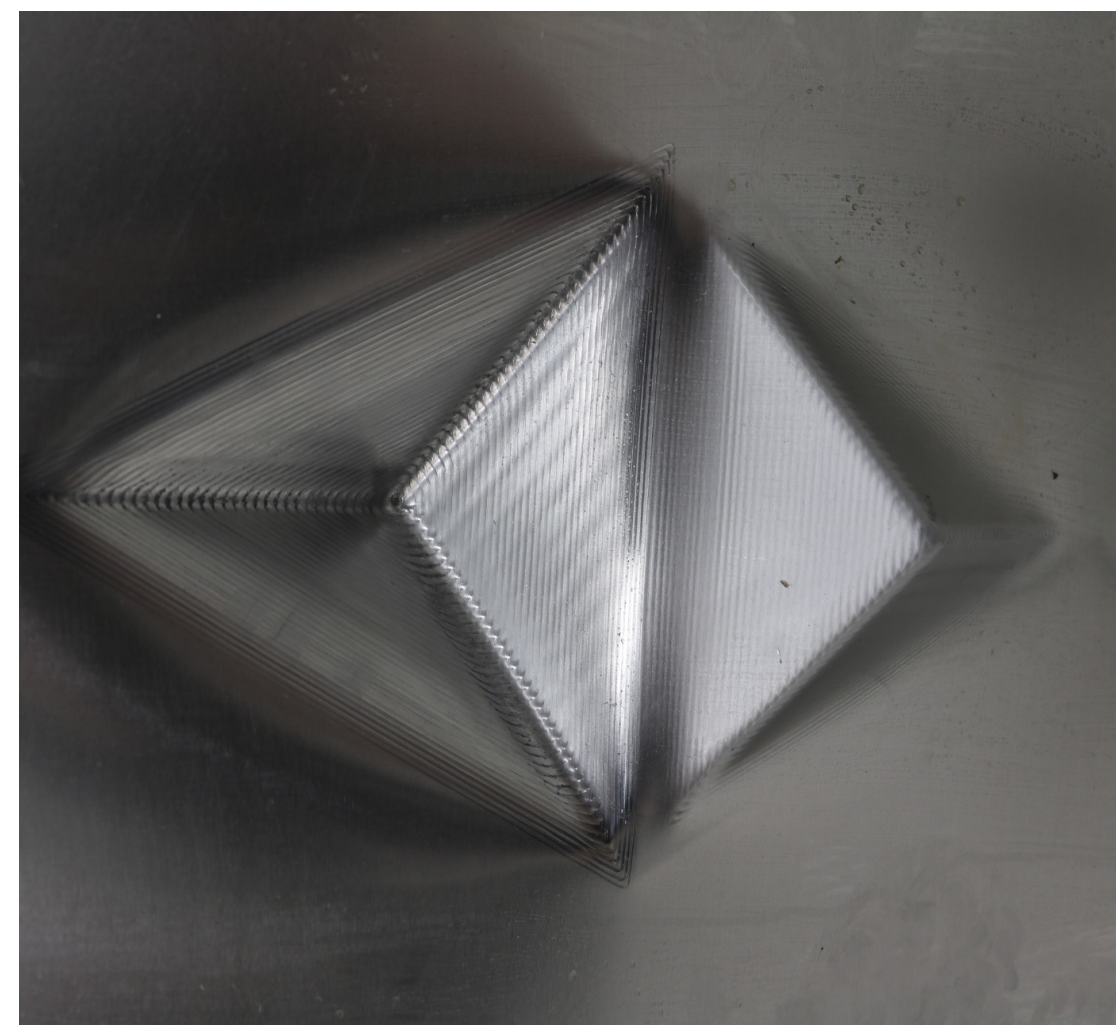

Figure. 42: Multi-directional triangle extrusion- Precursor for iteration B 

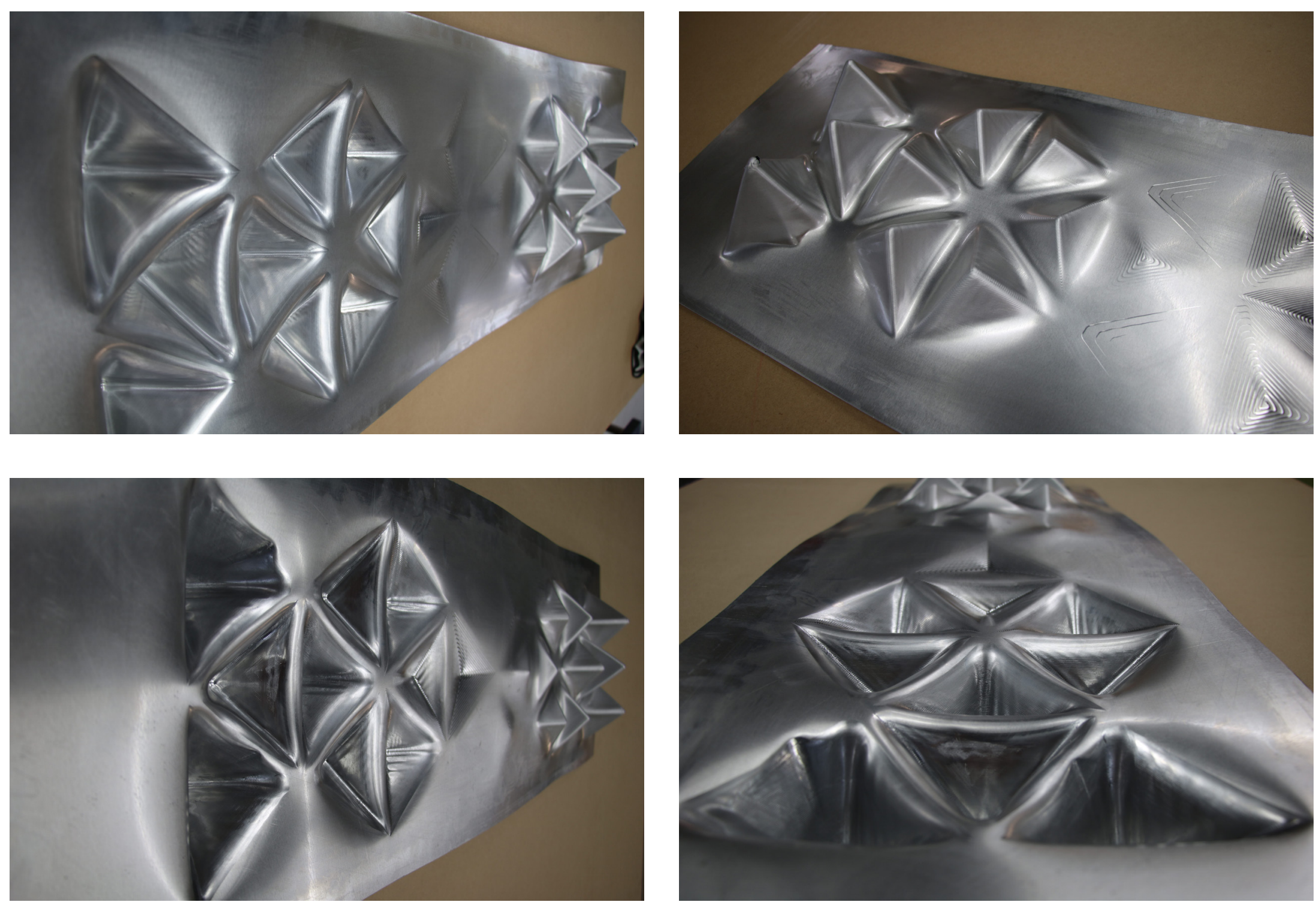

Figure. 43:tterative experimentation with triangular grid forming through parametric modelling: Final iteration deisng development 
The new system was a true model of the parametric design methodology. As the parameters were designed and that form could be developed, it also expressed the signature of the tools which allowed it to be created.

Generating the triangular geometries on Grasshopper and turning them into tool paths meant that some geometries had higher concentrations of points about their apex due to their altering volumes. This concentration of points created a tool path that the robot would eventually reject as it was no longer able to move the tool head to carry out the forming. As a direct result of this, the Grasshopper definition had to be edited to reduce the number of points in the tool path. This was done by increasing the step of the incremental forming path. However, this made for a more distinct forming indentation visible on the surface of the aluminium (Figure. 44). Through parametric design, the signatures of both Grasshopper's methodology of generating and deconstructing geometries and the fabrication machines forming characteristics could be incorporated into the design and accounted for so that geometries could still be generated by the program and the industrial robot.

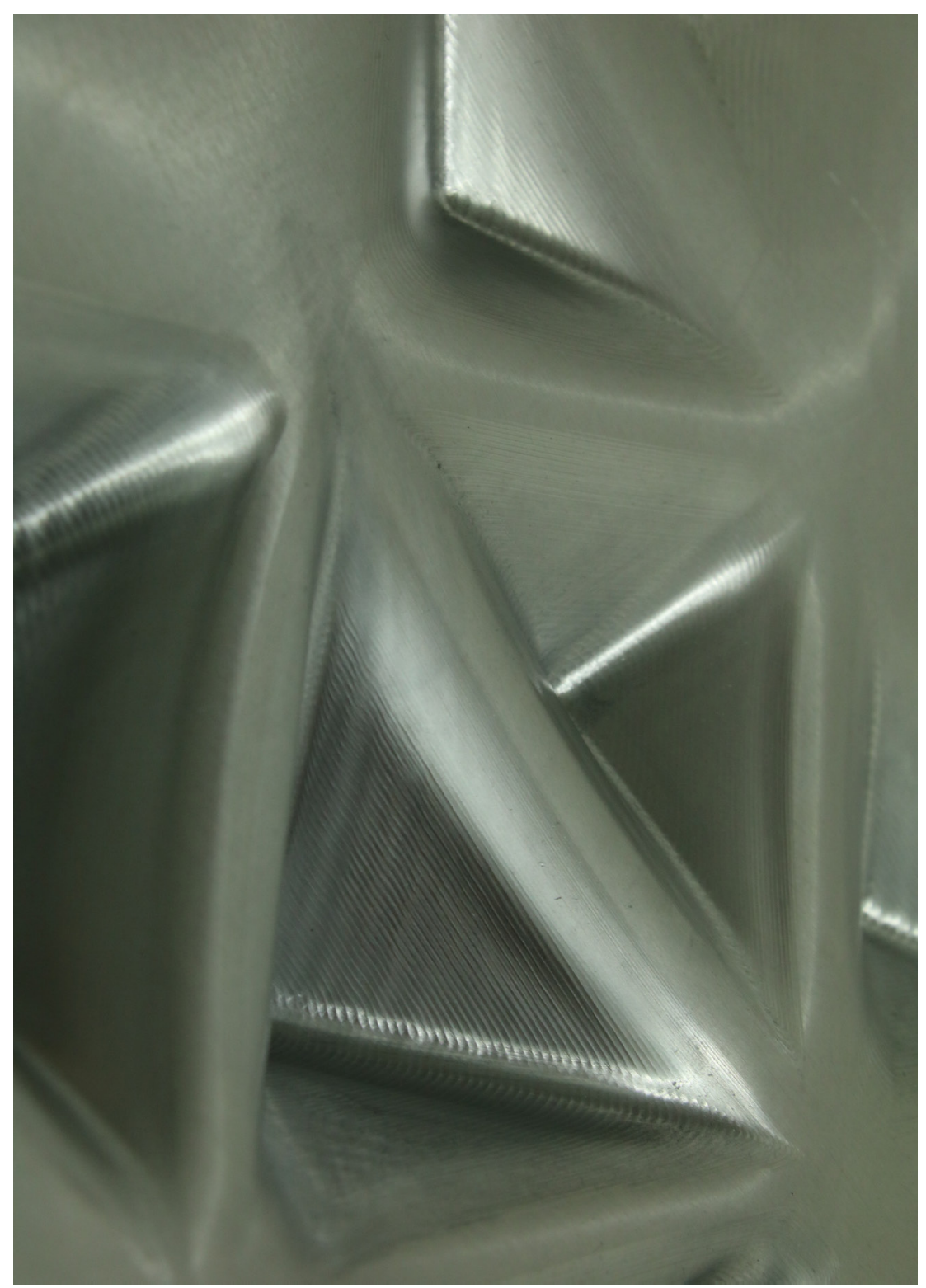

Figure. 44: Distinct forming indentation visible due to corrected incremental step of the forming path (1.2mm increment) 
Only a section of the parametric model was manufactured as the prototype (Explored in Figure. 46, Figure. 42, Figure. 47, Figure. 46), due to resource constraints.

A visualisation of the performative façade pavilion, that the prototype system is part of is displayed in the following figures; Figure. 49, Figure. 50, Figure. 51, Figure. 52 on the following pages 


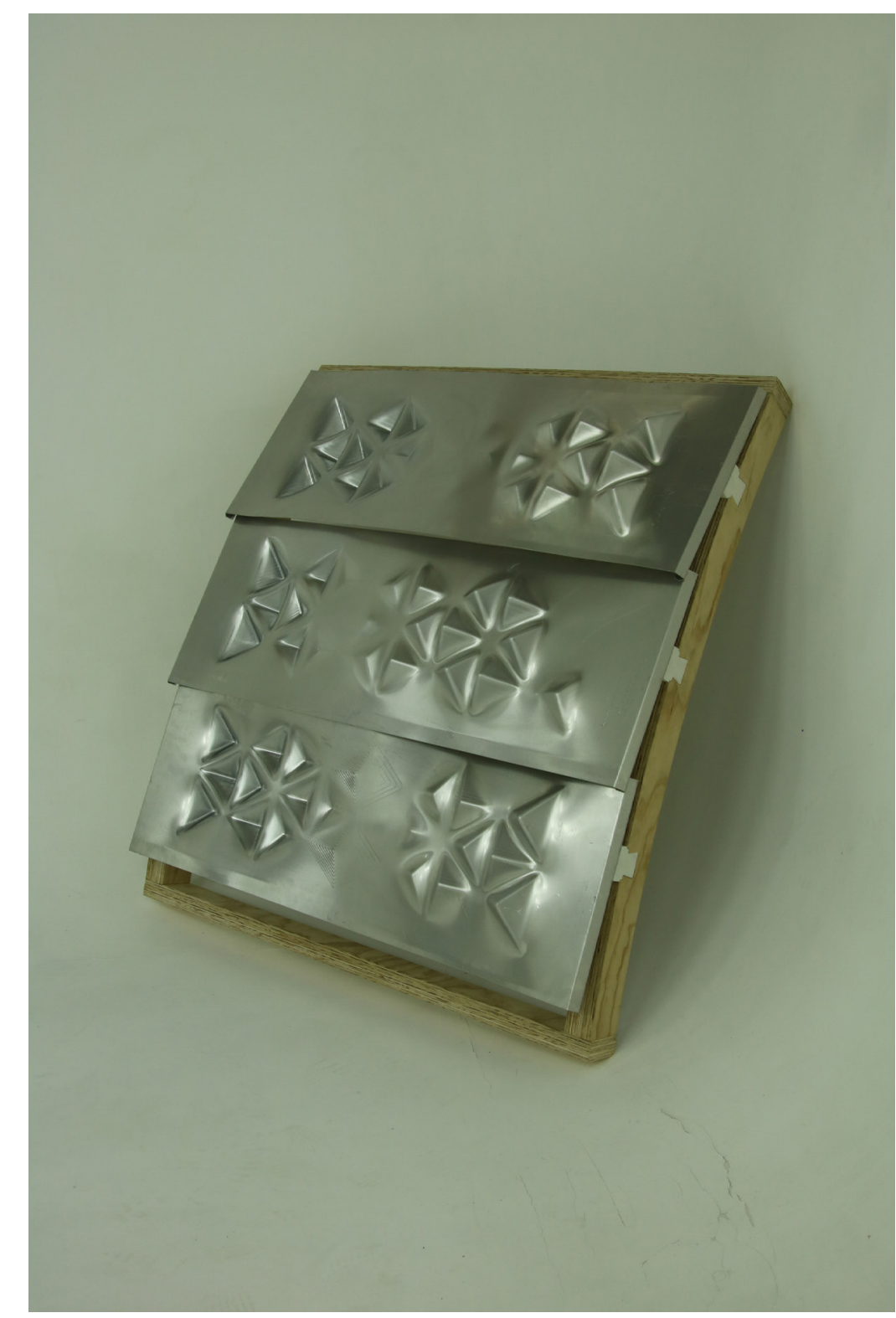

Figure. 46: Prototype development: Performative façade system- Iteration B- Front perspective

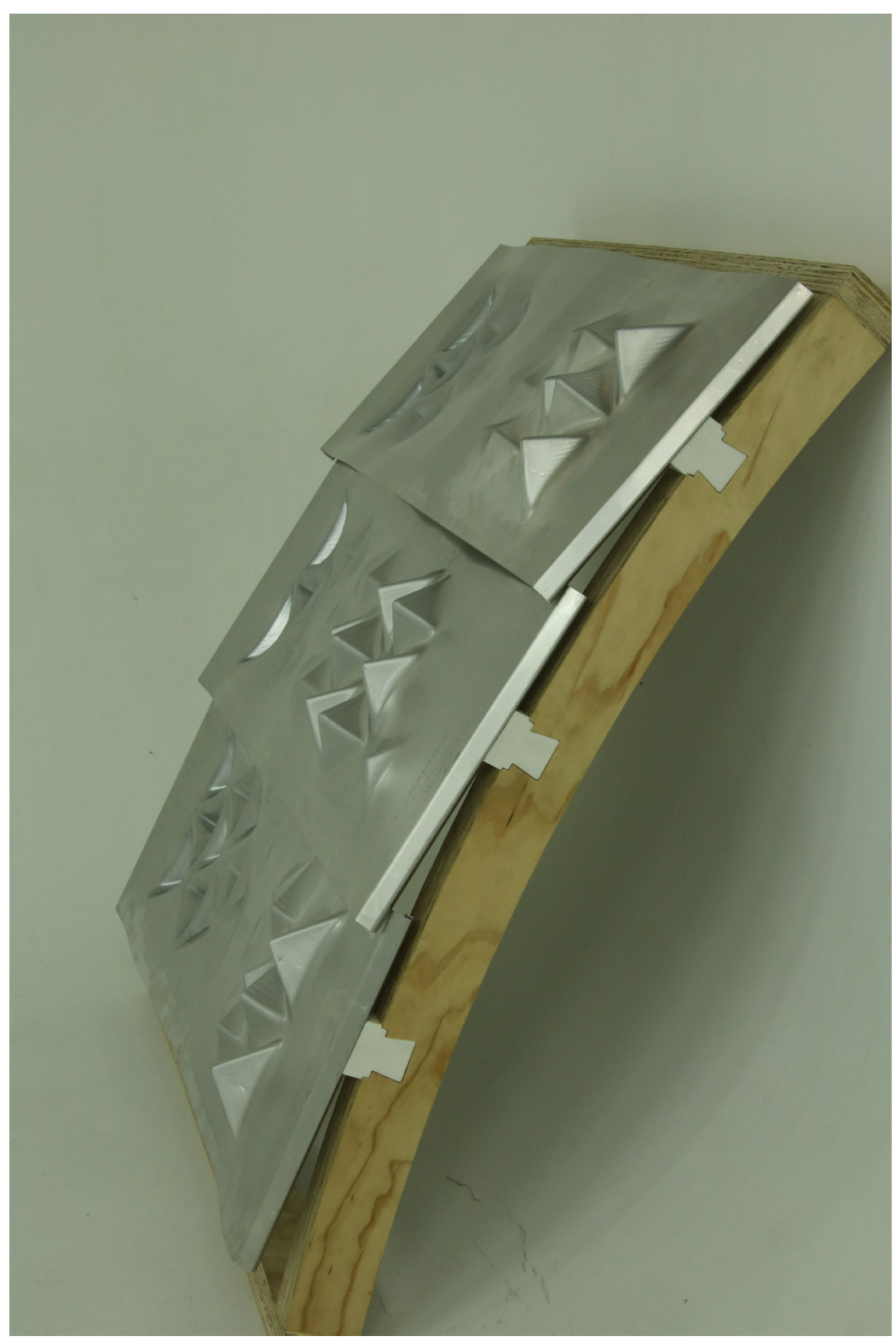

Figure. 45:Prototype development: Performative facade system- Iteration B- Side perspective 


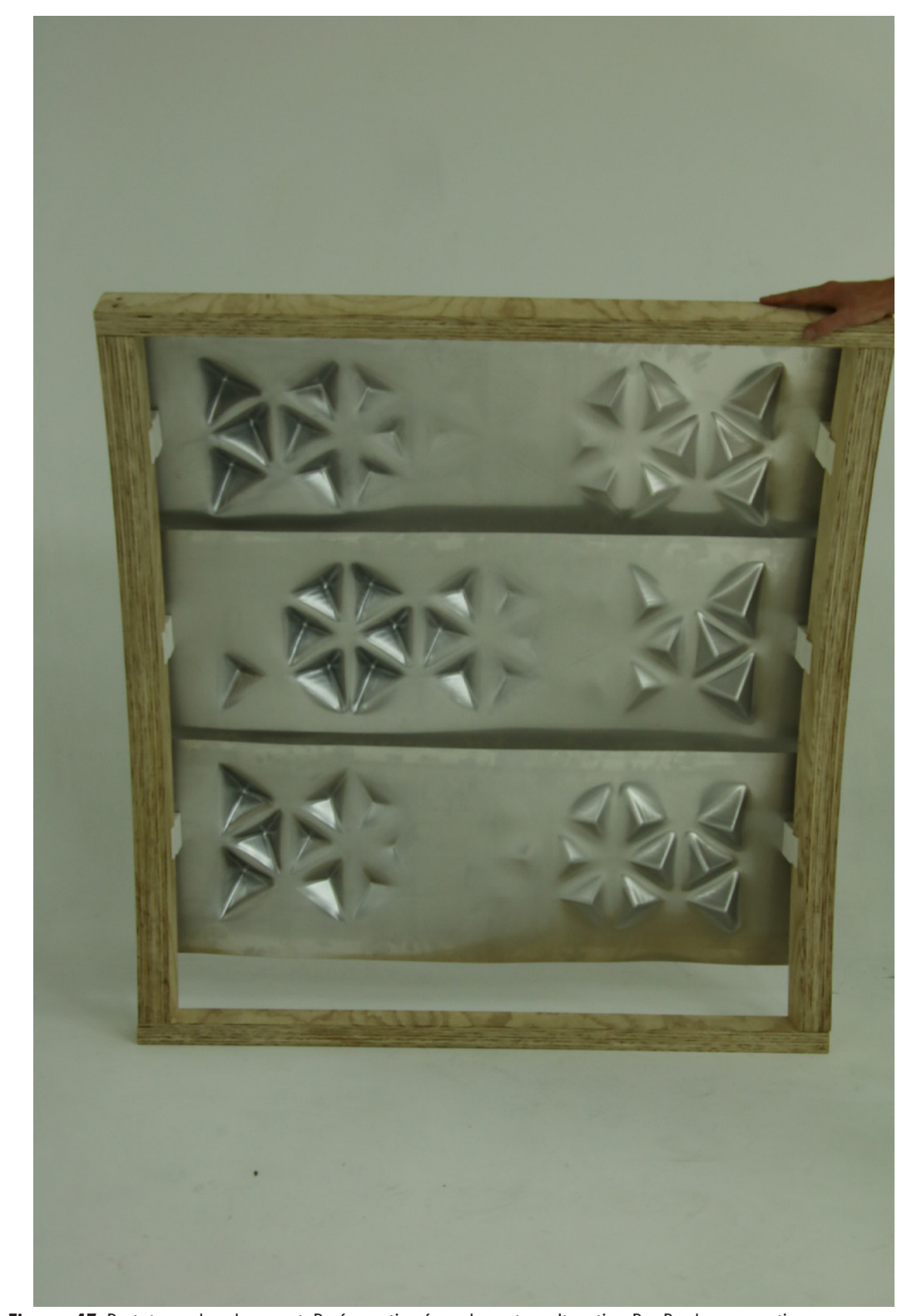

Figure. 47: Prototype development: Performative façade system- Iteration B- Back perspective

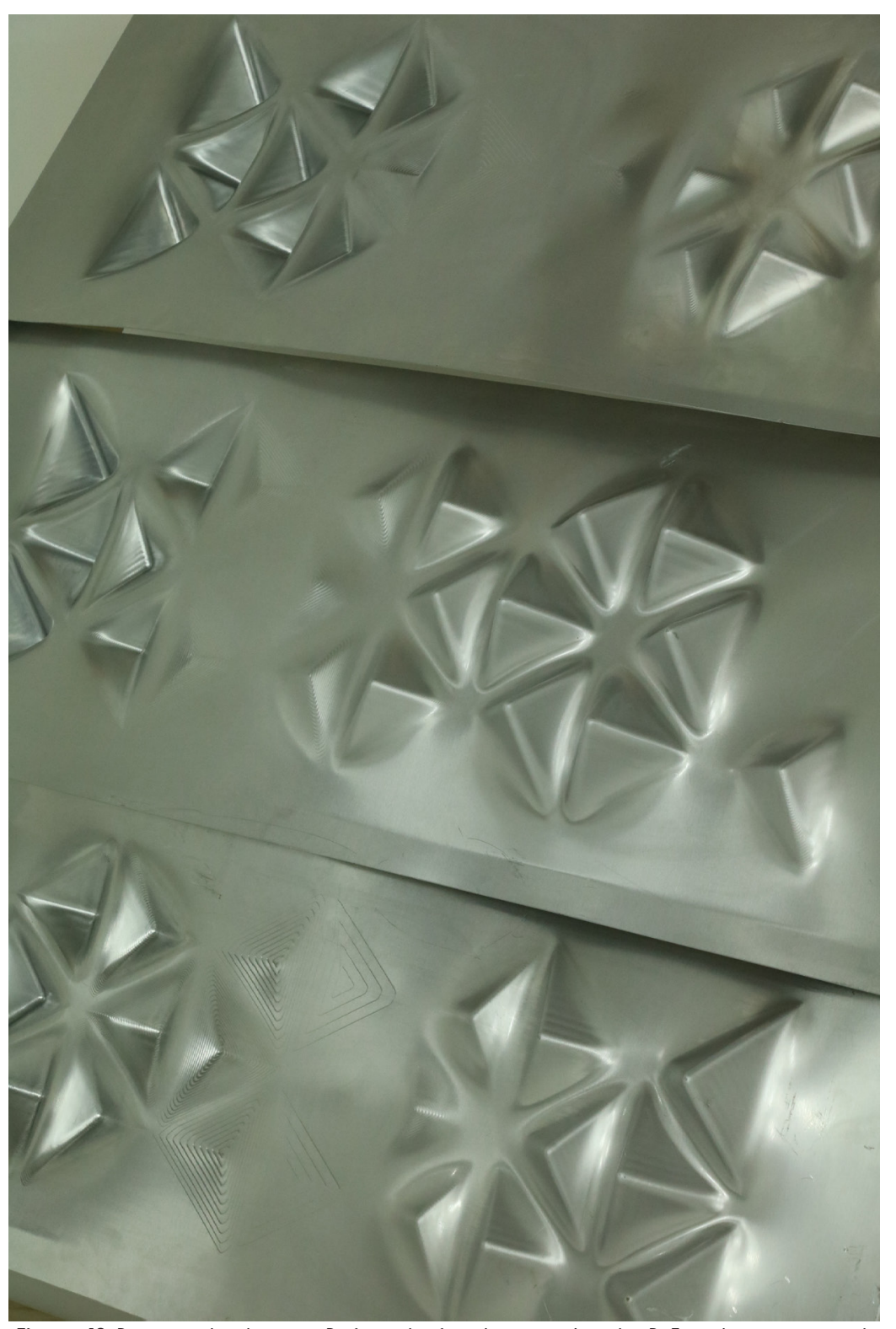

Figure. 48: Prototype development: Performative façade system- Iteration B- Fron close up perspective 


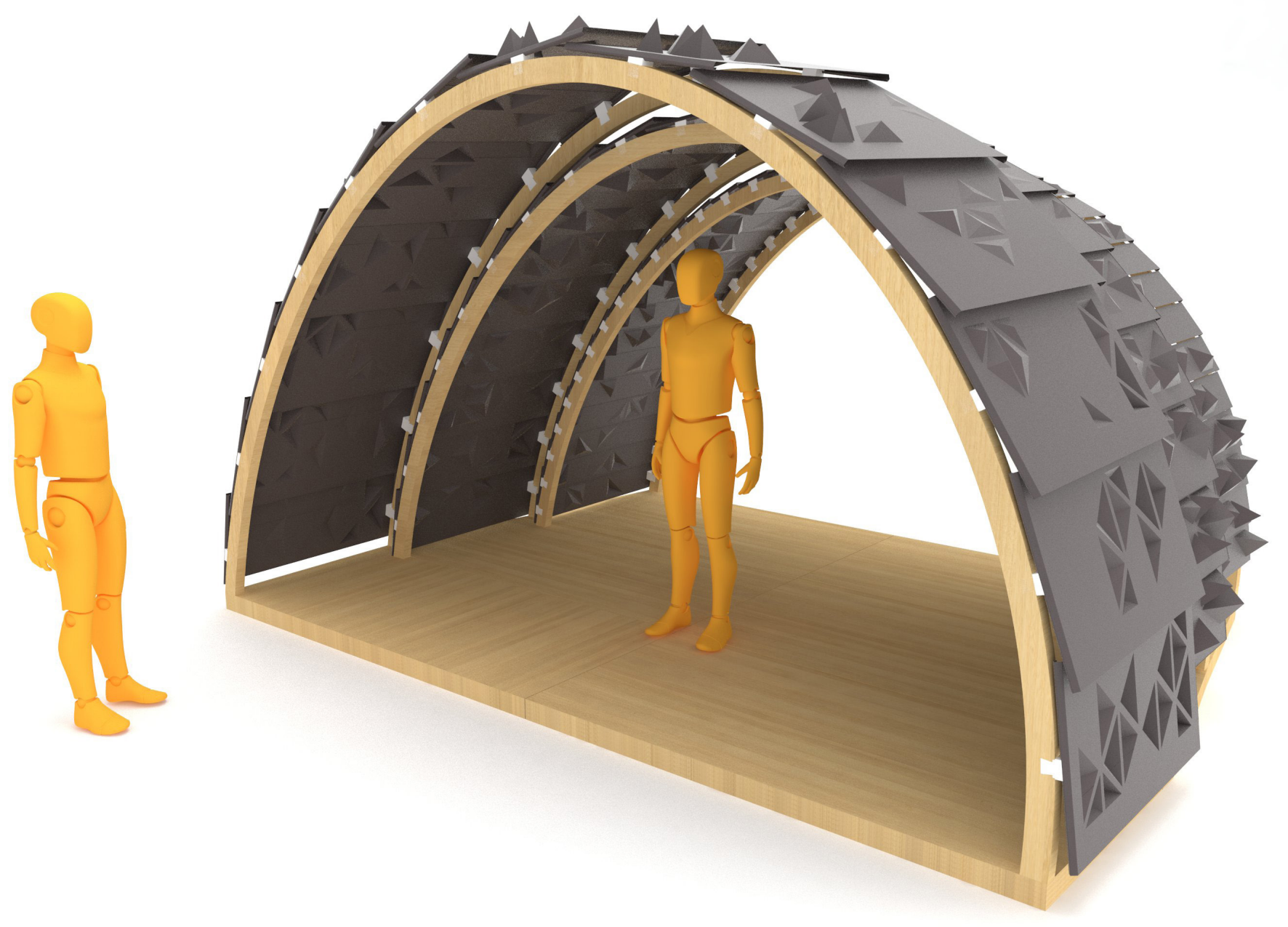

Figure. 49: Prototype Two- Performative façade pavillion- Iteration B- Render visualisation 


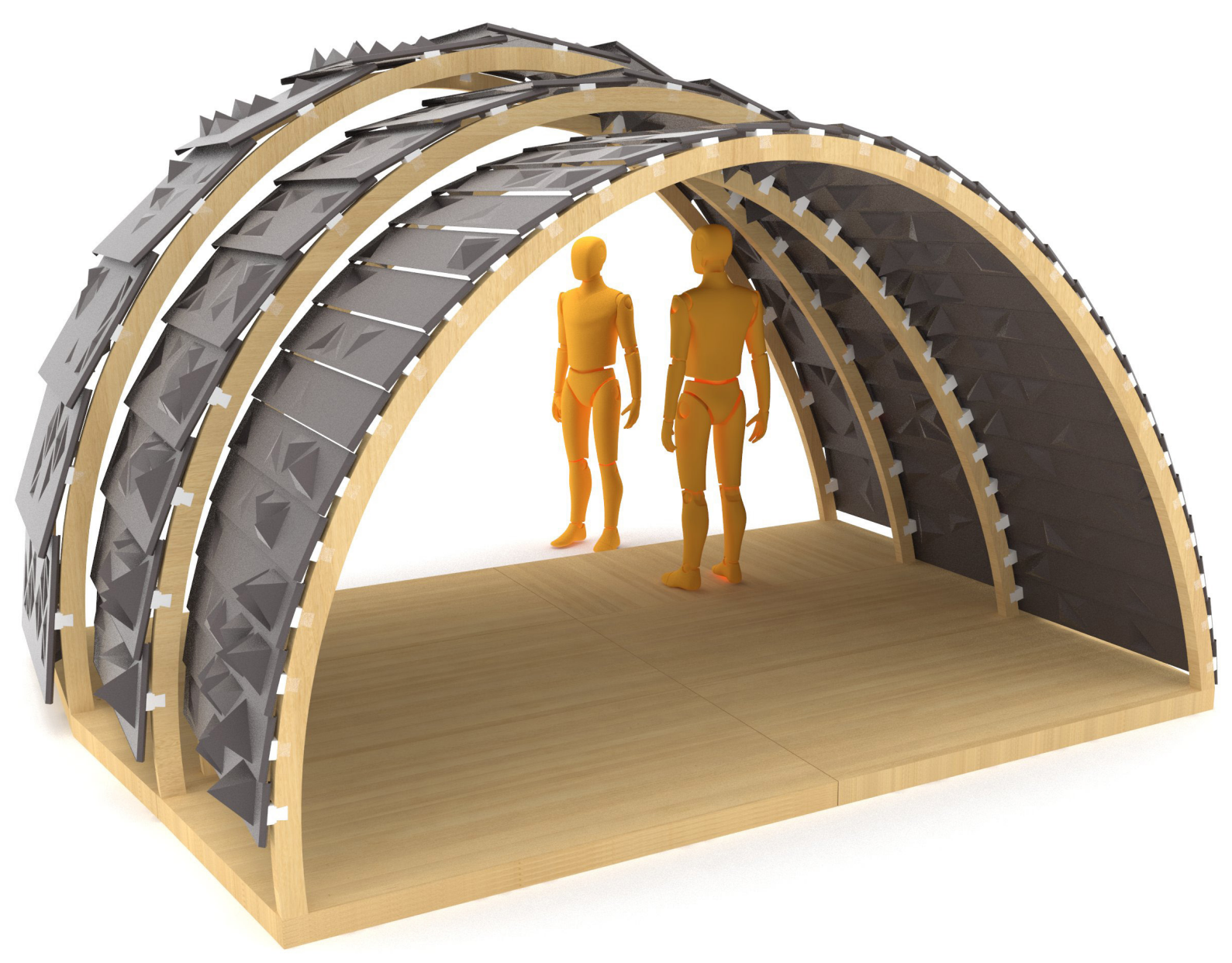

Figure. 50: Prototype Two- Performative façade pavillion- Iteration B- Render visualisation 


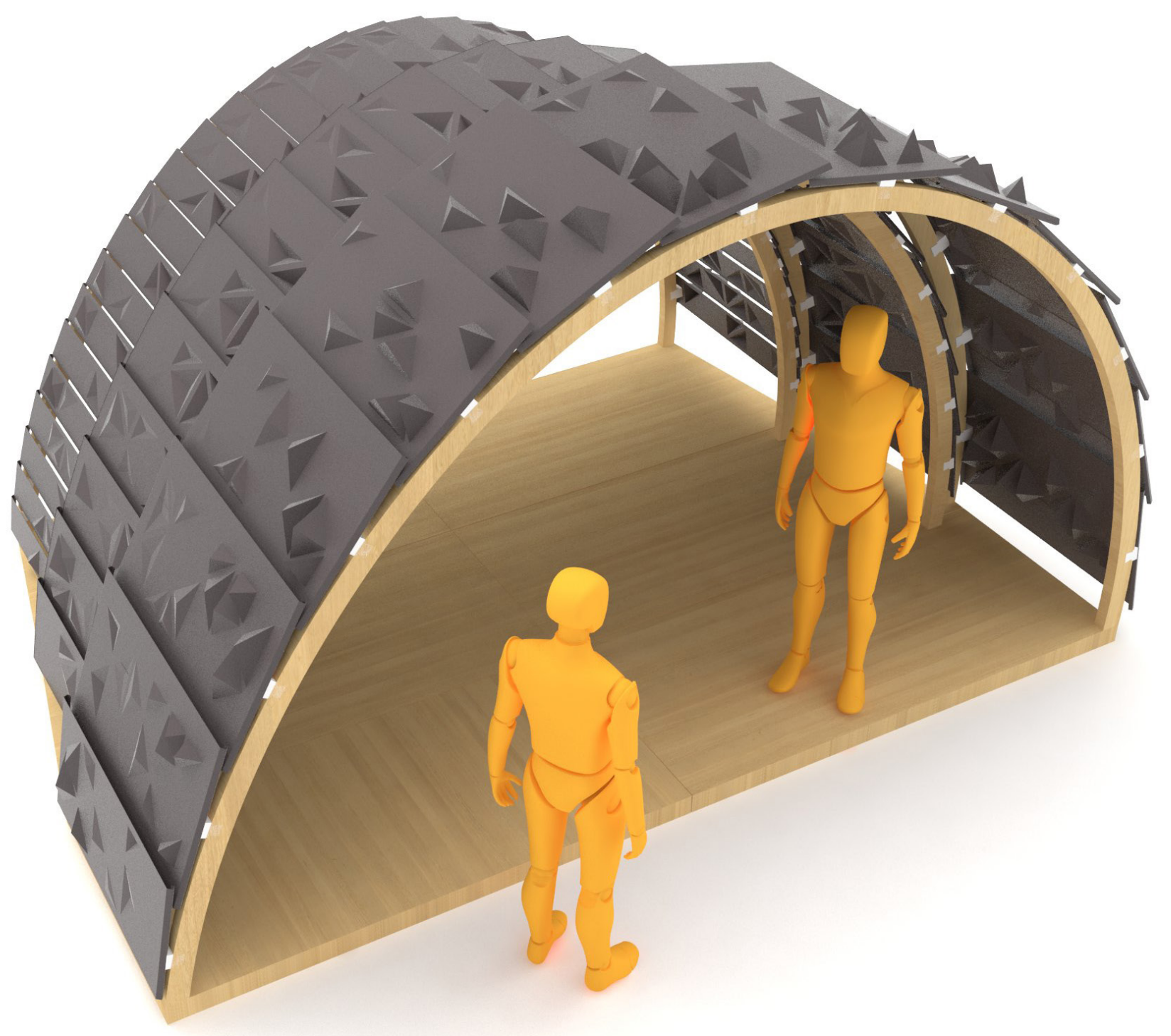

Figure. 51: Prototype Two- Performative façade pavillion- Iteration B- Render visualisation 


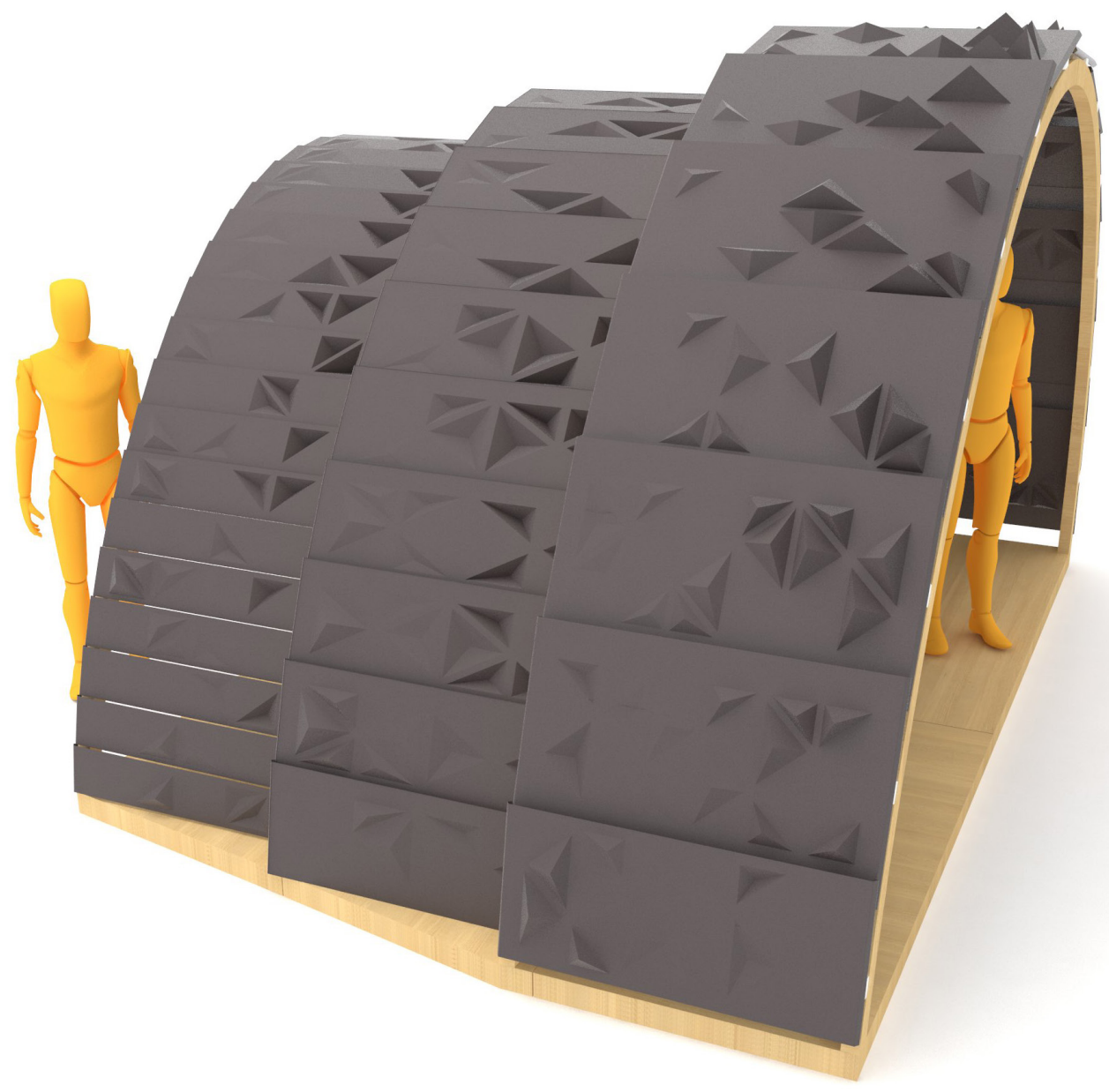

Figure. 52: Prototype Two- Performative façade pavillion- Iteration B- Render visualisation 


\subsection{Conclusion}

The research through design this thesis focused on led to the understanding of how parametric design could inform architecture. Looking at fundamental aspects of architecture as a form, parametric design gives the designer control of the form. With the aid of a contemporary digital workflow, parameters allow the design to be tested promptly and edited if needed. Phase Three shows how parametric design allowed the research to develop a form finding system. This system could then be used to experiment with a form.

Phase Three began with a conceptualised dome system, which was then prototyped and analysed through the workflow. After analysis of the prototype, the dome system was undesirable aesthetically as there was no hierarchy of the form pattern but a confusion with its legibility. Nonetheless there were some aspects such as the multidirectional surface of the forms that were successful.

With this analysis in mind the parametric system could then be edited rather than remade from scratch. This was because the relationships established with the parameters meant the system itself would adapt to the change of the form. The workflow also ensured that the past successfu 
experiments were acknowledged and re-evaluated when the parametric system was augmented.

Designing the parameters also allows for explorations of materials and environmental or tool components to be expressed. Phase Three is an example of this, as the final iteration of the three-panel system evoked not only the forms found through a parametric form-finding definition, but also the signature of the tools that were used to generate it. Parametric design allowed these signatures to be expressed rather than ignored. With Phase Three the ability of the tool to perform certain movements was made clear.

After analysing these constraints and the logic of Grasshopper's visual code, a solution came to light. Within the parametric system, the increment step could be altered, meaning the point path could be optimised in Grasshopper. A refined tool path could then be generated, one that the robot could use to perform the forming. However because of this the surface of the formed aluminium would not be smooth but more ridged and rippled. The parametric system allowed the design to adapt the prototype and incorporate all the attributes of the tools to take control of the manufacturing process of the design. 



\section{0}

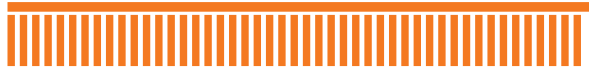

7.0 Discussion

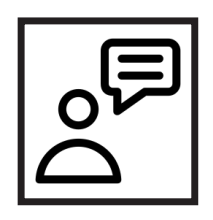


"In developing computer programs one is forced to question how people think and how design evolves. In other words, computers must be acknowledged not only as machines for imitating what is understood, but also as vehicles for exploring what is not understood (Terzidis, 2006b)" 


\subsection{Discussion}

This thesis has employed research through design to answer the question, how can an advanced parametric process, grounded in an understanding of a contemporary digital workflow, inform architectural space?

This research applied parametric design techniques to architectural applications, such as a folly shelter and a performative façade system, to test its hypothesis. It was found that parameters could be established to such an extent that the form of the designed project can be encoded into a system, through a series of conditions that share relationships with other components of the system. When these parameters are established, the designer can take control of the form, its ornamentation, and its aesthetic. In addition, the designer can control design production. Ultimately, this gives the designer more control of all aspects of the project, and from here the designer can establish a system. Referring back to the workflow, design control can be reinstated by the designer through the system, informing and allowing the designer to focus on what is important, the architectural space.

A fully defined parametric model can also provide the designer with a digital output that can rapidly 
output design iterations, due to the computers intensive computational capacity. These designs can be tested through digital fabrication processes, and investigated. Parametric design also provides the designer with ways of exploring the unpredictable. Defining a parametric system allows for unforeseen opportunities to arise, caused by direct interaction between the physical and digital worlds. Parametric design allows for these opportunities to be discovered, then capitalised on by incorporating them.

Parametric design can provide a designer with the instruments that generate design form in such a way that if alterations are to take place, the relationships established between components allow for the design to be augmented and incorporate the alteration.

Through graphical programming of Grasshopper and the feedback loop provided by the workflow, this research could replicate the methodology to incorporate lessons learnt from material experimentation, tool and environmental dynamics. These three factors can then be integrated into a parametric model which would generate a form, a form that an industrial robot could then fabricate. Failures such as material properties of the aluminium 
extrusion, and constraints such as the industrial robot's ability to traverse the environment were all implemented into the software definition as parameters. These parameters were then used to govern the form generation.

From this fundamental research into parametric design, parameters can be used to inform the level of control a designer has over a form. There will always be underlying parameters for all architectural projects, however the key parameters which influence a pure formfinding system are project-specific. Parameters are tools, tools the designer can use to extract the power behind contemporary machines and computers alike. Each design will have its own unique parameters, which allow the designer to express the signatures of the software and the tools used to create the forms designed by the software. 


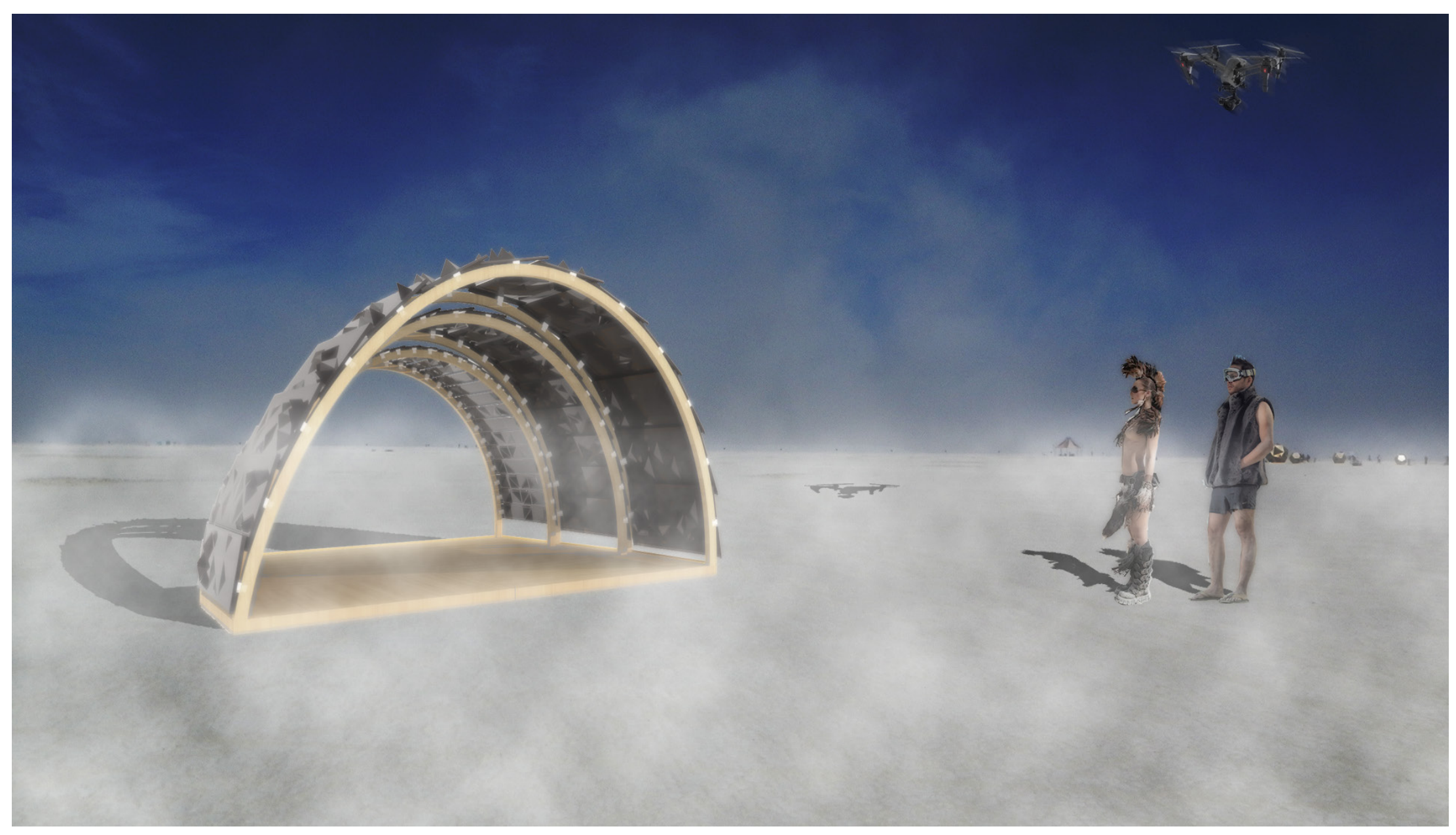

Figure. 53: Phase Three prototype: Iteration B- Performative façade pavillion -Conceptual render visualisation 



\section{0}

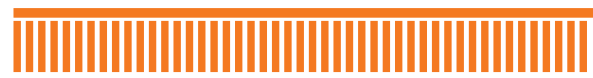

8.0 Bibliography

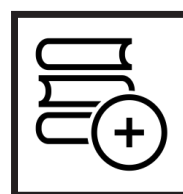


Ahlquist, S., \& Menges, A. (2011). Introduction: Computational Design Thinking. In A. M. S. Ahlquist (Ed.), Computational Design Thinking (pp. 10-29). United Kingdom: John Wiley \& Sons Ltd.

Alexander, C. (1964). Notes on the Synthesis of Form. United States of America: Harvard University Press, Cabridge Massachusetts.

Andrei, R. (2010). Form and space abstraction in architectural rehabilitation of industrial buildings. Bulletin of the Polytechnic Institute, 33-41.

ArchDaily. (2014). ICD-ITKE Research Pavilion 2013-14. Retrieved from http://www.archdaily.com/522408/icd-itke-research-pavilion-2015-icd-itke-universityof-stuttgart/

Architects, T. S. A. o. (Producer). (2014, 14/03/2016). Achim Menges: Rethinking Materiality Through Computation in Archiecture. Retrieved from https://www. youtube.com/watch?v=PbgArau_4vl

Ariza, I., \& Gazit, M. (2015). On-site Robotic Assembly of Double-curved Self-supporting Structures. Paper presented at the 19th Conference of the Iberoamerian Society of Digital Graphics. AS, S. O. (2011). Tverrfjellhytta / Snohetta.

Bechthold, M. (2014). Design Robotics: A New Paradigm in Process-Based Design

Brüninghaus, J., Krewet, C., \& Kuhlenkötter, B. (2012). Robot Assisted Asymmetric Incremental Sheet Forming. Paper presented at the ROB ARCH Robotic Fabrication in Architecture Art and Design, New York. In R. O. R. Oxman (Ed.), Theories of the digital in Architecture (pp. 293-298): Routledge, Taylor \& Francis Group.

Caneparo, L. (2014). Digital Fabrication in Architecture, Engineering and Construction. In A. Cerrato (Ed.), (pp. 218). New York: Springer.

Dino, I. G. (2012). Creative design exploration by parametric generative systems in architecture. METU Journal of the Faculty of Architecture, $207-224$. 
Dunn, N. (2012). Digital Fabrication in Architecture. London: Laurence King Publishing Ltd.

Friedman, J., Hosny, A., \& Lee, A. (2014). Exploring Structural Capacities in Metal Sheet Forming. Paper presented at the Robotic Fabrication in Architecture, Art and Design 2014, Taubman College of Architecture and Urban Planning Michigan

Garber, R. (2009). Optimization Stories: The Impact of Building Information Modeling on Contemporary Design Practice. Architectural Design, $79,144$.

Gerber, D. J. (2015). Material Swarm Articulations: The New View Reciprocal Frame Canopy. Paper presented at the 34th Annual Conference of the Association for Computer Aided Design In Architecture (ACADIA), Los Angeles CA.

Ismail, A., Smith, D., \& Kumarasuriyar, A. (2010). The impact of architectural form and space as an expression of political ideology, 13. Retrieved from Academia website:

Iwamoto, L. (2009). Digital Fabrications: Architectural and Material Techniques. New York: Princeton Architects Press.

Kalo, A., \& Newsum, M. J. (2014). An Investigation of Robotic Incremental Sheet Metal Forming as a Method for Prototyping Architectural Skins. Paper presented at the Robotic Fabrication in Architecture, Art and Design 2014.

Kalo, A., \& Newsum, M. J. (2014). Bug Out Fabrication: A Parallel investigation of the Namib darkling Beetle and Incremental Sheet Metal Folding. Paper presented at the ACADIA 2014 Design Agency, Los Angeles.

Kalo, A., \& Newsum, M. J. (2014). Robotic Incremental Sheet Metal Forming. Paper presented at the ACADIA 2014 Design Agency, Los Angeles. 
Katz, N. C. (2007). Parametric modeling in AutoCAD. AECbytes 2007. Retrieved from

Kierean, S., \& Timberake, J. (2004). Refabricating Architecture- How manufacturing technologies poised to transform building construction. New York: Mc GrawHill.

Kolarevic, B. (2005). Architecture in the Digital Age: Design and Manufacturing (B. Kolarevic Ed. First Edition ed.). New York: Taylor and Francis.

Krauel, J. (2010). Contemporary Digital Architecture Design and Techniques. China: Links International.

Oxman, R. (2006). Theory and design in the first digital age. Design Studies, 27(3), 229-265.

Pangaro, P. (2013). Cybernetics A Definition. 1991 Encyclopedia of Computers. Retrieved from "Getting Started" Guide to Cybernetics website: http://www. pangaro.com/definition-cybernetics.html

Pantazis, E., \& Gerber, D. (2014). Material Swarm Paper presented th the Proceedings of the 32nd eCAADe Conference, Newcastle, England.

Rybczynski, W. (2013). Parametric Design: What's Gotten Lost Amid the Algorithms. Retrieved from http://www.architectmagazine.com/design/parametricdesign-whats-gotten-lost-amid-the-algorithms_o

Simon, H. A. (1962). The Architecture of Complexity. Paper presented at the Proceedings of the American Philosophical Society

Terzidis, K. (2006). Algorithmic Architecture (Vol. First Edition): Elsevier Ltd.

Terzidis, K. (2006). Expressive Form. London; New York: Spon Press. 
The Bartllett, UCL Faculty of the Built Environment (Producer). (2012, 17/03/2016). Bartlett International Lecture Series 2012-13// Achim Menges. Bartlett International Lecture Series 2012-13. [Lecture Video Recording] Retrieved from https://www.youtube.com/watch?v=fSBJcJWfn2A

Wallisser, T. (2014). Parametric Adaptation. GAM: Architecture Magazine - Intuition and the Machine, 10, 343.

Woodbury, R. (2010). Elements of Parametric Design (pp. 300). New York: Routledge. 

9.0

\author{
$\| \quad||||||||||||||||||||||||||||||||||||||||||||||||$
}

9.0 Table of Figures

圆 
*All figures that are not referenced in this list are the authors own.

Figure. 1 Gerber, D. J. (2015). Perspective- Material Swarm Articulations. Retrieved From https://www.researchgate.net/ publication/278668847_MATERIAL_SWARM_ARTICULATIONS_THE_NEW_VIEW_RECIPROCAL_FRAME_CANOPY

Figure. 2 Gerber, D. J. (2015). Render Detail of Four Perforated Components. Retrieved From: https://www.researchgate. net/publication/278668847_MATERIAL_SWARM_ARTICULATIONS_THE_NEW_VIEW_RECIPROCAL_FRAME_CANOPY

Figure. 4 Kalo, A. \& Newsum, M. J. (2014) Bug Out Fabrication: A Parallel investigation of the Namib darkling Beetle and Incremental Sheet Metal Folding. 535.

Figure. 5 Kalo, A. \& Newsum, M. J. (2014) Bug Out Fabrication: A Parallel investigation of the Namib darkling Beetle and Incremental Sheet Metal Folding. 534.

Figure. 6 Asymptote Architecture. (2002). Hydra Pier. Retrieved Form http://www.asymptote.net/hydr-slideshow 
